\title{
The Erroneous Foundations of Law and Economics ${ }^{\dagger}$
}

\section{Mark Glick* and Gabriel A. Lozada **}

\author{
Working Paper No. 149
}

February $15^{\text {th }}, 2021$

\begin{abstract}
The fundamental originating principle of law and economics (L\&E) is that legal decisions should be (and are) based on maximizing efficiency. But L\&E proponents do not define "efficiency" in the way agreed to by most economists, as Pareto Efficiency. A Pareto optimal condition is obtained when no one can be made better off without making someone worse off. Pareto Improvements are win-win changes where no losers exist. In the judicial system, however, there are always winners and losers, because under Article III $\S 2$ of the Constitution a legal case does not exist unless there is a justiciable "case or controversy" in need of resolution. Unable to use Pareto Efficiency, L\&E scholars have been forced to adopt alternative definitions of efficiency. Most L\&E scholars claim to define "efficiency" based on the work of Kaldor and Hicks, but (perhaps unwittingly) instead use a definition of "efficiency" derived from the $19^{\text {th }}$ century idea of consumer surplus, which encompasses L\&E notions such as "wealth maximization," and "consumer welfare" in antitrust. Neither of these alternative definitions is viable, however. Outside of L\&E, the Kaldor-Hicks approach has long been recognized to be riddled with logical inconsistencies and ethical failures, and the surplus approach is even more deficient.

\footnotetext{
$\dagger$ The authors acknowledge support from the Institute for New Economic Thinking and would like to thank David Mangum and Thomas Ferguson for their helpful comments.

${ }^{*}$ Professor of Economics, University of Utah.

${ }^{* *}$ Associate Professor of Economics, University of Utah
} 
Remarkably, virtually none of the numerous L\&E textbooks even hint at such problems. Critically, all definitions of efficiency improvements in economics are biased in favor of wealthy individuals or firms, either because they are dependent on the status quo ante distribution of assets, or because they bestow large advantages on parties with political influence or who can afford to bring lawsuits quickly. Many L\&E practitioners treat efficiency improvements instead as being objectively good, an error revealing that L\&E is primarily motivated by its neoliberal policy agenda.

\section{https://doi.org/10.36687/inetwp149}

JEL codes: K1, D61, L4

Key words: law and economics, antitrust economics, efficiency, wealth maximization, legal realism, neoliberal theory, Kaldor Hicks, Pareto Optimality 


\section{Table of Contents}

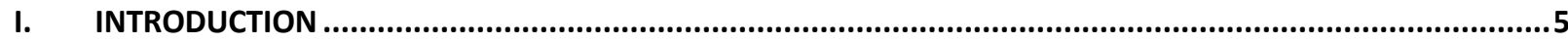

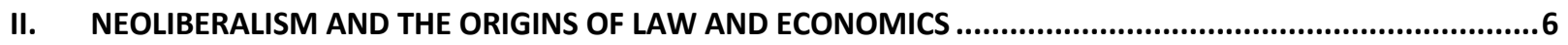

A. The Great Depression Brings an End to Laissez-Faire Economic Policy ....................................................... 7

B. Neoliberalism and its “Freedom” Narrative Emerge as a Response to the New Deal Consensus ........................ 8

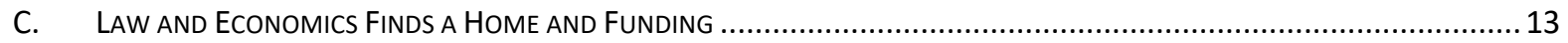

D. LaW \& Economics Advances the Modern Neoliberal Agenda ............................................................ 14

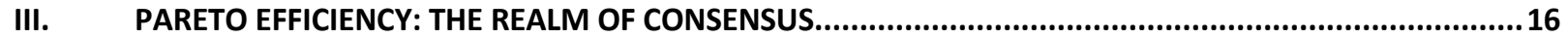

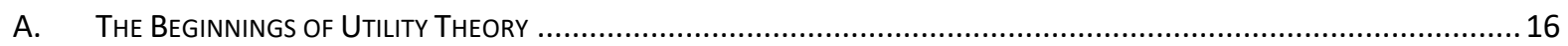

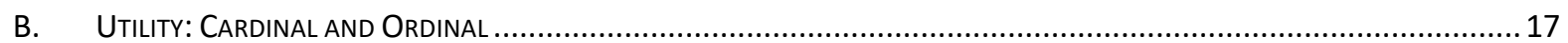

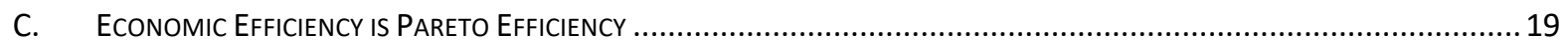

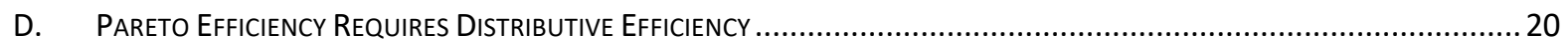

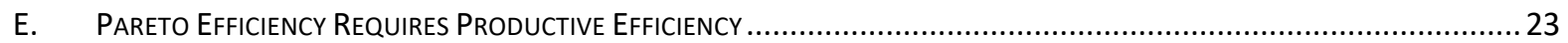

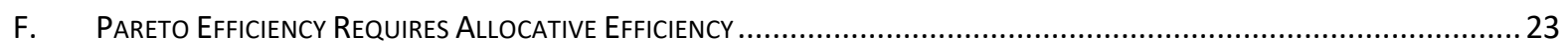

G. Pareto Efficiency Cannot be Used to EStablish a Theory of The Common LaW .............................................2 25

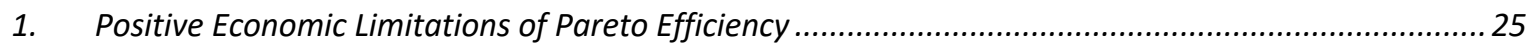

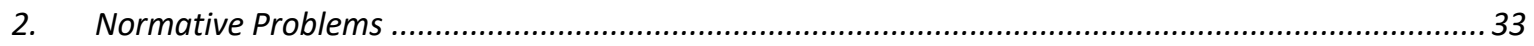

IV. THE CRITERIA OF KALDOR AND HICKS: THE REALM OF COERCION ......................................................

A. Value's Dual Nature: Willingness to Pay/Accept; Compensating/Equivalent Variation .............................. 36

1. Settings: Describing Various Policy Changes and the Units in which they are Valued ......................... 36

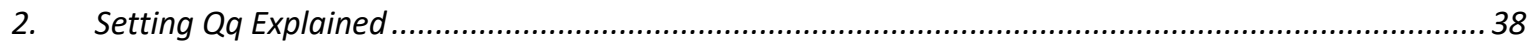

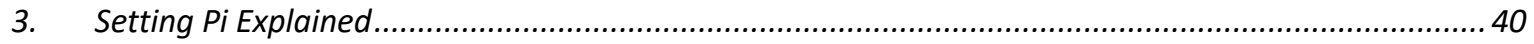

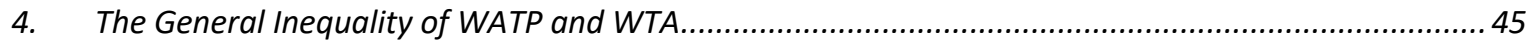

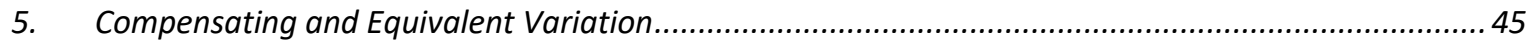

6. Nonexistent WATPs and Infeasible WTAs in Edgeworth Boxes.................................................... 51

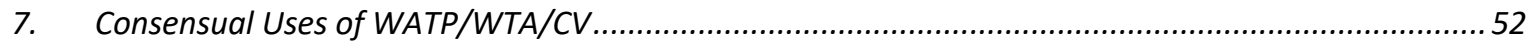

B. The Potential-Pareto/Kaldor-Hicks/Cost-Benefit-Analysis Criterion for Making Coercive Social Decisions 53

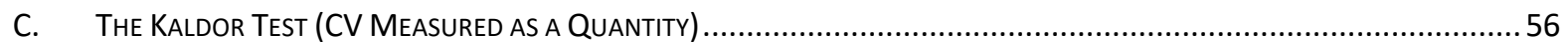

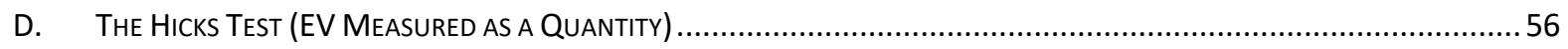

E. Positive Problems With CV \& EV Measured AS Quantities .........................................................................5

1. Potential Pareto Moves that Are Not, In Fact, Potentially Pareto Efficient........................................57

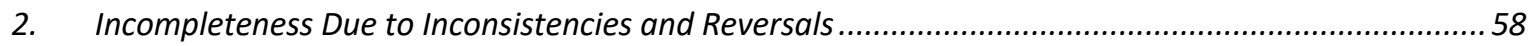

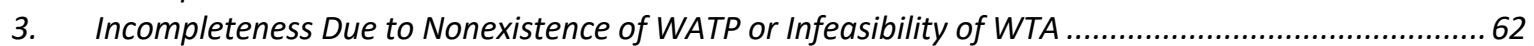

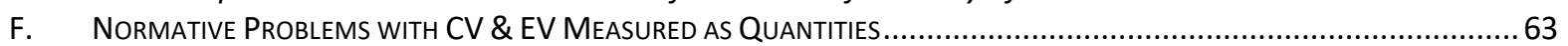

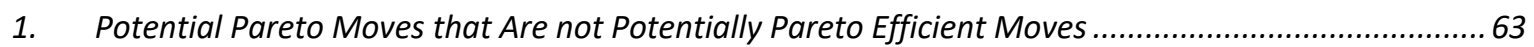

2. Complete Inequality Can Be an Efficient Outcome Under the Kaldor Test ..........................................64

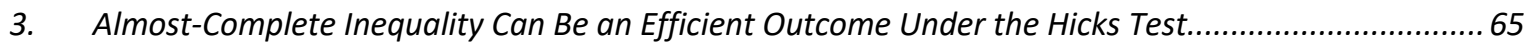

4. Application of the Kaldor and Hicks Criteria Can Result in Arbitrary Outcomes ..................................6 66

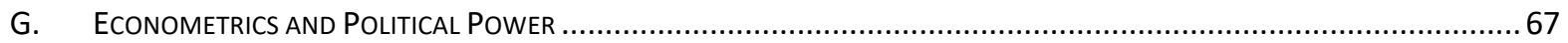

H. Positive Economic and Normative Problems With CV \& EV Measured in Dollars ............................................68

I. WATP Justifies ReSUltS THAT FAVOR THE WEALTHY (Positive THEORY) ............................................................. 71

J. WATP JUStIFIES RESULTS THAT FAVOR THE WEALTHY (NoRMATIVE THEORY) …….............................................. 72

K. The Complete Failure of Potential Pareto in a General Pure-Exchange Economy ....................................... 73

V. CONSUMER SURPLUS/CONSUMER WELFARE: COERCION, WITH LESS JUSTIFICATION ............................78

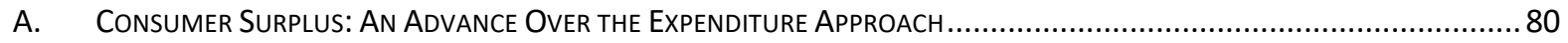

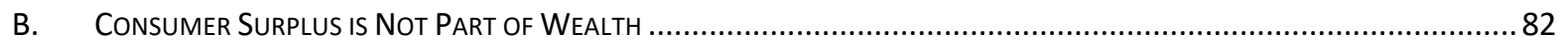

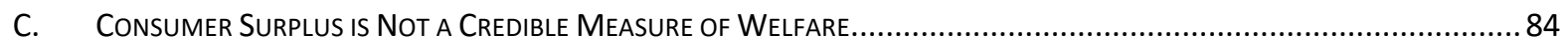

D. Willig's Claim that Consumer Surplus Approximates EV and CV Does Not SaVe Consumer Surplus ................86 


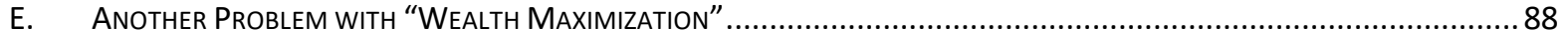

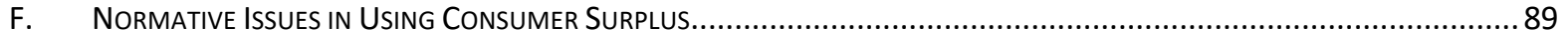

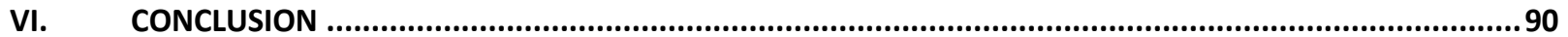




\section{INTRODUCTION}

The primary aim of the Law and Economics movement ("L\&E") has been to elevate the notion of economic efficiency as the sole basis of jurisprudence. In economics, there are several definitions of efficiency, all of which are unfortunately biased in favor of currently wealthy individuals, though to different extents. Since the most widely accepted definition of efficiency (Pareto Optimality) is inapplicable to legal disputes, L\&E was forced to resort to other definitions. But these definitions turn out to also be unsuited for legal analysis, and are rejected by quite a few economists. This paper exposes the foundational fallacy of the L\&E project and reveals what it is and, more importantly, what it is not. What it is not is a functional analytical construct for resolving legal disputes. What it is, in practice, is an apologist's tool justifying outcomes that enhance the position of the economically powerful-irrespective of any particular practitioner's intent.

Part II traces L\&E's origins from the "Free Market Study" and the "Antitrust Project" at the University of Chicago, work that was significantly advanced by Richard Posner and other Chicago economics and law faculty. Both the original work in L\&E and its rapid spread to law school faculties was funded by conservative organizations whose goal was to lift the constraints on big business imposed by the New Deal consensus. As explained by Posner at that time, the fundamental tenet of $\mathrm{L} \& \mathrm{E}$ is that the common law should be and is guided by the sole objective of economic efficiency, which, as applied by L\&E devotees, in turn implies cutting the public sector "down to the modest dimensions of the night watchman state."1 Thus, the policy prescriptions of L\&E were coextensive with the goals of the neoliberal movement and placed L\&E squarely within its narrative.

Part III begins the critical process of defining "economic efficiency." In most of traditional neoclassical economics, an "efficiency improvement" means a Pareto Improvement, which is a change that leaves no participant worse off. This is the definition of efficiency used by every major graduate textbook in economics. Part III describes several reasons why Pareto Efficiency cannot be used to establish a theory of the common law. The principal problem for L\&E is that Pareto Efficiency's requirement that there be no losers makes it unsuited for resolution of legal cases. A lawsuit in the United States requires real and non-speculative injury for constitutional standing - a requirement that perforce implies a winner and a loser.

But Pareto Efficiency is silent on any policy that has a loser. To extend the scope of economics so that it would be able to pass judgment on those kinds of policies, some economists embraced the "Potential Pareto" Criterion as a replacement for the Pareto Criterion.

The Potential Pareto Criterion, also known as Cost-Benefit Analysis and as the Kaldor and Hicks efficiency tests, is the subject of Part IV. As explained in more detail there, the Kaldor Test approves of policy changes for which the proponents could fully compensate the opponents and still be better off themselves, but the Kaldor Test does not ask the proponents to actually compensate the opponents at all. The Hicks Test disapproves of policy changes for which the opponents could fully compensate the proponents for foregoing the policy change and still be better off themselves, without actually asking the opponents to compensate the proponents at all. Part IV explains the connection between these Tests, compensating and equivalent variations, and "wealth maximization." It contrasts the logic of the Kaldor and

\footnotetext{
${ }^{1}$ Richard Posner, The Problems of Jurisprudence 307 (Harvard University Press 1990).
} 
Hicks criteria in several economic settings (in particular, the effect of price changes or of quantity changes), demonstrating that they constitute a theoretical structure riddled with inconsistencies and difficulties. Curiously, while many of these problems have long been understood by specialists in welfare economics, they have simply been ignored by L\&E proponents. By contrast, we catalogue and expand the list of problems, and show that only by reference to dubious assumptions can even some of these problems be avoided.

Part V addresses consumer surplus, another version of efficiency that has become the prevailing neoliberal goal of antitrust enforcement since it was introduced by Judge Bork in his book The Antitrust Paradox. We eliminate consumer surplus as a viable alternative to the Potential Pareto Criterion for L\&E by showing that consumer surplus theory only avoids the problems of the Potential Pareto Criterion identified in Part IV by using imprecision, which results in obfuscation, which in turn results in confusion or deception.

Two critiques of the L\&E literature form the appendices to the paper. In Appendix 1 (Part Appendix 1:) we review the leading L\&E textbooks on the critical issue of how to define "efficiency." We find these treatments, in general, incomplete at best, with many lacking any account of the many problems with whatever definition is advanced. Appendix 2 (Part Appendix 2:) reviews the notion of "efficiency" in some of the scholarly work of Richard Posner.

We conclude that while there may be ideological reasons to adopt efficiency (also called "wealth maximization" and "consumer welfare" by L\&E authors) as a goal in jurisprudence, there are no objective reasons for doing so.

Our critique is not based on rejection of standard economic assumptions - quite the contrary. Throughout this paper, we adopt all the assumptions sufficient to prove the First Fundamental Theorem of Welfare Economics, which is the modern statement of Adam Smith's "Invisible Hand" idea that laissez faire is socially optimal. These are sometimes called the Arrow-Debreu assumptions. The assumptions are that agents are fully rational, that there are no transactions costs, no strategic behavior, no asymmetric information, no "uncertainty in the sense of Frank Knight" (that is, no unknowable probability distributions), "complete" markets (markets for every asset in every state of the world), and that there are "convex" preferences and production possibility sets. We do not endorse these assumptions, ${ }^{2}$ instead we show that L\&E fails even under such strict assumptions. As a result, defenders of L\&E, implicitly or explicitly, must impose even stricter, more unrealistic assumptions. Part II raises at least the suspicion that they (or at least some of them) do so for ideological reasons.

\section{NEOLIBERALISM AND THE ORIGINS OF LAW AND ECONOMICS}

L\&E did not appear out of a theoretical vacuum. It was conceived by scholars and funded by institutions that were part of the neoliberalism movement of the 1970s, whose objective was to

\footnotetext{
${ }^{2}$ The Arrow-Debreu assumptions are not only unrealistic, they also do not guarantee or uniqueness of the competitive equilibrium, as proven by the Sonnenschein-Mantel-Debreu Theorem (see https://en.wikipedia.org/wiki/Sonnenschein \%E2\%80\%93Mantel\%E2\%80\%93Debreu theorem). Lack of uniqueness, in turn, imperils stability (see also infra note 13). In addition, the Arrow-Debreu requirements of complete markets and no Knightian uncertainty mean its treatment of dynamics is largely formal rather than substantive.
} 
eliminate and replace the New Deal policy consensus that existed at that time. In this Part we review these ideological origins of L\&E.

\section{A. The Great Depression Brings an End to Laissez-Faire Economic Policy}

At the turn of the twentieth century in the United States, the dominant economic policy regime could best be described as laissez-faire. The regulation of business was limited, fiscal policy was deemed illegitimate, monetary policy was governed by the gold standard, and banking interests were politically hegemonic. This laissez-faire policy regime lasted until the end of the 1920s. Then it lost all credibility because it was widely believed in the 1930s, and we think rightfully, that unbridled laissez-faire resulted in the great crash of the economy in 1929 . Although there is no simple explanation for the Great Depression, ${ }^{3}$ the laissez-faire policies of the 1920s unquestionably culminated in an unparalleled economic catastrophe that thoroughly discredited its policy prescriptions.

During the Great Depression, the federal government sought to change what were perceived to be the deficiencies in the laissez-faire approach. As a first measure, banks and financial institutions were regulated and their power limited. This resulted in the virtual absence of financial crises for about five decades. Then Savings and Loan institutions were deregulated in the early 1980's and the Savings and Loan Crisis followed a few years later. ${ }^{4}$ After that came more deregulation and further financial crises. At the core of the New Deal was the further belief that the excessive income and profits of big business compared to the incomes of the other social classes, including small business, farmers, and urban workers, were highly destabilizing. This view was widely held by economists during the Great Depression even before the rise in popularity of Keynesian macroeconomics. New Deal policies were fashioned to help workers by supporting their ability to unionize, establishing a minimum wage, and limiting the working week to 40 hours. The Social Security Act increased the income of the elderly and established a system of unemployment insurance. The Agricultural Adjustment Act increased the income of farmers, and the Works Progress Administration provided work for the unemployed. ${ }^{5}$ As the historian Ellis Hawley writes, the idea was to use the "government to promote the organization of economically weak groups, thus restoring economic balance...." 6 Such balance was viewed as a key element in achieving economic recovery.

It is often not recognized that the New Deal policies were spectacularly successful. As wages grew, industry responded with increased technological innovation, which led to greater productivity. As just one example, the baseline annual growth of total factor productivity between 1900 and 1920 was $1 \%$. The average for the decade of the 1920 s was $2 \%$. It increased to $3 \%$ in the $1930 \mathrm{~s}$ and $2.5 \%$ for the $1940 \mathrm{~s}$. It continued at $2 \%$ after World War II

\footnotetext{
${ }^{3}$ For a review of the theories of the Great Depression see Mark Glick, Antitrust and Economic History: The Historic Failure of the Chicago School of Antitrust, 64 Antitrust Bulletin 295-340, 309-311 (2019).

${ }^{4}$ Anthony Badger, The New Deal: The Depression Years 1933-1940, 73 (Noonday Press 1989).

${ }^{5}$ The Agricultural Adjustment Act was found unconstitutional in United States v. Butler, 297 U.S. 1 (1936).

${ }^{6}$ Ellis Hawley, The New Deal and the Problem of Monopoly: A Study in Economic Ambivalence 124 (Fordham Univ. Press 1995) ("The advantages of stronger economic organization had long been stressed by labor, farm, and small business groups. The relatively new element was the attempt of these groups to enlist governmental aid in developing market power.").
} 
until the crisis of the middle 1970s. ${ }^{7}$ There was also an explosion of R\&D expenditure during the New Deal and World War II, resulting in major technological advances and new productrelated patents. ${ }^{8}$ During World War II, the federal government invested heavily in industrial plants and equipment that were sold to private industry at bargain prices after the war. The federal government sponsored basic research that became essential to the post-World War II prosperity. Vernon Ruttan has argued that the federal government during this period was responsible for creating all the "general purpose technologies" that undergirded the post-war expansion, including aircraft design, nuclear power, and computers. ${ }^{9}$ The New Deal policy consensus continued after the war as the economy expanded with modern technology, high wages, strong unions, low inequality, and government management of the macroeconomy. The U.S. economy grew at an average of $4.4 \%$ per year with $2 \%$ inflation and consistent growth in productivity until the $1970 \mathrm{~s}$, when the crises of that decade allowed neoliberal policies to gain traction. Inflation was a fatal blow.

B. Neoliberalism and its "Freedom" Narrative Emerge as a Response to the New Deal Consensus

The neoliberal movement that spawned L\&E arose in the 1930s and 1940s to challenge the New Deal consensus. The neoliberals at this time were composed of a small group of conservative thinkers that held a wide spectrum of views. However, the movement had a unifying theme: the New Deal regulation of big business, its protection of unions, its regulation of trade, and its social programs were misguided. The neoliberal policies were similar to the laissez-faire consensus of the 1920s, but with some differences. For example, neoliberals supported some macroeconomic stabilization policies, and the gold standard of the laissez-faire period was never seriously resurrected. A small minority of the economics profession figured prominently among the neoliberal leaders. For example, frequent participants in the conferences of the important neoliberal Mont Pelerin Society included Friedrich Hayek, Ludwig Von Mises, Milton Friedman, George Stigler, Gary Becker, and James Buchanan. ${ }^{10}$ These economists produced important scientific works, but they also shared a political commitment to undermining the New Deal that was not based on science, but instead on a common pre-analytic ideological commitment to free markets. ${ }^{11}$ Moreover, in political practice, neoliberalism supported policies that gave free reign to big business interests that were

\footnotetext{
${ }^{7}$ Robert Shackleton, Total Factor Productivity Growth in Historical Perspective, Working Paper No. 2013-01, (Congressional Budget Office, March 2013) at 1.

${ }^{8}$ Mark Glick, supra note 3 at 315.

${ }^{9}$ Vernon Ruttan, Is War Necessary for Economic Growth? 13-14 (Oxford Univ. Press 2006).

${ }^{10}$ Philip Mirowski and Dieter Plehwe, The Road from Mont Pelerin: The Making of the Neoliberal Collective 140 (Harvard Univ. Press 2009). See also Quinn Slobodian, Globalists: The End of Empire and Birth of Neoliberalism 3-4 (Harvard U.P. 2018).

${ }^{11}$ Under normal conditions, scientists hold beliefs about the prevailing core theory that are themselves not the result of the scientific process. Joseph Schumpeter, History of Economic Analysis 41 (Oxford Univ. Press 1954) called these beliefs the scientist's "pre-analytic vision." This makes scientific advance difficult absent a "crisis." When we refer to "ideology," we mean a set of beliefs that support the interests of a particular class or group, but are presented as being in the general interests of all.
} 
being suppressed by New Deal policies. ${ }^{12}$ While the consensus among policy makers and social scientists shifted away from laissez-faire in the face of the empirical evidence of the crash and the success of the New Deal, the early neoliberals strongly resisted this shift.

Consider the classic neoliberal work by Friedrich Hayek, The Road to Serfdom. The central point of the book is that economic regulation of any kind undermines economic prosperity. Hayek criticized all forms of government regulation by lumping the New Deal with Nazi Germany and Soviet Russia. Hayek believed that in a laissez-faire economy, shortages would lead to higher prices, inducing more production, thus alleviating the shortage, while surpluses (excess supply of a good) would lead to lower prices, depressing production, thus alleviating the surplus. In this way, according to Hayek, laissez-faire economies automatically self-correct any shortages or surpluses of goods that develop over time. According to Hayek, any interference with a laissez-faire economy thwarted the operation of this natural equilibrating mechanism. While this argument provided a veneer of science, a careful reading of the book shows that it contains no theoretical or empirical justification for this argument, only an ideological defense of laissez-faire. Most macroeconomists were convinced by the Great Depression that laissez-faire economies were not self-equilibrating, and modern microeconomists have demonstrated that if the equilibrium in a single market is perturbed, freemarket price signals do not guarantee a return to equilibrium, i.e., markets in laissez-faire economies are not stable. ${ }^{13}$

Milton Friedman's influential book, Capitalism and Freedom, dropped the pretense of objectivity employed by Hayek. ${ }^{14}$ It described the market as the domain of "freedom" and government as the source of coercion and totalitarianism. For Friedman, the government can only be legitimately employed in a situation of market failure. ${ }^{15}$ The market is described as natural and existing prior to and independent of government because markets arise solely by individuals following self-interest. This is obviously untrue both logically and historically: markets cannot exist without secure property rights, control of theft and fraud, and contract rules adequate to facilitate trade. Such rules are determined collectively, through government,

\footnotetext{
${ }^{12}$ David Bromley, The Ideology of Efficiency Searching for a Theory of Policy Analysis," 19 J. of Env. Econ. and Management 86-107, 86, 87 (1990).

${ }^{13}$ Samuel Bowles, et al., Friedrich Hayek and the Market Algorithm, 31 J. of Econ Persp 215-230, 215 (2017) showed that there is no general proof of the "stability" of a competitive equilibrium. As noted in supra note 2, lack of uniqueness imperils stability; for more on lack of uniqueness, see Michael Mandler, Sraffian Indeterminacy in General Equilibrium, 66 Rev. Economic Studies 693-711 (1999).

${ }^{14}$ Milton Friedman, Capitalism and Freedom 14 (Univ. of Chicago Press 1962).

${ }^{15}$ Since Friedman's classic work, other neoliberal economists have gone even further and questioned the role of government even in the face of market failure. James Buchanan and other public choice theorists have argued that government failure is more serious than market failure, so government should not be employed in any economic situation. Eamonn Butler, Public Choice - A Primer 11 (Institute of Economics Affairs 2012) ("This self-interest operating in the political system will lead to 'government failure' because of the coercive power that government exercises and because government is not subject to a direct competitive process."). The public choice approach completely obscures the role of ideology and persuasion and the ability of groups to exercise and retain political power. Nancy Maclean, Democracy in Chains: The Deep History of the Radical Right's Stealth Plan for America (Penguin 2017).
} 
not by the market itself. ${ }^{16}$ It is not only these basic legal rules that are required for modern markets, however, markets often also cannot operate without additional regulation. ${ }^{17}$ As Bernard Harcourt describes:

The fundamental problem is that foundational categories of, on the one hand, "market efficiency" or "free markets" and on the other hand "excessive regulation," "governmental inefficiency," or "discipline," are illusory and misleading categories that fail to capture the irreducible individual phenomena of different forms of market organization. In all markets, the state is present. Naturally, it is present when it fixes the price of a commodity such as wheat or bread. But it is also present when it subsidizes the cultivation or production of wheat, when it grants a charter to the Chicago Board of Trade, when it permits trading of an instrument like a futures contract, when it protests the property interests of wheat wholesalers, when it facilitates the river transport of wheat, when it criminalizes the coordination of prices, when it allows the merger of grain companies, when it polices the timing of trades, and so on...All markets are highly regulated." 18

Friedman refers to the marketplace as "free" because transactions are "voluntary." But in a modern free-market economy most labor occurs within firms, within which decisions are made not on the basis of freedom but rather on the basis of command and control within a hierarchical governance structure. ${ }^{19}$ Ignoring the coercive nature of the organization of work within firms, Hayek and Friedman disingenuously treat firms as single private actors, as if the firm was a contracting individual with no more power than its employees: ${ }^{20}$ "Enterprises are private so that the ultimate contracting parties are individual." 21

Nor is the decision to accept employment necessarily "voluntary," or an agreement among equals. The voluntary theory of the nature of employment was the basis for the Supreme Court's decision in Lochner v. New York, 198 U.S. 45 (1905), in which the Supreme Court overturned a New York statute limiting the working hours of bakers because it violated the workers' right to freedom of contract under the $14^{\text {th }}$ Amendment. The decision led to an

\footnotetext{
${ }^{16}$ Jules Coleman, Risks and Wrongs 61 (Cambridge Univ. Press 1992) ("Competition presupposes a stable, enforceable scheme of property rights. Any such scheme is a collective or public good."). Duncan Kennedy, The Structure of Blackstone's Commentaries, 28 Buffalo L. Rev. 205-382 (1981) ("Here is an initial statement of the fundamental contradiction: most participants in American legal culture believe that the goal of individual freedom is at the same time dependent on and incompatible with the communal coercive action that is necessary to achieve it.")

${ }^{17}$ Every market transaction requires contract enforcement, which must be coercive, to protect expectational interests. Voluntary exchange presupposes a world of collective external contract rules and enforcement. Betty Mensch, Freedom of Contract as Ideology, 33 Stan. L. Rev. 753-772 (1981).

${ }^{18}$ Bernard Harcourt, The Illusion of Free Markets 47 (Harvard University Press 2011).

${ }^{19}$ This is the point of Ronald Coase's famous article The Nature of the Firm, 4 Economica 386-405 (1937). For example: "If a workman moves from department $\mathrm{Y}$ to department $\mathrm{X}$, he does not go because of a change in relative prices, but because he is ordered to do so" (p. 387).

${ }^{20}$ However, while firms exercise "individual" power, Friedman and Hayek treat unions as illegitimate collective actors.

${ }^{21}$ Milton Friedman, supra note 14.
} 
avalanche of criticism by the Legal Realist School. As Robert Hale wrote in 1923, "[u]nless, then, the non-owner can produce his own food, the law compels him to starve if he has no wages, and compels him to go without wages unless he obeys the behests of some employer." 22

Much of the legal realist discourse did not effectively address the assumptions behind laissezfaire ideology. Robert Hale's work was an exception. For Hale, choices in the market are not voluntary because alternatives are limited by legal entitlements. Instead, Hale labelled market choices as "volitional." Volitional choices are those choices circumscribed by each market participant's opportunity set. Property rights determine the degree to which each participant's opportunities are expansive or limited. The institutional economist Warren Samuels probably best depicted Hale's distinction in the following passage:

If we define as volitional freedom the opportunity or capacity to choose between alternatives, and if we define as voluntary freedom the opportunity or capacity to determine the alternatives themselves between which one may choose, then it appears that the difference between voluntary and volitional freedom is very largely for present purposes the impact of the operation of choice by others, as manifest and embodied in, for example, particular legal arrangements, which is simply another way of saying that one economic actor is limited or constrained to bear the costs in various forms imposed by other economic actors jointly and severally either through market forces or the legal process. The impact of others' decisions and choices is transmitted to the one actor whose range of alternatives is thus circumscribed so that freedom is volitional and not voluntary. ${ }^{23}$

Using Hale's methodology, the neoliberal "free market" based on voluntary transactions is merely a volitional freedom. One's income and property rights determine the actual choices that are available. Choosing between starvation or farm labor is not the same human experience as choosing between fine restaurants to frequent, even though legally, no one is prevented from fine dining or starvation. The upshot is that the economy is a domain of coercion just as the government is, and property rights create the ability to exercise economic coercion against others. For example, for Hale, the price of any commodity, such as food, is

${ }^{22}$ Robert Hale, Coercion and Distribution in a Supposedly Non-Coercive State, in Fisher, et.al., American Legal Realism 103 (Oxford Univ. Press 1993). Indeed, long before the Legal Realists, Marx sarcastically summarized the laissez-faire vision of the free labor market:

The sphere that we are deserting, within whose boundaries the sale and purchase of labour-power goes on, is in fact a very Eden of the innate rights of man. There alone rule Freedom, Equality, Property and Bentham. Freedom, because both buyer and seller of a commodity, say of labourpower, are constrained only by their own free will. They contract as free agents, and the agreement they come to, is but the form in which they give legal expression to their common will. Equality, because each enters into relation with the other, as with a simple owner of commodities, and they exchange equivalent for equivalent. Property, because each disposes only of what is his own. And Bentham, because each looks only to himself. The only force that brings them together and puts them in relation with each other, is the selfishness, the gain and the private interests of each. Each looks to himself only, and no one troubles himself about the rest, and just because they do so, do they all, in accordance with the pre-established harmony of things, or under the auspices of an allshrewd providence, work together to their mutual advantage, for the common weal and in the interest of all. - Karl Marx, Capital Vol. I 172 (Progress Press 1972).

${ }^{23}$ Warren Samuels, Interrelations between Legal and Economic Processes, 14 J. of Law and Econ. 435-450, 440 441 (1971). 
the amount that must be paid to overcome the owner's legal right to withhold the commodity. ${ }^{24}$ As Hale stated regarding a starving person: "While there is no law against eating in the abstract, there is a law which forbids him to eat any of the food which actually exists in the community - and that law is the law of property." 25 The function of anyone's income is to give the person the ability to pay the owner of a commodity enough to induce that owner to forego his/her ability to exercise economic coercion. ${ }^{26}$ Smaller income reduces volitional freedom.

Thus, the neoliberals are incorrect in maintaining that freedom is maximized in an economic market when it is unregulated by any government action. In reality, government regulation does not increase coercion at all, it only shifts who is benefitted by the totality of economic and government coercion. Barbara Fried, in her book on Robert Hale, explains this point succinctly:

That situation meant that when the government intervened in private market relations to curb the use of certain bargaining power, it did not inject coercion for the first time into those relations; it merely changed the relative distribution of coercive power. ${ }^{27}$

Another implication of the fact that a legal structure must pre-exist for a market to operate is that the outcomes of voluntary trade are partially determined outside the market. Because property rights and other legal rights determine economic agents' opportunity sets, they also determine, along with preferences, the outcomes of "voluntary" trade. Each agent's substitute opportunities to any transaction - their "opportunity cost" or "threat values" of abstaining from trade - in part determine the equilibrium outcome of such trade. For example, if workers are given a right to a safe workplace, this alters the outcome of voluntary trade in the labor market compared to the situation where they have no such right.

Robert Hale's views were antithetical to laissez-faire ideology, but not the views of the economics profession. Economists have always recognized that power and coercion were exercised in the economy. For example, Adam Smith, David Ricardo, and Thomas Malthus explained that subsistence wages are the result of the lack of power by workers because of their chronic oversupply and lack of alternatives. Karl Marx emphasized that the workers had little economic power because they did not own the "means of production," meaning that their alternative opportunities for a livelihood were limited.

The American Institutionalist economists also analyzed economic power relations. Richard Ely, for example, was critical of laissez-faire judges who viewed all economic transactions as

\footnotetext{
${ }^{24} I d$. at 440 ("Private rights, for example, property rights, are in effect capacities to participate in the economic decision-making process as a coercive force; they define and delineate loci and conditions of power, or participation. This means [...] that the distribution of relative risk, business costs, and resource allocation, income distribution and general level of income are a partial function of law.”).

${ }^{25} I d$.

${ }^{26}$ While Hale focused on property rights, contract rights and other legal entitlements also impact income. For example, contract defenses such as "duress," "necessity," or "unconscionability" are distributional, as are inheritance laws and tort laws such as the duty to give aid.

${ }^{27}$ Barbara Fried, The Progressive Assault on Laissez-faire: Robert Hale and the First Law and Economics Movement 17 (Harvard Univ. Press 1998).
} 
free and voluntary. He wrote, "It must be observed here in criticism that in other contracts, especially labor contracts, the coercion of economic forces has not received that which must be demanded by a realistic jurisprudence based on the actual economic life of the twentieth century." 28

The neoclassical economic theory that arose in the 1870s similarly did not posit the economy as a domain of freedom devoid of differences in economic power. Neoclassical theory merely took existing income distribution as an input and proceeded from there. It stopped short of the neoliberals by simply leaving the origin of existing economic power unanalyzed, choosing instead to focus on the properties of a model with a given distribution of commodities and property rights (given "endowments," to use the economists' term). As described in the next section, the neoclassical concept of Pareto Efficiency does not divorce distribution from efficiency, and the initial property rights that set the endowments (along with preferences) determine the specific efficient market outcome (given the standard Arrow-Debreu assumptions).

C. Law and Economics Finds a Home and Funding

Until the 1970s, L\&E was represented in only a small minority of law schools and represented a fringe view of jurisprudence. It had gained an important foothold at the University of Chicago after Hayek helped bring Aaron Director to the University of Chicago Law School and secured funding from the Volker Fund for the "Free Market Study" that ran from 1953 to 1957. The Volker Fund also helped bring Ronald Coase to the Chicago Law School. The Free Market Study was followed by the "Antitrust Project." L\&E then grew out of the Chicago School's critique of antitrust law. In 1958 the Journal of Law and Economics was formed with Director, and later Coase, as its editor. The University of Chicago further sponsored law and economics fellowships that included Richard Posner as a recipient, and Posner was brought from Stanford to the Chicago Law School in 1969.

The economic crisis of the late 1960s and 1970s ushered in the main conservative political counterattack on New Deal policies. During the 1970 s unemployment grew to $6.22 \%$, inflation raged at an average $7.09 \%$, and corporate profits and productivity declined precipitously. ${ }^{29}$ Low profits and high inflation eroded high incomes. The income share of the top $1 \%$ of earners reached a post-World War II low in the 1970s. ${ }^{30}$ This induced a well-funded conservative backlash: the Business Roundtable was founded in 1972, ${ }^{31}$ the Heritage Foundation in 1973, and the Cato Institute in 1974 (by Charles Koch). ${ }^{32}$ In the early 1970's, Richard Posner wrote

\footnotetext{
${ }^{28}$ Richard Ely, Property and Contract in Their Relations to the Distribution of Wealth, Vol III 608 (Macmillan 1914). John Commons also stressed that property rights distribute economic power. "The economists, however, took property rights as self-evident and not needing justification or investigation; and founded their theories on a contradictory definition of wealth as materials and the ownership of materials." John Commons, Institutional Economics: Its Place in Political Economy 114 (Macmillan 1934).

${ }^{29}$ Mark Glick supra note 3 at 323-324.

30 Timothy Noah, The Great Divergence 24 (Bloomsbury 2012).

31 John Saloma, Ominous Politics 66-67 (Hill and Wang 1984).

${ }^{32}$ Kurt Andersen, Evil Geniuses: The Unmaking of America a Recent History, Part II (Ebury Press 2020).
} 
the first edition of his landmark work The Economic Analysis of Law ${ }^{33}$ in which he proposed the goal of economic efficiency, defined as "willingness to pay" or "wealth maximization," as the foundation stone of L\&E. He further purported to show how this basis could be employed to analyze virtually every area of legal analysis. Posner's book spawned an enormous literature on L\&E, which accepted his originating premise that efficiency should be, and in fact is, the basis of the common law.

During the rise of neoliberalism in the 1970s, conservative funding organizations funded L\&E scholarship at law schools and L\&E made tremendous strides among law faculties. ${ }^{34}$ Of particular importance in promoting L\&E was the work of the John M. Olin Foundation, which supported Henry Manne's Economic Institute for Federal Judges. In 1990, Manne's institute hosted $40 \%$ of the federal judiciary. ${ }^{35}$ Olin supported L\&E programs at many major law schools including Chicago, Yale, Columbia, Harvard, Penn, Stanford, Berkeley, Virginia, Georgetown, Cornell, Michigan and George Mason. ${ }^{36}$ These schools further turned out students trained in L\&E who populated the faculties of other law schools across the nation. As Steven Teles concludes, "simply measured in terms of the penetration of its adherents in the legal academy, law and economics is the most successful intellectual movement in the law of the past thirty years." ${ }^{37}$

\section{Law \& Economics Advances the Modern Neoliberal Agenda}

We discuss at length in this paper how inconsistent and flawed L\&E's notion of efficiency is. For now, it is important to understand that Posner's claim that legal decisions should be based on "wealth maximization"/"willingness to pay" is congruent with the neoliberal enterprise. Allocating resources based on "willingness to pay"- "willingness and ability to pay," more properly - simply asks judges to reproduce the prevailing economic power relationships in the market, since it is big business and wealthy individuals who have a greater ability to pay (see Sections IV.A.3, IV.I, and IV.J below). In addition, since Posner claims that efficiency is separate from distribution (which is false, see Section III.G.1(c) below), adopting his approach counsels judges to ignore the wealth distributional impacts of their decisions. Moreover, by endorsing efficiency as the only goal, $L \& E$ advocates that the goal of antitrust law should be limited to increases in consumer welfare, not to curb the business strategies of large firms that harm smaller firms and other groups or consumers on a basis other than higher prices. Using its own definition of efficiency, L\&E views property law as channeling transactions into the existing market without altering the opportunity sets of market participants, and views contract law as only facilitating these market transactions, not influencing their outcomes. Moreover, under this construct, tort law is understood as finding the lowest-cost method of controlling externalities, but it measures such costs at existing market prices (which depend on distribution), and criminal law takes the existing criminal statutes as a given and examines how

\footnotetext{
${ }^{33}$ Richard A. Posner, The Economic Analysis of Law (Little, Brown, copyright 1972/published 1973).

${ }^{34}$ Mark Glick, supra note 3 at 325.

${ }^{35}$ Steven Teles, The Rise of the Conservative Legal Movement: The Battle for Control of the Law, 112-113 (Princeton Univ. Press 2008).

${ }^{36} I d$. at 200.

${ }^{37} I d$. at 216.
} 
incentives can best be fashioned to conform to those laws and only those laws. Thus, the use of a flawed concept of efficiency provided a veneer of science for neoliberal ideology.

Posner himself candidly conceded that "wealth maximization" supported the interests of "dominant groups" in the economy:

Wealth maximization is an ethic of productivity and social cooperation - to have a claim on society's goods and services you must be able to offer something that other people value ... And an ethic of productivity and cooperation is more congruent with the values of the dominant groups in our society than the pure utilitarian ethic would be. ${ }^{38}$

Posner also openly committed to the Neoliberal agenda of reducing the scope of government: ${ }^{39}$

All modern societies depart from the precepts of wealth maximization. The unanswered question is how the conditions in these societies would change if the public sector would be somehow cut all the way down to the modest dimensions of the night watchman state that precepts of wealth maximization seem to imply [emphasis added]. ${ }^{40}$

It is noteworthy that Posner's position attracted sustained criticism for its normative implications, which we expand on in Sections IV.F-IV.J, but not for his positive economics. ("Normative" refers to subjective matters involving value judgments, while "positive" refers to objective matters which can be proven to be either true or false.) In the face of these normative critiques, Posner retreated. By 1990, Posner, reflecting on his 1979 book The Problems of Jurisprudence, wrote that "The strongest argument for wealth maximization is pragmatic" 41 not ethical. By 2011, the ethical case supporting "wealth maximization"/"willingness and ability to pay" had all but collapsed, so that Scott Hershovitz could write, ${ }^{42}$ "...nowadays nearly no one thinks wealth maximization is an attractive ethical principle, except perhaps as a proxy."

Although Posner agreed he could not defend the "wealth maximization"/"willingness and ability to pay" version of economic efficiency on normative grounds, that version of efficiency has remained the foundation of L\&E. But its defects are not only normative. In Sections IV.E and IV.H we show that L\&E is also seriously defective on positive grounds, even accepting all the neoclassical assumptions of the Arrow-Debreu model. Because of those both positive and normative problems, the other notion of efficiency in economics, Pareto Efficiency, is much more widely accepted by economists (see Section III.C). While subject to considerably fewer problems than "willingness and ability to pay," Pareto Efficiency is not problem-free. Indeed,

\footnotetext{
${ }^{38}$ Richard A. Posner, supra note 1 at 391 . We discuss wealth maximization and its fundamental flaws in detail below.

${ }^{39}$ He believed that capitalism was more successful than socialism and that the wealth maximization goal supported free markets. Richard A. Posner, supra note 1 at 384 ("we have reason to believe that markets work - that capitalism delivers the goods...").

${ }^{40}$ Richard A. Posner, supra note 1 at 387.

${ }^{41}$ Id. at 382

${ }^{4}$ Scott Hershovitz, Harry Potter and the Trouble with Tort Theory," 63 Stan. L. Rev. 67-114, 75 note 16 (2011).
} 
as we show in the next Part, even those less significant problems render Pareto Efficiency incapable of constituting a theory of the common law.

\section{PARETO EFFICIENCY: THE REALM OF CONSENSUS}

This Part sketches the historical development of the notion of economic efficiency, explains economists' modern understanding of that word, shows that efficiency cannot be completely separated from distribution, and describes why economic efficiency cannot serve as a foundation for L\&E. To lay the foundation for discussing efficiency, we begin by discussing the history of utility theory and by showing that there cannot be interpersonal comparisons of utility.

\section{A. The Beginnings of Utility Theory}

Prior to the development of neoclassical economics in the 1870s, the classical economists such as Adam Smith, David Ricardo, Karl Marx, and John Stuart Mill believed that prices were determined by a commodity's cost of production. The "value" of a good or service was the average direct and indirect labor time necessary for its production. For the classical economists, value was an objective measure and there was no concept that could be used as a basis for measuring human well-being, either at the level of an individual or at the aggregate level of an entire society.

Early neoclassical economists William Jevons, Leon Walras, and Carl Menger replaced the classical emphasis on the cost of production with a consumer-demand-based theory of shortterm prices. ${ }^{43}$ They introduced the concept of "utility," a measurement of happiness, to understand demand by consumers for goods and services. The consumer's demand for a product or service was based on the additional, or "marginal," utility the consumer received from consuming that last unit of the good or service, constrained by the consumer's income. It was not until Alfred Marshall published his Principles of Economics in 1890 that supply considerations were addressed and the cost of production was reintroduced into the analysis.

By placing the subjective concept of happiness at the heart of the theory of price formation, the neoclassicals were advancing a hedonic concept of an individual's utility - that is, utility was simply a number that represented a measure of human happiness.

In tandem with developing utility as a positive description of what motivates individuals' behavior, economists also developed a normative movement called Utilitarianism that drew implications from utility theory for public policy. Having developed a numerical measure of individual utility, it was a simple step for early neoclassical economists to further assert that there was a numerical measure of aggregate, social utility, or total welfare, which was simply the sum of the utility of all the individual consumers. (Producers were not ignored, but simply recognized in their role as consumers, the idea being that the term "consumers" encompasses all economic agents who are natural persons.) Maximizing this single number then became the proper purpose of all economic policy. This is Bentham's fundamental axiom of "the greatest

\footnotetext{
${ }^{43}$ William Jevons, The Theory of Political Economy (Macmillan 1871); Carl Menger, Grundsätze der Volkswirthschaftslehre [Principles of Pure Economics] (Braumüller 1871); Léon Walras, Eléments d'économie politique pur ou théorie de la richesse sociale [Elements of Pure Economics] (L. Corbaz 1874).
} 
happiness principle" or "the principle of utility." 44 Many Utilitarians, including Alfred Marshall, posited diminishing returns in utility when a person consumes more and more of a particular product or service. For example, the tenth scoop of ice cream is less satisfying then the first. Marshall thought that diminishing returns also applied to money: the more total wealth an individual has, the less additional utility is obtained from another dollar. This property, referred to as the declining marginal utility of money, implies that total social utility can be increased by equalizing wealth, and equalizing wealth therefore became a common policy prescription among the later Utilitarians. ${ }^{45}$

\section{B. Utility: Cardinal and Ordinal}

In the early twentieth century the notion of measuring "happiness" came to be recognized as unacceptably vague: there is simply no method for objectively identifying and measuring happiness. Moreover, a single number cannot capture the multidimensional nature of happiness. Happiness could include feelings of dignity, relief, pride, contentment, respect, and numerous other distinct thoughts and emotions. ${ }^{46}$ Alfred Marshall was one of the first to reframe utility as a measure of satisfaction of a desire or want, rather than happiness per se. ${ }^{47}$ By the time of Jacob Viner's classic 1925 article on this topic, virtually all economists had adopted the "satisfaction of desire" view of utility. ${ }^{48}$ Today, utility refers to a number that represents a measure of satisfaction of a want or desire.

This reinterpretation addressed the problem that the prior interpretation was unacceptably vague, but did not address the growing concern that Marshall's utility numbers were simultaneously, albeit in a different way, unacceptably precise. That is, these numbers were "cardinal" in nature. When a quantity is "cardinally" measurable, the notion of "twice" an initial quantity is meaningful. For example, weight is cardinally measurable, and the notion that one object weighs twice as much as another is meaningful; whereas temperature or calendar date are not cardinally measurable because the notion that one temperature or calendar date is "twice as large" as another is not meaningful. (Saying January 1, 2000 was "twice as large" as January 1, 1000 has no meaning because it is false if one switches to any other equally valid calendar. Saying that a temperature of 200 degrees Fahrenheit is "twice as large" as a temperature of 100 degrees Fahrenheit has no meaning because those temperatures are the same as 93.3 and 37.8 degrees Celsius, the former of which is not twice the latter.) Quantities

\footnotetext{
${ }^{44}$ Alesssandro Roncaglia, The Wealth of Ideas, A History of Economic Thought 175 (Cambridge University Press 2005).

${ }^{45}$ A.C. Pigou, The Economics of Welfare 89 (Macmillan $4^{\text {th }}$ ed 1932 ( $1^{\text {st }}$ ed 1920)): "Nevertheless, it is evident that any transference of income from a relatively rich man to a relatively poor man of similar temperament, since it enables more intense wants to be satisfied at the expense of less intense wants, must increase the aggregate sum of satisfaction. The old 'law of diminishing utility' thus leads securely to the proposition: Any cause which increases the absolute share of real income in the hands of the poor, provided that it does not lead to a contraction in the size of the national dividend from any point of view, will, in general, increase economic welfare."

${ }^{46}$ Indeed, the list of positive experiences is very long. Modern neuroscience has found several hormones that produce pleasurable feelings from different types of activities including dopamine, serotonin, oxytocin, and endorphins. One must suspend one's intuition about living life as a human being to accept a single number for happiness.

47 Alfred Marshall, Principles of Economics (Macmillan $8^{\text {th }}$ ed 1920).

${ }^{48}$ Jacob Viner, The Utility Concept in Value Theory and its Critics, 33 J. Pol. Econ. 369--387 (1925).
} 
that can only be ordered (ranked), but not otherwise measured, are called "ordinal." An example is the letters in the English alphabet: they have a traditional order, "a" first and " $\mathrm{z}$ " last, but this order has no cardinal meaning (there is no sense in which " $b$ " is twice as large as "a" or one larger than "a"). Similarly, economists came to recognize that it is impossible to assign a meaning to "twice as much satisfaction." 49 When a consumer's utility from consuming one bundle of goods is assigned the number 4, and the utility from consuming a different bundle of goods is assigned the number 2, we cannot conclude that the first bundle gives that consumer "twice as much satisfaction." There is simply no basis to understand consumer satisfaction in this way. Marshall's utility numbers were cardinal numbers and therefore conveyed information about both order and intensity of satisfaction, but most economists today agree that we cannot infer intensity of satisfaction from observation of actual consumer choices. From those choices we can only infer whether a consumer prefers one good or bundle of goods over another. That is an ordinal ranking, not a cardinal measurement. Since ordinal numbers represent order but not intensity, economists now understand utility to be only ordinally measurable. ${ }^{50}$ An implication of this is that when a consumer's utility from consuming one bundle of goods is assigned the number 4, and the utility from consuming a different bundle of goods is assigned the number 2 , each of the numbers " 4 " and " 2 " can be replaced by any other number as long as the first number is larger than the second number. For example, we could choose to assign the first bundle of goods the utility value "one million" and the second bundle of goods the utility value "negative 17"; or we could assign the first bundle a utility of "negative 0.0003 " and the second bundle a utility of "negative 1000. ."

Once economists began to abandon cardinal utility in favor of ordinal utility, Utilitarian ideas lost favor with them. The shift to ordinal utility at the level of individual consumers makes Utilitarianism at the level of society even more untenable because it makes no sense to add numbers that only represent order. In other words, since adding together or comparing different people's utilities is meaningless, no interpersonal comparisons of utility are possible. ${ }^{51}$ This destroyed "the sum of utilities" as the lodestar of economic policy.

One reaction to this loss was to adopt something called "the sum of social surplus" as the new lodestar for economic policy, which is the topic of Part V below. Briefly, this approach strongly resembles the "sum of utilities" approach in that even though it fortunately no longer

\footnotetext{
${ }^{49}$ W. Stanley Jevons, The Theory of Political Economy 14 (Macmillan $3^{\text {rd }}$ ed. 1888): "The reader will find, again, that there is never, in any single instance, an attempt made to compare the amount of feeling in one mind with that in another. I see no means by which such comparison can be accomplished." Lionel Robbins, Interpersonal Comparisons of Utility: A Comment, 48 Economic J. 635-641, 640 (1938): "I still cannot believe that it is helpful to speak as if interpersonal comparisons of utility rest upon scientific foundations...."

${ }^{50}$ When studying decision-making under uncertainty, economists often use cardinal utility. They do so whenever using the "Expected Utility Hypothesis." Perhaps not coincidentally, this is one of the least successful parts of microeconomic theory, and part of another field, behavioral economics, has arisen in opposition to it. See for example Avinash Dixit, Critiques of Expected Utility Theory, Notes for Lectures, Eco 317 Economics of Uncertainty [Princeton University] (Fall Term 2009), available at https://www.princeton.edu/ dixitak/Teaching/EconomicsOfUncertainty/Slides\&Notes/Notes10.pdf.
}

${ }^{51}$ Peter Hammond, Interpersonal comparisons of Utility: Why and How They Should be Made, Dept. of Econ, European Univ. Inst. (1990) ("This paper discusses reasons why interpersonal comparisons of utility (ICU's) have been eschewed in the past and argues that most existing approaches, both empirical and ethical, to ICU's are flawed."). 
adds up cardinal utility of different people to come up with a grand total of utility for all of society, it does use cardinal "surplus," and it adds up the cardinal "surpluses" of different people to come up with a grand total of "surplus" for all of society. The "surplus" approach predates ordinal utility theory, and Alfred Marshall advocated it more or less in tandem with his advocacy of Utilitarianism. However, Marshall realized that the surplus approach failed to correctly describe how consumers react to income changes. Kaldor and Hicks later modified the surplus approach by fixing that aspect of it, giving rise to the "Potential Pareto" approach which is the topic of Part IV below.

The other reaction to the loss of the "sum of utilities" as the lodestar of economic policy was to throw out any cardinal measurement of either individual or social welfare, and therefore to reject using a sum to consolidate the experiences of all of society's different people into a single number. This more modern approach was begun by Vilfredo Pareto and is the topic of the rest of this Part III.

\section{Economic Efficiency is Pareto Efficiency}

Vilfredo Pareto, in his Manual of Political Economy first published in 1906, was one of the first economists to reject cardinal utility and the interpersonal comparability of utility. ${ }^{52}$ His replacement for "the sum of utilities" as the basis of economic policy today bears his name: "Pareto Improvements" are defined as changes in which at least one agent is benefitted while none are harmed. (The amount of benefit, which would be cardinal, is irrelevant: only direction matters.) Pareto defined, for the first time, the word "efficiency" in the context of economic policy: he defined a situation to be "efficient" if no Pareto Improvements from it are possiblei.e., there is no possible change that would benefit one agent without making another worse off. Then, Pareto asserted that the purpose of economic policy should be to eliminate any situation that is not Pareto Optimal. This "Pareto Principle" uses only ordinal utility and no interpersonal utility comparisons.

Every major first-year Ph.D.-level microeconomics textbook today adopts Pareto's definition of efficiency, although they sometimes redundantly introduce the terms "Pareto Efficiency" and "Pareto Optimality" as synonyms for "efficiency." (Even more confusing is economists" penchant to use "Optimality" as a synonym for "Pareto Optimality" even though this clashes with economists' use of the word "optimal" in many other contexts.) In the well-known texts of Varian ${ }^{53}$ and of Jehle and Reny, ${ }^{54}$ the word "efficiency" is exclusively used as a synonym for Pareto Efficiency. In the well-known text of Mas-Colell, Whinston, and Green, "efficient production" means "it is impossible to produce more of one output and no less than any output

\footnotetext{
52 Vilfredo Pareto, Manual of Political Economy, (Oxford Univ. Press 2014).

${ }^{53}$ Varian neither defines nor uses the single word "efficiency" in the text of his book. It appears in some of his headings, such as "13.10 Efficiency and Welfare," but the accompanying text always puts the word "Pareto" before "efficiency." See Hal R. Varian, Microeconomic Analysis 226, 227 (W. W. Norton $3^{\text {rd }}$ ed. 1992).

${ }^{54}$ See for example Geoffrey A. Jehle and Philip J. Reny, Advanced Microeconomic Theory 186 (Pearson Education Limited $3^{\text {rd }}$ ed. 2011): "Now it would seem that to obtain an efficient outcome, the total surplus - the sum of consumer and producer surplus - must be maximised. Otherwise, both the producer and the consumer could be made better off by redistributing resources to increase the total surplus, and then dividing the larger surplus among them so that each obtains strictly more surplus than before. But we must take care...." (emphases added).
} 
while simultaneously using no more of any input" (p. 150); but every other use of the word "efficiency" in that book means Pareto Efficiency. ${ }^{55}$

We examine in turn three concepts of efficiency that are part of Pareto Efficiency: distributive efficiency, productive efficiency, and allocation efficiency.

\section{Pareto Efficiency Requires Distributive Efficiency}

The simplest model of an economy considered by economists has no production of new commodities. The economy is limited only to exchange of previously existing goods. Such an economy is called a "pure exchange" economy. In a pure exchange economy, provided certain simplifying assumptions are made, a Pareto Efficient allocation has the following property. Suppose that, upon taking one unit of a commodity - say, apples - from one person - say, Jones - it is the case that Jones would accept " $x$ " units of another commodity - say, bananasas full compensation for his loss of the apple. The number $x$ is called Jones's marginal rate of substitution ("MRS") of bananas for apples. At a Pareto Efficient allocation, i.e., where no more Pareto improvements are possible, all persons in the economy must have equal MRS of bananas for apples. ${ }^{56}$ In this situation, where the economy is limited to exchange, we say that we have achieved "distributive efficiency."

Figure 1 is an Edgeworth Box and is used to illustrate distributive efficiency. ${ }^{57}$ The width of this Box represents the number of apples in the economy and the height of the box represents the number of bananas in the economy. The "apple" (horizontal) and "banana" (vertical) coordinates of a point such as F represent the number of apples and bananas consumed by Smith. Simultaneously, the banana consumption of the other person (Jones) in the economy is measured down along the right-hand axis, and Jones's apple consumption is measured to the left along the upper axis. The upper right-hand corner of the Box represents Jones consuming no commodities and all the economy's commodities being consumed by Smith.

\footnotetext{
${ }^{55}$ See for example Andreu Mas-Colell, Michael D. Whinston and Jerry R. Green, Microeconomic Theory 307, 308 (Oxford University Press 1995): "An economic outcome is said to be Pareto optimal if it is impossible to make some individuals better off without making some other individuals worse off. This concept is a formalization of the idea that there is no waste in society, and it conveniently separates the issue of economic efficiency from more controversial (and political) questions regarding the ideal distribution of well-being across individuals."

${ }^{56}$ The proof of this result is by contradiction. Begin by supposing that the situation is Pareto Efficient but that there are the two consumers, Jones and Smith, whose MRS's of apples for bananas are different. Suppose Jones's MRS is 3 and Smith's MRS is 2. Now take an apple away from Smith. Give Smith two bananas taken from Jones, thus leaving Smith as well off as she was initially; and give Jones the apple taken from Smith. Had Jones been left with one more apple and three fewer bananas, Jones would have been as well off as he was originally, but he is actually left with one more apple and two fewer bananas, so he is better off than he was originally. With Smith equally well off as she was originally and Jones better off than he was originally, the original situation cannot have been Pareto Efficient because additional improvement was possible. This contradiction establishes the proof. The case in which Jones's MRS was less than Smith's is proven similarly.

${ }^{57}$ The Edgeworth Box was introduced by Francis Ysidro Edgeworth in 1881, further developed by Pareto in 1906, and popularized by Bowley in 1924.
} 


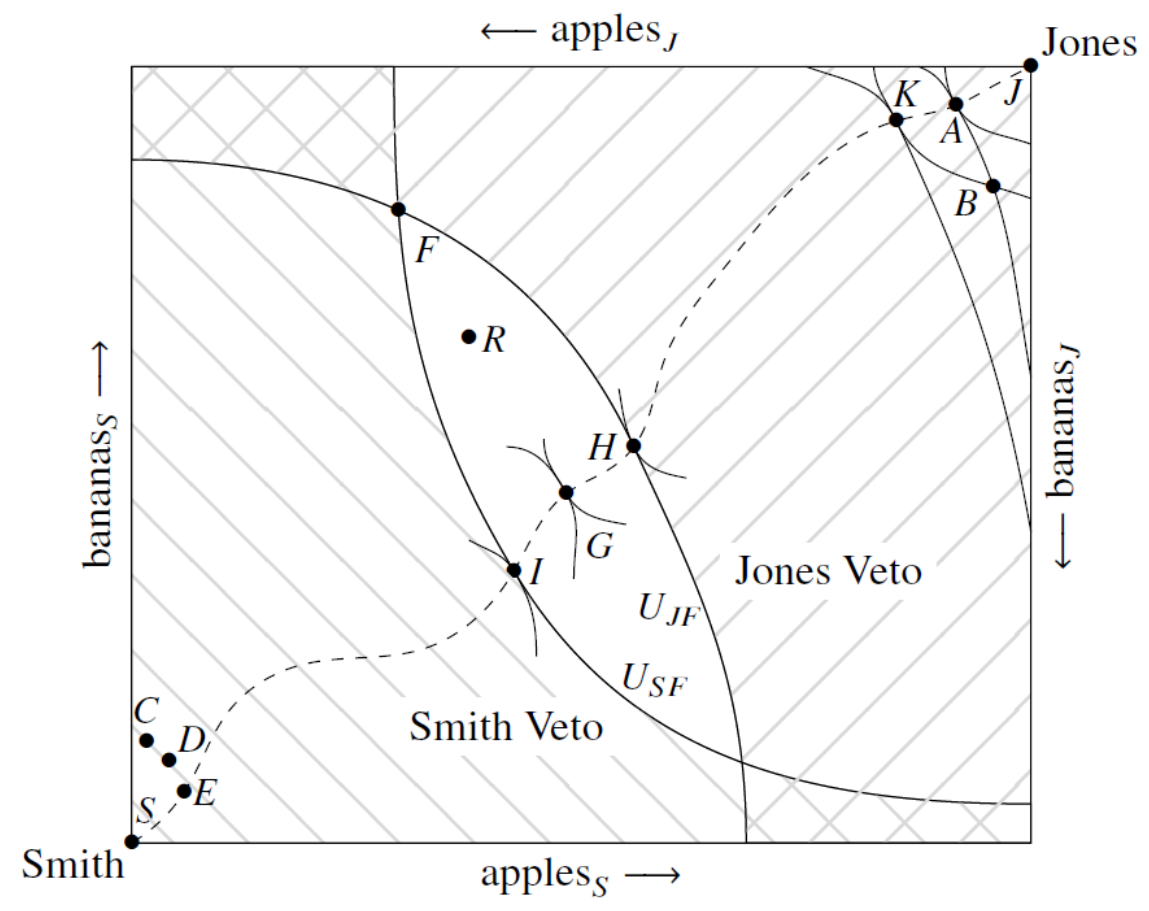

Figure 1. An Edgeworth Box and its contract curve.

All the combinations of apples and bananas belonging to the curve going through points $\mathrm{F}$ and I represent points giving Smith the same utility as point $\mathrm{F}$ and point I; that curve is therefore called an "indifference curve," " $U_{S F}$." All the combinations of apples and bananas belonging to the curve going through points $\mathrm{F}$ and $\mathrm{H}$ give Jones the same utility as point $\mathrm{F}$ and point $\mathrm{H}$, so that is one of Jones's indifference curves, " $U_{J F}$." Each consumer has an infinite number of indifference curves. Smith's indifference curves represent higher utility for Smith the more right and higher the curve is, while Jones's indifference curves represent higher utility for Jones the more left and lower the curve is. Indifference curves have ordinal, not cardinal values: if one has a higher value than another, it means that the consumer has higher utility along the first than along the second, but "how much more utility" is not a meaningful question.

If the economy begins at point $\mathrm{F}$, then Smith would veto any redistributive policy that moved into the "Smith Veto" region of the graph because such policies would result in less than the level of utility $U_{S F}$ to Smith. Jones would similarly veto any redistributive policy that moved into the "Jones Veto" region of the graph because such policies would result in less than the level of utility $U_{J F}$ to Jones. However, there is an unshaded region of the graph that neither party would veto. A policy suggesting a move into this region or onto its edge, such as to Points $\mathrm{G}$ or $\mathrm{H}$ or I, would be vetoed by no one. (Remember our assumption that Smith and Jones only care about the number of apples and bananas they consume, and not about the fairness of an allocation, which involves the number of apples and bananas the other person consumes.) A move to Point G would improve Smith's utility compared to Point F, since Point $\mathrm{G}$ represents more apples (a rightward movement) and more bananas (an upward movement) for Smith compared to Point I, and Point I gives Smith the same utility as Point F did, namely $U_{S F}$. A move to Point G would also improve Jones's utility compared to Point F, since Point G represents more apples (a leftward movement) and more bananas (a downward movement) for Jones compared to Point H, and Point H gives Smith the same utility as Point F did, namely 
$U_{J F}$. Moving from $\mathrm{F}$ to $\mathrm{G}$ is therefore a Pareto Improvement, proving that point $\mathrm{F}$ is not a Pareto Optimal point.

Points G, H, and I are, however, Pareto Optimal points. For example, if one were to sketch the "Jones Veto" and "Smith Veto" areas for Point G, the union of those areas would include every point in the Box. In general, at inefficient points like $F$, the indifference curves of the agents will not be tangent, whereas at efficient points like $\mathrm{G}, \mathrm{H}$, and I, the indifference curves of the agents will be tangent. This turns out to be identical to the observation made above that at efficient points the agents' MRS's are equal. ${ }^{58}$

There are an infinite number of points of tangency like G, H, and I, stretching from the lower left of the box (Point S) to the upper right (Point J). This set of efficient points is called the "contract curve" because (from the rather naïve viewpoint of pre-1970's microeconomics) there is no reason for the parties to sign a final contract that is not located on that curve. It is indicated by the dashed lines in Figure 1.

Each point on the contract curve generates a certain utility for Smith and for Jones. Hence each point on the contract curve generates a point on a new graph, Figure 2, depicting Smith's utility on one axis and Jones's utility on its other axis. In the Edgeworth Box, Smith's utility will be least for points on the contract curve near the lower left and most for points on the contract curve near the upper right; Jones's utility will be least for points on the contract curve near the upper right and most for points on the contract curve near the lower left. Hence along the contract curve, as one agent's utility goes up, the other agent's utility goes down. Therefore in Figure 2, depicting Smith's utility on one axis and Jones's utility on the other axis, the graph depicted will be downward sloping, showing an inverse relationship between the utility of the two agents once attention is confined to efficient points. This is expected: were the utility of the agents not related inversely, or "antagonistically," to each other, the utility of both agents could rise together, hence the original situation could not have been an efficient one. The relationship in Figure 2 is called the "utility possibility frontier." 59 Since utility is measured ordinally, there are utility possibility frontiers representing the same preferences as Figure 2 but having somewhat different shapes (where "somewhat different" means that the consumption bundle generating point $\mathrm{T}$ in Figure 2 would still have to generate a point on any such alternative utility possibility frontier that would lie above and to the left of the point generated by the consumption bundle that in Figure 2 gives rise to point W, even though how much the first point would lie above and to the left of the second could be different than in Figure 2).

\footnotetext{
${ }^{58}$ Along the edges of Edgeworth Boxes, it can happen that efficient points occur when indifference curves are not tangent to each other, because then the alternative contemplated in the proof in supra note 56 may be infeasible.

${ }^{59}$ Since utility numbers are ordinal, the utility possibility frontier could be in any quadrant or quadrants. It need not be in the first quadrant, although that is how we have drawn it. For the same reason, the utility possibility frontier need not be concave: see Figure 10.B.1 of Mas-Colell, Whinston, and Green, supra note 55.
} 


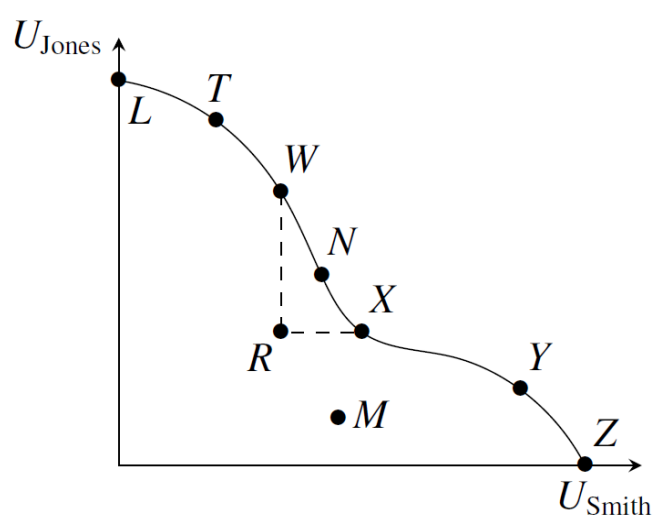

Figure 2. A utility possibility frontier.

Point L on the utility possibility frontier corresponds to the lower left-hand corner of the Edgeworth Box (its Point S), where Jones's utility is at a maximum and Smith's utility is at a minimum. Point $\mathrm{Z}$ on the utility possibility frontier corresponds to the upper right-hand corner of the Edgeworth Box (its Point J), where Smith's utility is at a maximum and Jones's utility is at a minimum. As one moves from the lower left to the upper right in the Edgeworth Box along the contract curve, one moves from $\mathrm{L}$ to $\mathrm{T}$ then $\mathrm{W}$ then $\mathrm{N}$ then $\mathrm{X}$ then $\mathrm{Y}$ then $\mathrm{Z}$ along the utility possibility curve.

An inefficient point, such as $\mathrm{F}$ in Figure 1, corresponds to a point such as $\mathrm{R}$ inside the utility possibility frontier. Moving in Figure 1 from F to I, along an indifference curve of Smith, corresponds to moving from R to W in Figure 2, keeping Smith's utility constant. Moving in Figure 1 from $\mathrm{F}$ to $\mathrm{H}$ corresponds to moving from $\mathrm{R}$ to $\mathrm{X}$ in Figure 2. Moving in Figure 1 from $\mathrm{F}$ to $\mathrm{G}$ corresponds to moving in Figure 2 from $\mathrm{R}$ to $\mathrm{N}$ or a point nearby it.

\section{E. Pareto Efficiency Requires Productive Efficiency}

In an economy with production, an important concept is the "marginal rate of technical substitution" ("MRTS") of different "factors of production" (for example, land and irrigation water) into output (for example, apples or bananas). The "MRTS of land for water in the production of apples" is the extra amount of land needed to keep the number of apples produced constant if one reduced the amount of water used by one unit. In an economy with more than one output, Pareto Efficiency requires "efficient production," which in turn requires equality of the MRTS's in each industry; otherwise, a rearrangement of the utilization of the factors of production could result in greater output of one commodity and no smaller output of any other commodity. Thus, for example, "efficient production" would require equality of "the MRTS of land for water in the production of apples" and "the MRTS of land for water in the production of bananas." We omit the proof, which is essentially identical, mutatis mutandis, to that described for distributive efficiency above, in the interest of space.

\section{F. Pareto Efficiency Requires Allocative Efficiency}

Allocative efficiency means that neither an economy's utilization of its factors of production nor its distribution of produced goods can be altered to make some people better off without making some others worse off. An economy has allocative efficiency if it has both distributive efficiency and productive efficiency. When economists refer to "efficiency" (modified by no 
adjective) in an economy with production, they mean "allocative efficiency." An economy with production is Pareto Efficient if and only if it has allocative efficiency. ${ }^{60}$

To illustrate allocative efficiency, put the Edgeworth Box used to illustrate exchange into a larger production possibility frontier, which is the relationship between the economy's potential outputs of apples and bananas, and is illustrated by the curve $p_{1} p_{2}$ in Figure 3. (The curve from the lower left to the upper right of the Edgeworth Box is the contract curve.) The slope of the dashed tangent line at $J$ is the tradeoff at the margin between apple output and banana output (supra note 60's "marginal rate of transformation"). By assumption, at point $m$, the indifference curves $U_{S m}$ and $U_{J m}$ are tangent to each other, and the slope of the dashed common tangent line at $m$ is the MRS for both Jones and for Smith. The allocation $m$ is Pareto Efficient if and only if the dashed tangent lines at points $J$ and $m$ are parallel. At this point no Pareto Improvement is possible, and the economy is allocatively efficient.

Allocative efficiency, as illustrated in Figure 3, is a much more complicated idea than distributive efficiency illustrated in Figure 1; it is not even clear that positions like $J$ and $m$, which have tangents parallel to each other, will exist in general, and if they do exist, proving their existence is typically only possible using advanced mathematics. ${ }^{61}$

\footnotetext{
${ }^{60}$ The proof of this result is too lengthy to present here, but we can show the proof of a closely related result in a model with a simpler description of production. To this end, abstract away from factors of production (land and irrigation water, in our discussion above), and define the "marginal rate of transformation" to refer to the ultimate tradeoff at the margin between apple output and banana output. In particular, assume that, adjusting land and irrigation water appropriately, reducing output by one apple would result in the ability to produce four more bananas, and vice versa, so that the MRT of bananas for apples is four. Under such circumstances, any situation in which the common MRS of bananas for apples of Jones and of Smith was not equal to four would not be Pareto Optimal. To prove this, assume by way of contradiction that the situation is Pareto Optimal but that the MRT is not equal to the MRS: suppose that although the MRT of bananas for apples is 4, the MRS of bananas for apples of Jones and Smith is 5. Create two more apples, one each for Jones and Smith, by using as inputs 8 bananas, 4 each from Jones and Smith. Each person now has one more apple and four fewer bananas. Had each person been left with one more apple and five fewer bananas, they would be equally as well off as before, but actually they are left with one more apple and four fewer bananas, so they are better off than they were before; hence, the original situation was not Pareto Optimal. This contradicts our premise that the original situation was Pareto Optimal and establishes the proof. The case in which the MRT is greater than the joint MRS is proven similarly.

${ }^{61}$ In particular, by using an Arrow-Debreu general equilibrium setup. In such a setup, exactly as in an Edgeworth Box, the initial endowment of commodities to each consumer is a given (see Hal R. Varian supra note 53 at 344 , after Debreu, Theory of Value (Wiley 1959): "Each consumer holds an initial endowment vector in the interior of his consumption set"). Also, as in an Edgeworth Box, the initial distribution of endowments will determine the set of Pareto Efficient points, and they, in turn, will generate a utility possibility frontier of the same general shape as Figure 2 but more complicated to calculate.
} 


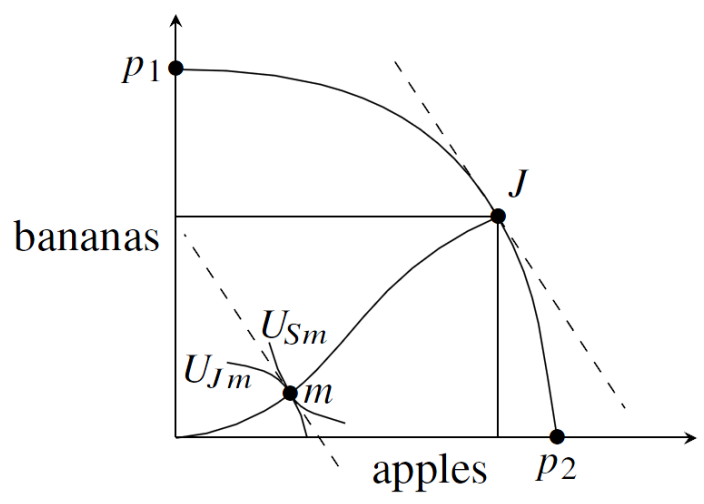

Figure 3: Allocative efficiency

G. Pareto Efficiency Cannot be Used to Establish a Theory of the Common Law

Having established that for an economy with production to be Pareto Efficient the economy must have allocative efficiency, and that that in turn requires productive efficiency and distributive efficiency, this section explains why Pareto Efficiency cannot form the basis for a theory of the common law, i.e., what judges do or should do. We separate our claims into "positive economic limitations" and "normative problems."

\section{Positive Economic Limitations of Pareto Efficiency}

(a) Pareto Optimality Cannot be Used to Resolve Legal Controversies.

The first problem with Pareto Efficiency for use in the courtroom is that it will never or almost never be applicable to a real-world legal dispute. A legal controversy only comes to court when a dispute has a potential winner and a potential loser. Under Article III $\S 2$ of the Constitution, standing (the ability to bring suit) in federal court is limited to "cases" and "controversies." Most state constitutions follow this same limitation. Courts do not offer "advisory opinions" and a plaintiff bringing a case must show that there is a real and concrete dispute to be resolved. For cases seeking damages, most causes of action such as tort and contract cases also require "injury" as an essential element of the claim itself, which must be pled in the operative complaint. If damages are awarded, they are paid by the defendant to the plaintiff. Accordingly, both a plaintiff and a defendant will experience harm from an adverse judgment or "loss" of a lawsuit. But Pareto efficiency requires that there be no "loser." Thus, Pareto-efficient outcomes are inconsistent with court processes and, if they are ever attained, they would probably be uncovered by the parties themselves or in mediation. Accordingly, it is highly unlikely that judicial decisions would be based on the Pareto principle.

\section{(b) Pareto Optimality is an Incomplete Ordering}

In addition, even if a judicial decision could result in no "loser," the Pareto criteria may still be inapplicable because the Pareto Principle results in an incomplete ordering: that is, although the Pareto Principle can rank some situations as 'better' or 'worse' than some other situations, it cannot supply a complete ordinal ranking of all social states. For example, in Figure 2 above, the Pareto Principle can rank points W, N, and X as "better than" point R. However, the Pareto Principle cannot rank points on the utility possibility frontier, such as $\mathrm{L}, \mathrm{T}, \mathrm{W}, \mathrm{N}, \mathrm{X}, \mathrm{Y}$, or Z, 
vis-à-vis each other, because movements from one of these to another are not Pareto Improvements. For example, the situation in which Smith is a slave and Jones owns Smith might be point L (very low utility for Smith, very high utility for Jones), and the situation in which neither is a slave might be point W (compared to L, Smith's utility has increased and Jones's utility has decreased); the Pareto Principle cannot rank-order points L and W. (This could also raise normative concerns - see Section III.G.2.)

The Pareto Principle also cannot rank R vis-à-vis another point like $\mathrm{M}$, which is also inside the utility possibility frontier, but which has a greater utility for one person and a smaller utility for the other person. The Pareto Principle would rank point $\mathrm{R}$ worse than a point between $\mathrm{R}$ and $\mathrm{W}$; it would rank point $\mathrm{R}$ worse than a point between $\mathrm{R}$ and $\mathrm{N}$; and it would rank point $\mathrm{R}$ worse than a point between $\mathrm{R}$ and $\mathrm{X} .{ }^{62}$ In general, the only points that the Pareto Principle can rank higher than $\mathrm{R}$ are points lying above and to the right of $\mathrm{R}$; that is, points between the dashed lines in Figure 2. Similarly, the only points which the Pareto Principle can rank lower than R are points lying below and to the left of $\mathrm{R}$. The Pareto Principle cannot rank vis-à-vis $\mathrm{R}$ points like $\mathrm{M}$, in the area below and to the right of $\mathrm{R}$, or points in the area above and to the left of $\mathrm{R}$. Thus, many situations that may arise in court cases are simply not subject to comparison using Pareto efficiency and application thereof cannot aid in resolution of such cases.

(c) Pareto Efficiency Depends on Distribution: The Separation Hypothesis, Pie Analogies, and the "Efficient Allocation of Property Rights"

L\&E's free market ideology counsels that judges should ignore distributive justice and instead use efficiency as their sole criterion for adjudication. This requires belief that efficiency improvements can be identified independent of distribution. We call this idea that efficiency improvements and distribution are completely separate from each other "the Separation Hypothesis."63 L\&E often explains the Separation Hypothesis by using the analogy of a pie: increasing the size of the pie corresponds to efficiency improvements, while the way the pie is sliced and handed out corresponds to distribution.

To show that this analogy is not apt and that the Separation Hypothesis is false, consider an Edgeworth Box such as the one in Figure 1 above. If the "pie" analogy were correct, then in such an Edgeworth Box of a pure exchange economy, wherein the size of the box (i.e., the amount of each commodity) is fixed, efficiency (the size of the pie) would be fixed and unchangeable. Moves within the Box would only reflect changes in distribution not efficiency. Clearly this is not the case: changes in distribution like that from $F$ to $G$, or even from $F$ to a point halfway between $\mathrm{F}$ and $\mathrm{G}$, generate efficiency improvements. It is as if changes in the way a pie is sliced affects the size of the pie. Since actual pies do not behave in this way, the pie analogy in economics is misleading and should be dropped.

Figure 1 can be used to show more precisely how distribution affects efficiency improvements. If the initial distribution of commodities is at Point $\mathrm{F}$, the only points that are Pareto improvements are the points that lie neither in the "Smith Veto" hatched area nor in the "Jones

\footnotetext{
${ }^{62}$ Jules L. Coleman, Efficiency, Utility, and Wealth Maximization, 8 Hofstra L. Rev. 509-551, note 12 (1980) makes similar points.

${ }^{63}$ An early statement of the Separation Hypothesis is in Nicholas Kaldor, Welfare Propositions of Economics and Interpersonal Comparisons of Utility, 49 The Economic J. 549-552, 551 (1939). Kaldor says the idea is originally due to Pigou.
} 
Veto" hatched area. However, if the initial distribution of commodities is at Point B, the set of Pareto-improving points would shift to the lens-shaped area that includes points $\mathrm{K}$ and $\mathrm{A}$. Finally, if the initial distribution were at $\mathrm{S}$ or $\mathrm{J}$, the set of Pareto-improving points would be empty. The Separation Hypothesis says that efficiency improvements can be identified separately from distribution, but this example shows that distribution determines what points are and are not Pareto improvements. If we define the new term "efficiency improvements" to be a synonym for "Pareto improvements," then we can say that distribution determines efficiency improvements. (Note that distribution does not determine the set of efficient points, which is the entire contract curve and is independent of distribution: thus, distribution determines efficiency improvements, not efficiency.)

In an economy with prices there is yet another way to see that distribution affects efficiency. Suppose a society is composed of two factions, one that is quite fond of banana cream pies and the other that despises banana cream pies. In such a society, the value/"size" of a banana cream pie will be much higher if the first faction of people is rich and the second faction is poor than if the reverse holds.

To extend this argument to an economy with production, suppose the only input to production is human-capital-adjusted labor. Suppose it is the only commodity in anyone's endowment. There are two types of people, Type A and Type B. Type A people like apples but do not like bananas. Type B people like bananas but do not like apples. Further, suppose that Type A has a large amount of human-capital-adjusted labor and Type B has very little. Under such conditions, the "optimal" allocation of labor is to put labor into the production of apples; producing bananas is not "productive." But if Type A has very little human-capital-adjusted labor and Type B has a great deal, then the "optimal" allocation of labor is to put labor into the production of bananas and producing apples is not "productive." So "100 apples and 0 bananas" is "a big pie" in one situation and "no pie at all" in the other situation. Distribution of endowments determines pie size, thus disproving the Separation Hypothesis. This also means, in turn, that if one measures "output" using market prices, as for example is done in calculating GNP, then one's measure of "output" depends on the distribution of wealth. The concept of economic "output" is distribution dependent. ${ }^{64}$

The goal of proponents of the Separation Hypothesis was to separate economic policy questions into two aspects, "efficiency improvements," which economists and judges could "objectively" identify, and "distribution improvements," which they could not. However, the set of points which are Pareto Improvements completely depends on what the original distribution was, and distribution affects prices, which in turn affect the valuation of any

\footnotetext{
${ }^{64}$ Hausman and McPherson similarly note: "There are many problems with this argument, and many of these problems are inherited by the practical implementation of this line of thought in contemporary cost-benefit analysis. The central problem is that the separation that Kaldor and Hicks envisioned between questions concerning efficiency and distribution, between the size of the pie and the way it is sliced is not in general to be had." Daniel M. Hausman and Michael S. McPherson, The Philosophical Foundations of Mainstream Normative Economics, in Daniel M. Hausman, ed, of The Philosophy of Economics: An Anthology 244 (Cambridge University Press $3^{\text {rd }}$ ed 2007). For a similar sentiment see Mark Blaug, Economic Theory in Retrospect 575 (Cambridge University Press $5^{\text {th }}$ ed 1997): “Thus, the long discussion on welfare criteria-from Pareto through Barone to Hicks, Kaldor and Scitovsky - has brought us no further in evaluating policy changes which benefit some people but harm others on purely 'positive' grounds. Efficiency questions appear to be inseparable from equity questions."
} 
commodity bundle. Therefore, the notion that efficiency improvements can be determined independently of distribution is false.

(d) The Coase Theorem Does Not Support the Separation Hypothesis.

The "Separation Hypothesis" entered economics in the first part of the twentieth century via Kaldor and Pigou (supra note 63), but it entered the L\&E tradition in 1960 via the famous Coase Theorem, ${ }^{65}$ which states that one may obtain "the" efficient outcome regardless of how property rights are distributed. This conclusion flatly contradicts the argument against the Separation Hypothesis we just made in Section III.G.1(c), so it is impossible for the Coase Theorem and our earlier argument to both be true under an identical set of assumptions. Recall, we make all the Arrow-Debreu assumptions of market perfection, and therefore our task in this subsection is to show that under those Arrow-Debreu assumptions, the Coase Theorem is false. Note that the Arrow-Debreu assumptions rule out strategic behavior and transactions costs. Therefore, our discussion will be quite different from the discussion of many other Coase Theorem critics, who show that the Coase Theorem fails upon the introduction of strategic Coasian Bargaining considerations ${ }^{66}$ or who show that it fails upon the introduction of transactions costs. ${ }^{67}$ In contrast, we demonstrate that it fails even in the absence of strategic behavior and even in the absence of transactions costs.

Figure 4 illustrates the Coase Theorem.

\footnotetext{
${ }^{65}$ Ronald H. Coase, The Problem of Social Cost, 3 J.L.\& Econ 1-44 (1960).

${ }^{66}$ William Samuelson, A Comment on the Coase Theorem, in Alvin E. Roth, ed, Game-Theoretic Models of Bargaining (Cambridge University Press 1985).

${ }^{67}$ Ronald Coase himself was a critic of the "Coase Theorem" because of its assumptions of no transaction costs. Glenn Fox, The Real Coase Theorems, 27 Cato J. 373-396 (2007), makes a convincing case that the main thrust of Ronald Coase's entire career was that "no transactions costs" assumptions were completely irrelevant to the real world. The theorem really ought to be called "Stigler's Coase Theorem" and readers should be reminded that in Coase's Nobel lecture he called it "infamous"-and he meant "infamous" in the traditional, pejorative sense of that word. See https://www.nobelprize.org/prizes/economic-sciences/1991/coase/lecture.
} 


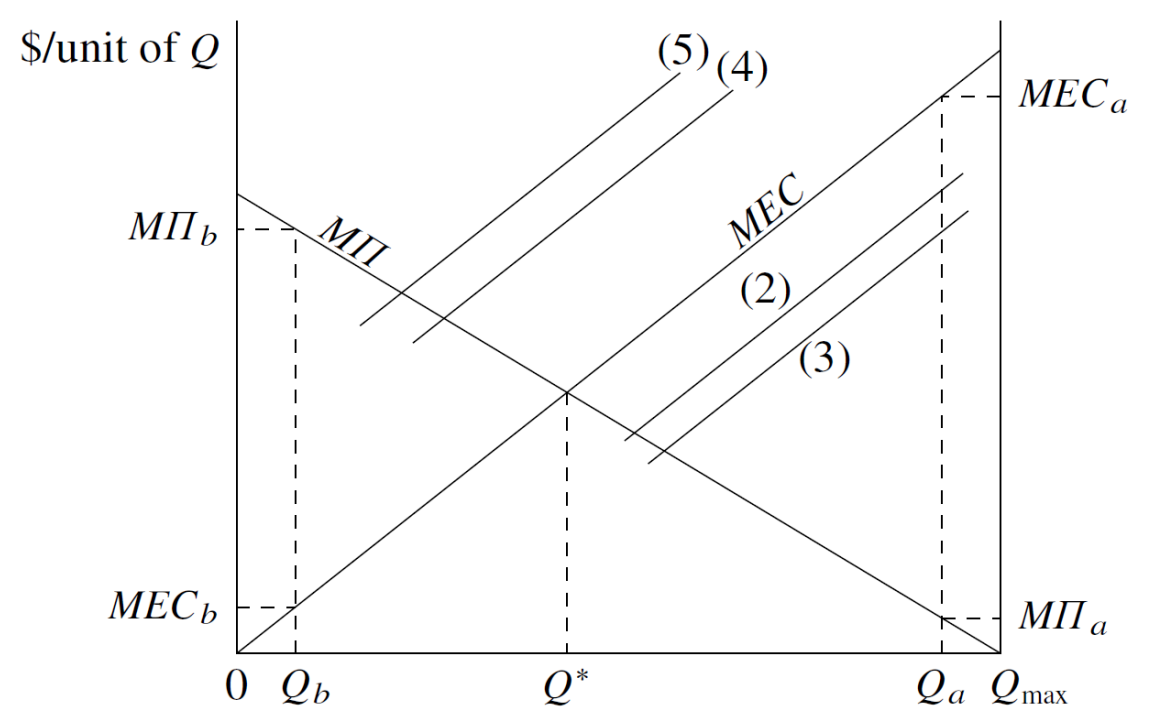

Figure 4. The Coase Theorem

In the figure, $M \Pi$ denotes the marginal profit that a firm earns if it produces one more unit of an output called $Q$. Left unregulated, the firm will produce $Q$ until further units of $Q$ are worthless to it; that is, it will produce until marginal profit is zero, which is at output level $Q_{\max }$. (Total profit will be at its maximum where marginal profit is zero.) Next, suppose production of this output generates air pollution, and assume that pollution victims are willing and able to pay for some pollution reductions. Calling their willingness and ability to pay to reduce pollution "external cost" because that is the way pollution's cost is measured in neoclassical economics, Figure 4's $M E C$ curve illustrates the marginal external cost, that is, the external cost of the $Q$ th unit of production. If producers have the property right to pollute as much as they wish, they will plan to produce at $Q_{\max }$. However, pollution victims would be willing and able to pay the firm $M E C_{a}$ (or less) in return for a reduction in planned output to $Q_{a}$. Firms would only require a payment of $M \Pi_{a}$ (or more) in return for reducing output to $Q_{a}$. Since $M E C_{a}>M \Pi_{a}$, for any payment amount between those two values, both parties would gain by the pollution victims paying that amount to the firm in return for a reduction in output to $Q_{a}$. Similar further rounds of bargaining would result in output falling until it finally gets to $Q^{*}$, beyond which $M E C>M \Pi$ is not true anymore and bargaining stops. ${ }^{68}$

On the other hand, if pollution victims have a property right to clean air, they would enforce that right and plan to compel the firm to produce zero output. However, the firm would be willing and able to pay the victims $M \Pi_{b}$ (or less) in return for a reduction in planned output to $Q_{b}$. Pollution victims would only require a payment of $M E C_{b}$ (or more) in return for allowing output to increase to $Q_{b}$. Since $M \Pi_{b}>M E C_{b}$, for any payment amount between those two values, both parties would gain by the firm paying that amount to the pollution victims in return for an increase in output to $Q_{b}$. Further rounds of bargaining would result in output rising until it finally gets to $Q^{*}$, beyond which $M \Pi>M E C$ is not true anymore and bargaining stops. The

${ }^{68}$ This assumes that if a trade which is mutually beneficial in the short run exists, then that trade will actually take place. This assumption is, from the point of view of the modern theory of repeated games, naïve. See supra note 66. 
Coase Theorem thus concludes that, regardless of the initial assignment of property rights, the amount of output produced will be $Q^{*}$, which is the (unique) socially-optimal level of output because it is Pareto Efficient.

The flaw in this argument is that once pollution victims have paid money to the firm in return for a reduction in output from $Q_{\max }$ to $Q_{a}$, the pollution victims do not have as much money as they had before, and (if clean air is a normal good) their demand for clean air will fall — an "income effect" or a "wealth effect"-so $M E C$ is not going to remain fixed, it is going to fall to a position such as (2) in the graph. Additional payments by consumers in exchange for further reductions in $Q$ beyond $Q_{a}$ will shift the $M E C$ curve further, for example to position (3). (If clean air were an inferior good, the $M E C$ curve would shift upwards to positions such as (4) and (5).) Thus, the bargaining process will never get to $Q^{*}$. Similarly, if the pollution victims have the property right, then once the firm pays the pollution victims money in exchange for an increase in $Q$ from zero to $Q_{b}$, the pollution victims will have more money than they did before, and hence their demand curve for clean air, $M E C$, will shift up (say to position (4)) if clean air is a normal good, and shift down (say to position (2)) if clean air is an inferior good. Additional payments by firms in exchange for further increases in $Q$ beyond $Q_{b}$, will shift the $M E C$ curve even further, for example to position (5) or, respectively, to position (3). Again, the bargaining process will never get to $Q^{*}$. Only in the theoretically uninteresting and empirically irrelevant case in which the good is exactly on the borderline between being normal and being inferior will the $M E C$ curve not shift and will the bargaining, under all the other (unrealistic) assumptions required for the Coase Theorem to work such as no transactions costs, end up at $Q^{*}$.

The upshot is that the Coase Theorem's interpretation of $Q^{*}$ as an economically efficient or optimal point irrespective of the distribution of income is misguided. The economically "efficient" amount of clean air a society will produce, just like the amount of bread it produces, is a direct consequence of the prior distribution of income, wealth, and property rights. The assignment of property rights determines the position of $M E C$, and each change in property rights as the steps of bargaining occur changes the position of $M E C$. Thus, the notion that the position of $Q^{*}$ is independent of all property rights is as unlikely as the idea that demand curves do not depend upon income. ${ }^{69}$

\footnotetext{
${ }^{69}$ A numerical example of the above argument is given in a working paper by Gabriel A. Lozada available at https://content.csbs.utah.edu/ lozada/Research/CompEquivW.pdf.
}

The discussion in the text is a minor variation on that given in E. J. Mishan, The Postwar Literature on Externalities: An Interpretative Essay, 9 J. Economic Literature 1-28, 20 (1971). It is also an extension of C. Edwin Baker, The Ideology of the Economic Analysis of Law, 5 Philosophy \& Public Affairs 3-48 (1975), who realized that the initial position of a curve like the $M E C$ curve depends on income, although he did not analyze how things changed as Coasian bargaining progressed. Baker wrote (pages 12, 13, and 16):

But Coase's analysis is subject to an important qualification, a qualification which is vital for understanding the biases implicit in Posner's, and much legal-economic, analysis. The initial assignment of a right can affect the wealth of the parties which in turn can affect the parties' "valuation" of the right, and thus affects the ultimate use of the resource. An extreme example, given by Posner, of the initial assignment determining the use which ultimately prevails is the case of a "right to a barrel of water as between two dying men in a desert" [....] If the barrel of water is assigned to the one for whom it is most valuable, the one willing and able to pay the most for it, the water would be assigned to the richer of the two men. But the analysis is moving too fast. Why would the initial assignment-contrary to the 
We have not yet argued that the $M \Pi$ curve will also shift, but we need to, because otherwise the Coase Theorem would hold if both sides of the problem were firms, such as a rancher and a farmer, rather than a firm and an individual. If the polluter has the property right to pollute, receipts of payments from pollution victims can be thought of as decreases in the fixed cost of production (as well as prohibitively large increases in the marginal opportunity costs of production for levels of $Q$ past wherever the final bargaining point ends up). The resulting increase in profit will have to be competed away in long-run equilibrium, or else continual entry of firms would occur. The only mechanism for that is a decrease in product price (due to a shift outward in the product's supply curve), which would shift the $M \Pi$ curve down,${ }^{70}$ or an increase in marginal production costs (due to increased demand from this industry shifting the demand curve for inputs out), which would also shift the $M \Pi$ curve down.

Thus, we have proven that the Coase Theorem fails under the Arrow-Debreu assumptions.

\section{(e) The Equity-Efficiency Tradeoff Fallacy}

As ubiquitous as the "pie" analogy (the Separation Hypothesis) is in L\&E, just as common in L\&E is another position which contradicts it - not in the correct way described by Section III.G.1(c) but in an incorrect way. This other position holds that the more evenly one cuts pieces of the pie, the smaller the pie becomes. In other words, it holds that policies promoting equity damage efficiency. In this subsection we prove this position similarly fallacious.

In an Edgeworth Box of a pure exchange economy, it is easy to disprove the contention that increasing equity impairs efficiency. In Figure 1 above, moving from an inequitable position such as $\mathrm{S}$ or $\mathrm{J}$ to a more equitable position such as $\mathrm{I}, \mathrm{G}$, or $\mathrm{H}$ does not change the size of the box at all. Therefore, as a theoretical microeconomics proposition, there is no necessary tradeoff between equity and efficiency, and the "Equity-Efficiency Tradeoff" is a fallacy. (Whether it is a fallacy as a historical proposition is addressed in the paragraph after next.)

The Second Fundamental Theorem of Welfare Economics extends this argument. It says that "we can achieve any desired Pareto Optimal allocation as a market-based equilibrium using an appropriate lump-sum wealth distribution scheme." 71 For example, starting from an unequal point such as S, J, C, D, or E in Figure 1, one could achieve the more equitable position $\mathrm{G}$ in the following way: impose (against one party's wishes) a lump-sum redistribution moving the economy to a point somewhere near $\mathrm{F}$, then begin protecting property rights and establish perfect competition; the free market transactions that follow will on their own move the

standard reading of Coase - make a difference? [...] An assignment of the right to the barrel of water (or a right to be free from pollution or a right of property owners not to have their property damaged by sparks from trains) increases the wealth of the party assigned the right. [...] a person's wealth affects how much that person is willing and able to pay for a specific desired right...the initial assignment may determine who "values" the right the most. [...] No neutral efficiency analysis exists which can avoid or segregate the distributive question; in the legal dispute the value maximizing award depends on what initial distribution is assumed while the content of the initial distribution is the precise issue in dispute.

\footnotetext{
${ }^{70}$ Explicitly detailing the mechanism would be nontrivial because the fixed costs constitute a nonconvexity. There is a countervailing tendency: the payments from the pollution victims have essentially been transmitted onward to the consumers of the product through the fall in price, and if the product is a normal good, the income effect will cause demand for it to rise, shifting the $M \Pi$ curve up - but the net result must still be for the $M \Pi$ curve to shift down to be consistent with the fall in the product price.

${ }^{71}$ Andreu Mas-Colell, Michael D. Whinston and Jerry R. Green, supra note 55 at 551.
} 
economy to $\mathrm{G}$ (which is not only more equitable than $\mathrm{S} / \mathrm{J} / \mathrm{C} / \mathrm{D} / \mathrm{E}$, it is also Pareto Optimal, unlike $\mathrm{C}$ and $\mathrm{D}$ ). In other words, starting from point $\mathrm{S}$ or $\mathrm{C}$, then expropriating much of Jones's endowment and giving it to Smith, does not hamper the ability of the economy to then achieve, through competitive trading, an efficient point. Obviously, there is no EquityEfficiency Tradeoff here, in this Arrow-Debreu world of the Second Fundamental Theorem of Welfare Economics. No one would be interested in the Second Theorem if lump-sum redistributions in favor of the poor caused Edgeworth Boxes to shrink, because the Second Theorem assumes the Edgeworth Box stays the same size when the redistributions occur. Yet not only are economists "interested" in the Second Theorem, they also often call it a "Fundamental Theorem," one of only two theorems in all of economics to be called that. Economic theorists thus are clearly not taking the Equity-Efficiency Tradeoff seriously.

We concede that models (like an Edgeworth Box of unchanging size) are only models, not the real world, and results that are extremely important in economic theory (like the Second Fundamental Theorem of Welfare Economics) may be much less important in the real world. While the Equity-Efficiency Tradeoff is a fallacy insofar as it is a theoretical statement (a statement of general applicability), we would require historical evidence to argue that it is fallacious as an empirical regularity of the real world. Fortunately for us we have such evidence as already presented in Part II: the more equitable distribution of the New Deal Consensus resulted in higher growth, higher productivity increases, and more investment than the period of more unequal distribution after $1980 .{ }^{72}$ Therefore, we conclude that the EquityEfficiency Tradeoff is a fallacy both as a matter of economic theory and as a matter of the U.S. historical experience. ${ }^{73}$

\footnotetext{
${ }^{72}$ From the perspective of elementary economics this seems to pose a theoretical enigma: shouldn't high income taxes generate disincentives to work, depressing economic activity and diminishing national wealth? Once one abandons the simplistic "work yields disutility/leisure yields utility" framework and considers the many ways that work can bring nonpecuniary benefits (for example the feeling of not being a parasite on society, or the pride in creating things valued by others, or the enjoyment from exercising control over other people in the workplace), the picture becomes considerably more complex. The Queen of England does not work because of the paycheck (which she would probably get anyway), and Bill Gates now works at giving his money away. Such motivations are described as "internal incentives" in Greg Davidson and Paul Davidson, Economics for a Civilized Society (W.W. Norton 1988); they should not be ignored. At the level of elementary macroeconomic theory, an EquityEfficiency Tradeoff is dubious because redistribution from rich to poor increases the economy-wide average marginal propensity to consume and thus shifts the aggregate demand curve out. Finally, even if high income taxes on highly-paid people did constitute a disincentive for those people to work, that might be a good thing. In an economy like the US with very advanced division of labor, many highly-paid people are highly-paid because they have specialized knowledge, which is to say, they have large informational advantages over the principals who hire them as agents. Giving them incentives to work harder could result in greater principal-agent inefficiencies and lower national income. Would the 2008 financial crisis have happened if bond traders were compensated like schoolteachers instead of being eligible for bonuses in the seven figures? Would the opioid crisis be happening if the family that owns Perdue Pharma (maker of OxyContin) had faced a 100\% marginal income tax rate on income above a few million dollars? Therefore, high income taxes might increase the size of the economy by decreasing the amount of socially-destructive work more than high income taxes decrease (if they even do) the amount of socially-useful work. For more on this see Neal Gabler, Disincentivizing Greed, Los Angeles Times (August 22, 2010).

${ }^{73}$ There is also international evidence to support our position, such as the post-World War II German "Wirtschaftswunder" period (see for example https://en.wikipedia.org/wiki/Wirtschaftswunder) and the postWorld War II land reform in Taiwan (see Anthony Y.C. Koo, Economic Consequences of Land Reform in Taiwan, 6 Asian Survey 150-157 (1966).
} 


\section{Normative Problems}

In this section we consider some observers' normative objections to using Pareto Efficiency as a foundation of jurisprudence.

\section{(a) Perverse Preferences and the Monotonicity Assumption}

Pareto Optimality requires that no one be made worse off, it only allows for decisions based on unanimous consent. For example, the Pareto Principle would require us to refrain from punishing criminals because no criminal would consent to punishment that harms him. Thus, the Pareto Principle is unattractive in a world with criminals or, more broadly, in a world with people whose preferences are perverse. Most economists deal with the problem of perverse preferences by simply assuming that perverse preferences do not exist - an assumption called the "monotonicity" assumption of welfare economics. Evidently, the Pareto Principle is attractive only in a world in which the monotonicity assumption holds. This has not bothered economists much because they have shown great enthusiasm for the monotonicity assumption.

However, if perverse preferences exist, judges, unlike theoretical economists, cannot simply assume them away. In a world where monotonicity fails and there are perverse preferences, moral philosophers convincingly object to the notion, endorsed by the Pareto Principle, that there is no reason not to "increase the utility of an undeserving person, or someone satisfying morally objectionable preferences, so long as no one else is harmed." Jules Coleman writes:

Generally, a policy that makes A better off and no one worse off would be Pareto superior, even if A had no right to be made better off, or if he deserved to be made worse off, or even if B not A should have been better off. Until we know something about the rights and deserts of individuals affected by alternative courses of conduct, we should remain agnostic about the moral value of those policies that would otherwise be recommended to us as Pareto superior. In the absence of a prior nonefficiency-based theory of rights and moral deserts, it would be irrational to consent to Pareto superiority as a moral maxim. ${ }^{74}$

The zeal with which economists embrace the monotonicity assumption in order to be able to ignore such considerations is difficult to overstate. In none of the texts of Varian, Jehle and Reny, or Mas-Colell, Whinston, and Greene is there any suggestion that this assumption be abandoned.

Pareto Optimality makes no sense without the monotonicity assumption. Economists embrace the monotonicity assumption, eliminating this objection to Pareto Optimality. The real world of legal decisions in the courtroom cannot.

\section{(b) Is Pareto Optimality Sufficient or Necessary for Social Optimality?}

In Figure 1 above, point $\mathrm{S}$ is Pareto Optimal. Surely, however, that would not be sufficient for most people to describe $\mathrm{S}$ as a socially optimal point, or to define a society at $\mathrm{S}$ as a just society. Dasgupta and Heal ${ }^{75}$ write,

\footnotetext{
${ }^{74}$ Jules L. Coleman, supra note 62 at 547.

${ }^{75}$ Partha S. Dasgupta and Geoffrey M. Heal, Economic Theory and Exhaustible Resources 17 (Cambridge University Press 1979).
} 
The fact that a vector of acts is Pareto efficient does not offer sufficient ground for it to be regarded as optimal - or even desirable. Typically, one would be concerned with the distribution of utilities, and it is possible that a vector of acts sustains an equilibrium [and is efficient]... and at the same time yields a distribution of utilities that one may deplore.

The Second Fundamental Theorem of Welfare Economics can help in understanding how social well-being could be enhanced by abandoning a Pareto Optimal point such as S or E in Figure 1. If one started with an endowment point like $\mathrm{S}$ or $\mathrm{E}$ but then confiscated enough apples and bananas from Jones and gave them to Smith so that the endowment point was changed to $\mathrm{F}$, then under the Arrow-Debreu assumptions, competitive trading from $\mathrm{F}$ will achieve an efficient point somewhere on the contract curve between I and $\mathrm{H}$. In other words, if society has a sufficiently great aversion to inequality, a one-time wholesale, even revolutionary, reassignment of property rights would - so long as afterwards property rights are respected and voluntary trades are allowed - enhance social well-being by moving society's fate away from Pareto Optimal points S or E to I or G or H. In such societies, Pareto Optimality is clearly not sufficient for social optimality.

In an Arrow-Debreu world, most observers would agree that Pareto Optimality is a necessary condition for social optimality (in other words, no point which is not Pareto Optimal can be socially optimal). Given the monotonicity assumption of Section III.G.2(a), it cannot be socially optimal to refrain from engaging in a Pareto Improving move. However, in a nonArrow-Debreu world, suppose in Figure 1 that for some reason the points in the lens-shaped area generated by $\mathrm{F}$ - in other words, the points that belong to neither the "Smith Veto" region nor the "Jones Veto" region - are not feasible. A reasonable person might then prefer a nonPareto-Optimal point like F to a Pareto Optimal point like E, meaning that Pareto Optimality would not be a necessary condition for social optimality. Paul Samuelson, a Nobel laureate and one of the greatest economists of the twentieth century, held such a view. ${ }^{76}$

We conclude Part III having established that in economic theory "efficiency" means Pareto Efficiency. But this has fatal positive and normative deficiencies that render it incapable of being the foundation for a theory of the common law. Its most glaring deficiency is that it is inapplicable to what judges do. As a result, L\&E has adopted alternative definitions of efficiency, referred to as "Kaldor-Hicks." What exactly L\&E textbooks mean by "KaldorHicks" we will take up in Appendix 1 (Part Appendix 1:); what we do immediately next is discuss what economists mean by the approaches of Kaldor and Hicks. As we detail, however, the Kaldor and Hicks definitions of "efficiency" have deficiencies, both positive and normative, that make Pareto Efficiency's deficiencies look miniscule by comparison.

\section{The CRiteria of Kaldor And Hicks: The ReAlm OF COERCION}

The hallmark of Pareto Efficiency, which as we have seen is not a viable theoretical underpinning for $L \& E$, is that no one is hurt by Pareto improving moves. The alternative "efficiency" criteria L\&E advocates have retreated to are alternatives that not only tolerate, but affirmatively result in hurting people. Writings of L\&E advocates may praise "freedom" and

\footnotetext{
${ }^{76}$ In Kotaro Suzumura, An interview with Paul Samuelson: welfare economics, "old" and "new", and social choice theory, 25 Social Choice and Welfare 327-356, 336 (2005), Samuelson describes "the following common error: if a situation $\alpha$ is Pareto optimal and $\beta$ is not, then always society should prefer $\alpha$ to $\beta$ " (our emphasis).
} 
denounce "government coercion" but it must be made completely clear at the outset that making social decisions according to the criteria that L\&E advocates recommend means, in every instance, using State power to coercively reallocate resources and property rights to the detriment of some people in the society.

For idiosyncratic historical reasons, this alternative approach to economic efficiency goes by three names which mean the same thing: the "Potential Pareto" Approach; Cost-Benefit Analysis (or Benefit-Cost Analysis); and the "Kaldor-Hicks" Approach or Criterion. Usually we will describe this approach using only one of these three terms (often chosen randomly), but sometimes we will use two or even all three of the names to remind readers that they all mean the same thing. ${ }^{77}$ The first two names are straightforward, but the last is a misleading name because the Kaldor Test (or Kaldor Criterion) and/or the Hicks Test (or Hicks Criterion) are different from each other. Believing that Kaldor and Hicks had the same approach is not only historically incorrect, it also, much more importantly, obscures many flaws of the "Potential Pareto" approach because those flaws arise from differences between the Kaldor Test and the Hicks Test.

In this Part, we carefully examine separately the Kaldor test and the Hicks test in several alternative settings and show that these tests can be inconsistent with each other and express normative values that are incompatible with most ethical theories. First, though, we need to explain why the fundamental nature of "economic value" is dual, which gives rise to the positive problems which plague the Potential Pareto approach.

The presence of these positive problems should not come as a surprise. The great strength of the Pareto Efficiency approach is that it keeps very far away from any attempt to measure utility change in a cardinal way. The Potential Pareto approach, as well as its inferior cousin the Surplus approach of Part V, on the other hand are attempts to measure utility changes using a cardinal measurement, called "value." These attempts are doomed to fail because utility changes simply are not cardinal. We understand the motivation to wish that utility changes were cardinal. It would be wonderful if economists were able to say that "John Doe values one apple at two bananas" or "John Doe values one apple at \$1.23." But economists cannot say such things. ${ }^{78}$ Our next Section, IV.A, describes how close they can come: economists are able to supply two answers to the question "what value does John Doe put on one apple?" This is considerably worse than being able to supply one answer to that question, and generates many difficulties, but it does provide some useful information. Part V's Surplus approach, on the other hand, is an attempt to totally evade the problem by pretending that economists can provide one answer to the question "what value does John Doe put on one apple?" That approach is worse than useless because it fools some people into thinking that it is possible to measure value in a non-dual way.

\footnotetext{
${ }^{77} \mathrm{We}$ acknowledge that, since the three names are used by different subdisciplines of economics (welfare economics, industrial organization, L\&E, environmental economics), each name is now connected to a tradition which has evolved in ways that the other subdisciplines could have evolved, and still could evolve, but have not evolved. For example, practitioners of "Cost-Benefit Analysis" may sometimes deviate from strict adherence to the approach in order to ameliorate unfavorable outcomes to the poor, while practitioners of "the Kaldor-Hicks approach" may not— but either group could adopt the practice of the other.

${ }^{78}$ We are discussing non-marginal changes so the "marginal rate of substitution" is irrelevant.
} 
A. Value's Dual Nature: Willingness to Pay/Accept; Compensating/Equivalent Variation

One of the most fundamental questions in all of economics is "what is the value of a commodity?" In the same way there is no single number that is the right measure of human blood pressure - there are two numbers (the systolic and diastolic pressures), equally valid and important though different - there is also no single number that is the right measure of the economic value of a commodity to a person - there are two numbers, equally valid and important though different. One is the value a person puts on a commodity he or she has been given (for free); the other is the value a person puts on that same commodity if he or she will not be given it. These numbers are different because in the first situation the person is richer than he or she is in the second situation, and a person generally behaves differently when he or she is richer than poorer.

One way economists approach understanding economic value is by imagining a consumer, say Ms. Smith, who possesses no apples and five bananas, and asking how many bananas Ms. Smith would be willing and able to pay ("WATP," traditionally shortened to "willing to pay," "WTP") for an apple. A second approach is to determine how many bananas Ms. Smith would be willing to accept ("WTA") as compensation for not receiving that apple. We will see that in general, WATP, which is measured assuming Ms. Smith has become better off by receiving the apple, is not equal to WTA, which is measured assuming Ms. Smith will never receive the apple.

\section{Settings: Describing Various Policy Changes and the Units in which they are Valued}

In the example just discussed, the contemplated change (perhaps arising from a proposed government policy) was a change in the quantity of one commodity (apples), and it was valued using WATP and WTA measured in terms of the quantity of another commodity (bananas). We will call this setting "Setting $Q q$ " because two quantities are involved: the first one, denoted by the capital letter, is the initial change, and it is measured ("valued") in terms of the second one, denoted by the lower-case letter. Setting Qq was introduced into economics by Shogren et al. in 1994. ${ }^{79}$ Setting Qq applies to the study of shifting property rights because property rights are generally rights to a certain quantity of property. Setting Qq will be our most commonly used setting, and the only setting used in Sections IV.A.2, IV.A.6, IV.C, IV.D, IV.E, and IV.F.

In the study of antitrust, however, the initial policy change is often a change in a price, and economists often would prefer the corresponding WATP and WTA to be valued in units of money income. For example, "how much money (how much of her income or wealth) would Ms. Smith be WATP for a decrease in the price of apples," or "how much of an increase in income would Ms. Smith be WTA to compensate her for a refusal to decrease the price of apples?" We call that situation "Setting P $i$," where, again, the capital letter represents the initial change, which is in a price, and the lower-case letter represents how that change is valued, which is in income. Setting Pi was first studied around 1940 by John R. Hicks (winner of the 1972 Nobel Prize in Economics) and Nicholas Kaldor, although the "WATP" and

\footnotetext{
${ }^{79}$ Jason F. Shogren, Seung Y. Shin, Dermot J. Hayes and James B. Kliebenstein, Resolving Differences in Willingness to Pay and Willingness to Accept, 84 The American Economic Review 255-270 (1994). This paper does not mention that the very first author to use Setting Qq was actually legal scholar Jules Coleman; see Jules L. Coleman supra note 62 at 514 note 8.
} 
"WTA" terminology came much later. Setting Pi will be our second-most commonly used setting, and the only setting used in Sections IV.A.3 and IV.H. Section IV.H also makes use of a generalization of Setting Pi called "Setting *i," in which the initial policy change can be any number of different things, but each of them is valued in terms of income.

In 1943 Hicks also developed "Setting Qi," 80 in which the proposed policy is a quantity change and the corresponding WATP and WTA are measured in units of income. Setting Qi was little studied or used until the 1991 work of Hanemann ${ }^{81}$ demonstrated its relevance to rationing programs, and to public goods and to environmental economics more broadly. This work gave rise to Setting Qq three years later, but for our purposes Setting Qi has little importance otherwise.

"Setting QQqq," in which the proposed policy change is a change in the quantity of (say) apples and also the quantity of (say) bananas, and the corresponding WATP and WTA is expressed by a quantity of apples and also a quantity of bananas, is employed by Hayashi, ${ }^{82}$ and serves particularly well to highlight the ethical consequences of the Potential Pareto approach in its purest form. We use it only in Section IV.K.

We next describe in more detail the settings we use most frequently, Settings Qq and Pi.

\footnotetext{
${ }^{80}$ J. R. Hicks, The Four Consumer's Surpluses, 11 The Review of Economic Studies 31-41, 35, 36 (1943).

${ }^{81}$ W. Michael Hanemann, Willingness to Pay and Willingness to Accept: How Much Can They Differ?, 81 The American Economic Review 635-647 (1991). Hanemann's framework has one unpriced good and all its other goods have prices.

${ }^{82}$ Takashi Hayashi, General Equilibrium Foundation of Partial Equilibrium Analysis 18-19 (Palgrave Macmillan UK 2017).
} 


\section{Setting Qq Explained}

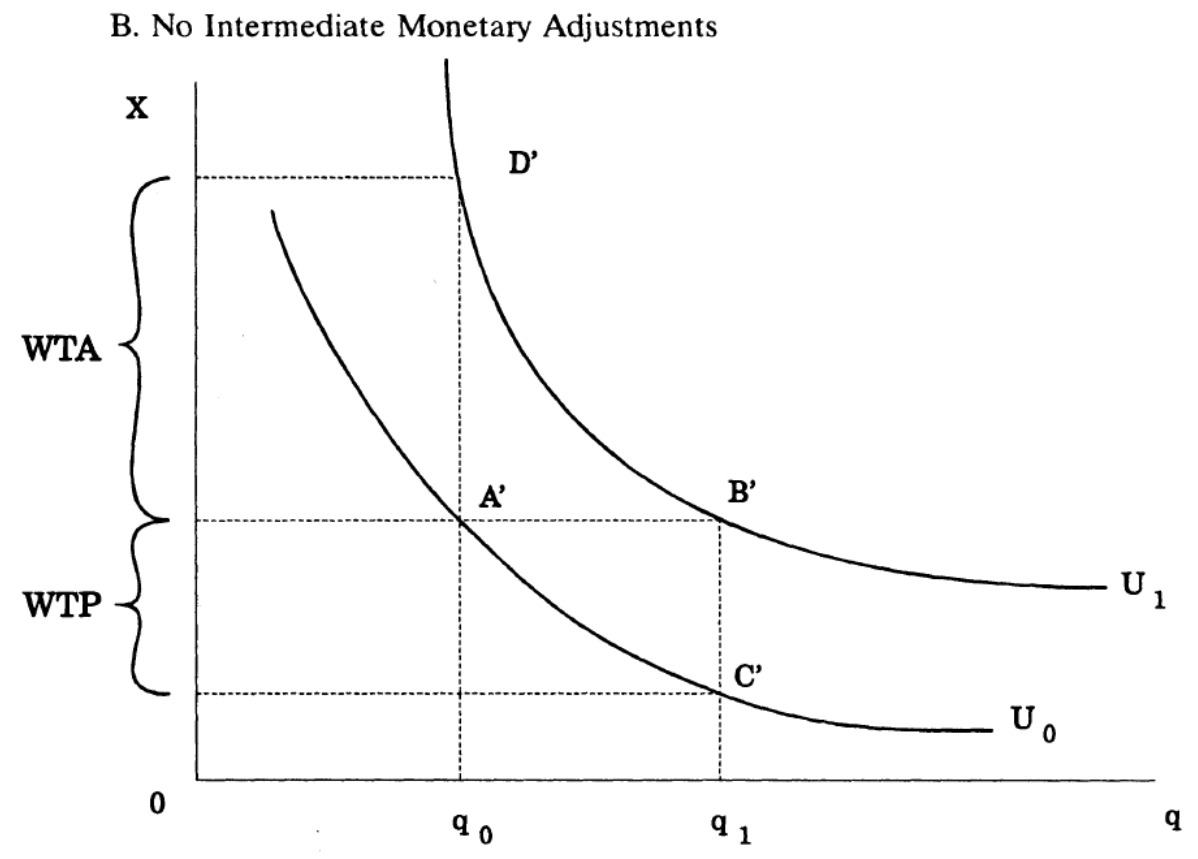

Figure 1. The Simple Analytics of the WTA-WTP Divergence

Figure 5. An indifference curve graph showing Setting Qq's WATP and WTA (from Shogren et al.).

In Setting Qq, consider Figure 5, taken from the paper by Shogren et al. In it, commodity $q$ is graphed on the horizontal axis, commodity $x$ is graphed on the vertical axis, and the indifference curves $U_{0}$ and $U_{1}$ of one person are shown. The initial point is assumed to be $A^{\prime}$ and the prospective policy is a move from $q_{0}$ to $q_{1}$. As reflected in the figure, if that move is done, the consumer would be willing and able to pay "WTP" of Good X in exchange; paying any more than WTP would reduce utility below its initial $U_{0}$ level, while paying any less would leave the consumer better off than at $U_{0}$. If that move- which would increase utility to $U_{1}-$ were not done, the consumer would accept in compensation "WTA" amount of Good X, because that would also increase utility to $U_{1}$. The upshot is that the question "what is the value of $q_{1}-q_{0}$ units of good $q$ ?" has two valid but different answers: its value is $B^{\prime} C^{\prime}$ units of Good X if the consumer is given the $q_{1}-q_{0}$ units of good $q$, but its value is $A^{\prime} D^{\prime}$ units of Good $\mathrm{X}$ if the consumer is not given the $q_{1}-q_{0}$ units of good $q$. Both answers for "the value of $q_{1}-$ $q_{0}$ units of good $q$ " are cardinal, so they are much more useful than " $U_{1}$ minus $U_{0}$," since we could have assigned literally any numbers to $U_{0}$ and $U_{1}$ as long as the one we assigned to $U_{0}$ was less than the one we assigned to $U_{1}$. (See also Section III.B.) The success in moving from the merely ordinal $U_{0}$ and $U_{1}$ to the cardinal " $B^{\prime} C^{\prime}$ and $A^{\prime} D^{\prime}$ amounts of Good $\mathrm{X}$ " is welcome. However, the fact that $B^{\prime} C^{\prime}$ is not equal to $A^{\prime} D^{\prime}$ means value has a dual nature, so our attempt to "cardinalize" utility is only a partial success - and the more we study this dual-natured value, the more we will be vexed by paradoxes and enigmas generated by its "dual-ness." 83

\footnotetext{
${ }^{83}$ We avoid the word "duality" because it has an unrelated technical meaning in economics.
} 
In order to be able to address L\&E's advocacy of "wealth maximization" later in this paper, we need explain that what the last paragraph showed is that value is not a function. To start, let us explain why utility is a function. In Figure 5, we could choose to represent this person's preferences by choosing as their utility function one which assigns the value "negative 17 " to $U_{0}$ and "positive 3" to $U_{1}$. But since utility is ordinal, we could make an infinite number of other choices for this person's utility function, as long as it set the utility $U_{0}$ less than the utility of $U_{1}$. Once one chooses a utility function, moving from $A^{\prime}$ to $B^{\prime}$ then back to $A^{\prime}$ returns utility back to its original value. For example, if one did set $U_{0}=-17$ and $U_{1}=+3$, then moving from $A^{\prime}$ to $B^{\prime}$ increases utility by 20 , and moving from $B^{\prime}$ back to $A^{\prime}$ decreases utility by 20 , returning utility back to its original $U_{0}=-17$ level. Value, though, does not work that way. Moving from $A^{\prime}$ to $B^{\prime}$ increases value by WATP, but moving from $B^{\prime}$ back to $A^{\prime}$ decreases value by WTA, and since WATP minus WTA is not usually equal to zero, value after this round trip does not return to its initial level. Value is thus defective as a description of utility. A mathematical economist would call value a "correspondence" not a function, because value assigns not one but two numbers to "the value of $q_{1}-q_{0}$ units of good $q$." In short, one can study how a consumer is affected by economic policy or by a legal judgment either by working with an ordinal function (namely utility) ${ }^{84}$ or with a cardinal correspondence (namely value). "Ordinal" is more troublesome to work with than "cardinal" because only the sign, not the magnitude, of a difference such as $U_{1}-U_{0}$, has any meaning. Correspondences are more troublesome to work with than functions because correspondences cannot be maximized or minimized, and because they can generate inconsistent rankings, as is easily imagined if one were asked to "rank patients by their blood pressure"-systolic? diastolic? some mixture of both? Part III's Pareto approach took the "ordinal function" route; Part IV's approach takes the "cardinal correspondence" route. (Part V's approach tries to have the best of both worlds by taking a "cardinal function" route, but consumer preferences cannot be correctly represented that way. ${ }^{85}$ )

In Figure 5, WTP/WATP is less than WTA. In fact, if one moved the $U_{1}$ indifference curve a bit more to the right, WTA would be infinite. As in Figure 5, so also in surveys of consumers taken to estimate WATP and WTA for specific (often environmental) issues, WTP/WATP is typically less than WTA.

Only in unusual, "knife-edge" cases could WATP be equal to WTA. Shogren et al. illustrate such a case:

\footnotetext{
${ }^{84}$ Actually, working with one of a class of utility functions, all representing the same preferences.

85 Though see supra note 50.
} 


\section{A. Intermediate Monetary Adjustments}

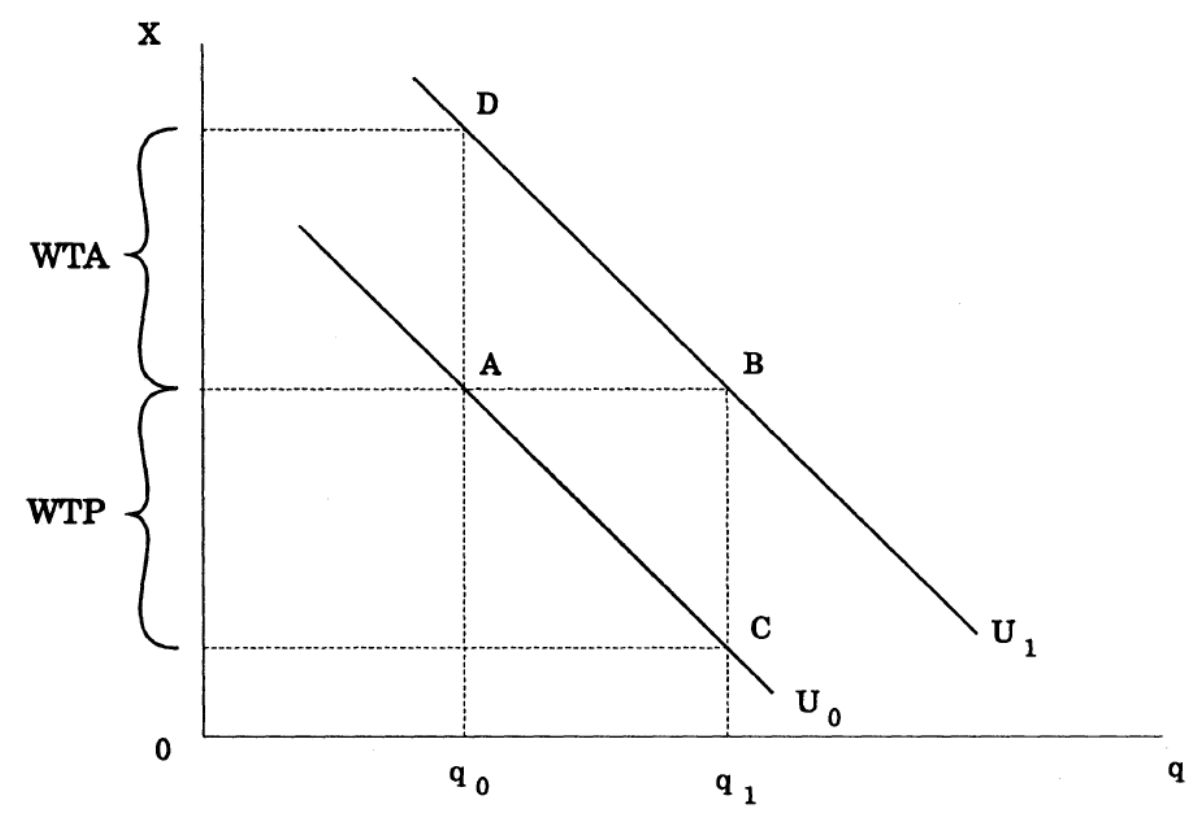

Figure 6. An example in which WTA $=$ WATP in Setting $Q q$ (from Shogren et al.).

This is the case in which $q$ and $X$ are perfect substitutes and the indifference curves are parallel to each other. This is certainly not a case of general interest. It is true that, in Figure 5, it would be possible, if $U_{1}$ had been different in a way that lowered $D^{\prime}$ just the right amount, to make WTP equal to WTA, but that would also be a "knife-edge" situation of little interest.

Another implication of the fact that "in Figure 5, if one moved the $U_{1}$ indifference curve a bit more to the right, WTA would be infinite" is that WTA is not always well-defined. WATP is not always well-defined, either: for example, it would not be well-defined if, in Figure 5, the indifference curve $U_{0}$ intersected the $q$ axis between $q_{0}$ and $q_{1}$, eliminating point $C^{\prime}$ from the graph.

\section{Setting Pi Explained}

In Setting Pi, consider a prospective policy of decreasing the price of apples. A consumer's WATP for this is illustrated in Figure 7. There, $B C_{0}$ is the original budget constraint, $B C^{\prime}$ is the new budget constraint, $U_{0}$ is the original maximized utility, which is obtained at point $A$, and $U^{\prime}$ is the new maximized utility, which is obtained at point $C$. In exchange for the new, lower price of apples, this consumer would be willing for his income to be reduced until his budget constraint was the dashed line, so the gap between $B C^{\prime}$ and the dashed line is related to WATP; this gap is known as "the income effect of a fall in the price of apples." WATP itself, in dollars, is most easily obtained from " $\Delta b_{p}$ times the price of bananas $\left(p_{b}\right)$," but it can equivalently be obtained from " $\Delta a_{p}$ times the new price of apples $\left(p^{\prime}{ }_{a}\right)$." Since $\Delta b_{p}$ has to be smaller than ef, and since ef is the maximum number of bananas the consumer could buy if the consumer bought no apples, namely income $I$ divided by $p_{b}$, we have $\Delta b_{p}<e f=I / p_{b}$, so $W A T P=\Delta b_{p} * p_{b}<I$, that is, WATP has to be less than income. Most economists call WATP "willingness to pay," "WTP," but since it is limited by income, "willingness and ability 
to pay" is a more appropriate name for it. After all, your WATP to reduce air pollution near where you live is almost certainly much less than Bill Gates's WATP to reduce air pollution near where he lives, ${ }^{86}$ but this difference in WATP stems overwhelmingly from the "ability" part, not the "willingness" part (the part reflecting pure preferences).

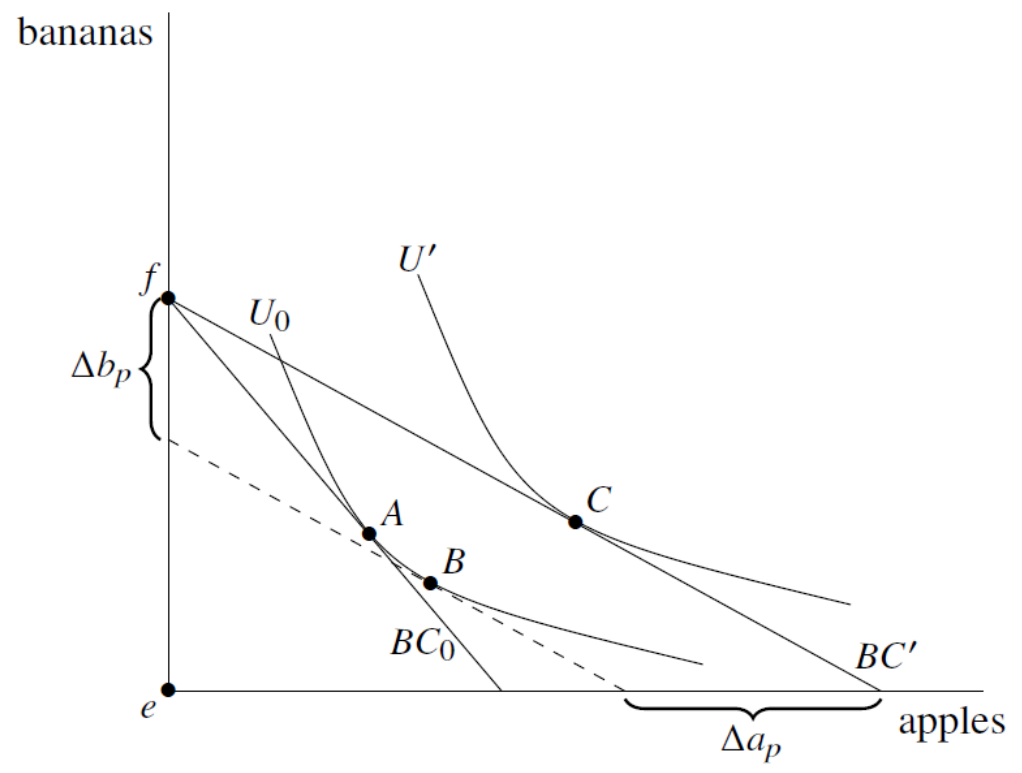

Figure 7. WATP illustrated. The motion from B to $C$ is the income effect of a fall in the price of apples.

By contrast, this consumer's WTA for this policy is illustrated using Figure 8. In return for foregoing the new, lower price of apples (which would increase utility to $U^{\prime}$ ), this consumer would be willing to remain at the old prices and accept the dashed line as his budget constraint, consuming at point $D$. The gap between $B C_{0}$ and the dashed line is related to WTA; this gap is known as "the income effect of a rise in the price of apples" even though what we are considering is a fall in the price of apples. WTA itself, in dollars, is most easily obtained from " $\Delta b_{a}$ times the price of bananas $\left(p_{b}\right)$," but it can equivalently be obtained from " $\Delta a_{a}$ times the old price of apples $\left(p_{a 0}\right)$." Since $\Delta b_{a}$ does not have to be smaller than $e f$, WTA does not have to be less than income. However, WTA will usually be affected by income, and in particular, a person who is poorer will have a $B C_{0}$ that is shifted towards point $e$ (the origin), which would make $\Delta b_{a}$, and hence WTA, smaller, all else equal. ${ }^{87}$ Because it is difficult to express the dependence of "willingness to accept" on income in just a few extra words, we accept its "WTA" conventional abbreviation.

${ }^{86}$ Zachary Liscow, Is Efficiency Biased? 85 The University of Chicago Law Review 1649-1718, 1672 (2018), writes, "Rich people tend to be willing to pay a relatively large amount for amenities like clean air that produce good health," then cites collaborating empirical evidence by Bengt Kristrom and Pere Riera, Is the Income Elasticity of Environmental Improvements Less Than One?, 7 Envir \& Res Econ 45-55, 47-48 (1996).

${ }^{87}$ To simulate a smaller income while keeping all else equal, change the scale of the graph's axes. 


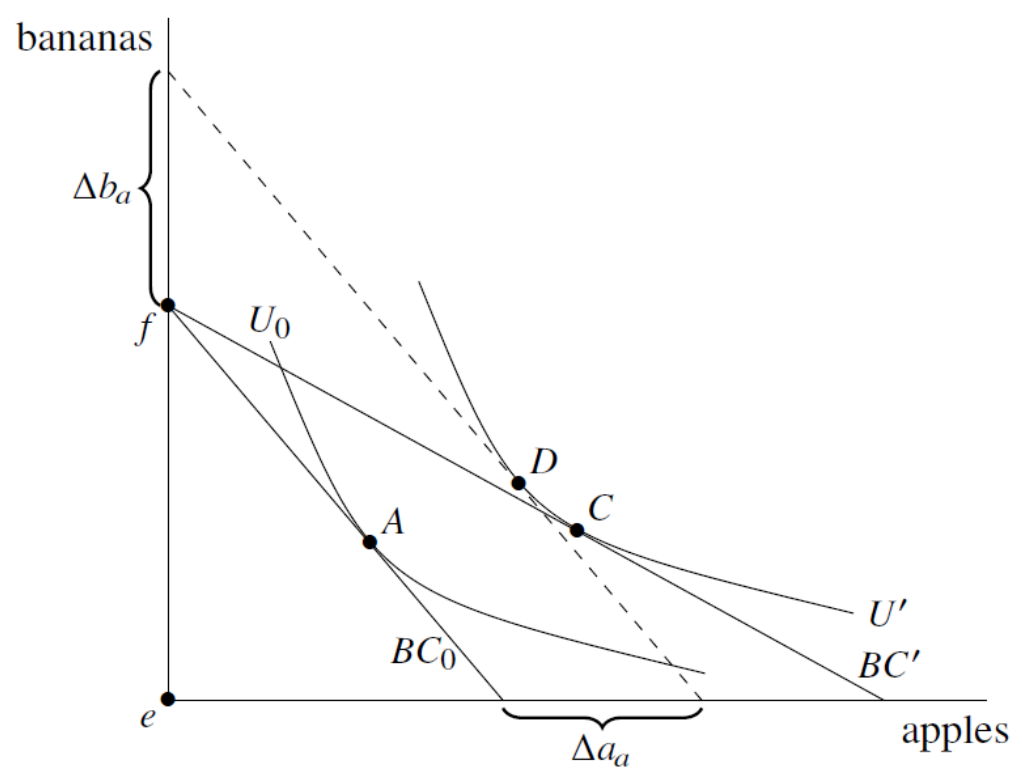

Figure 8. WTA illustrated. The motion from A to D is the income effect of a rise in the price of apples.

To compare WATP and WTA, it is easiest to compare them expressed in terms of bananas since the price of bananas does not change: $W A T P=\Delta b_{p} * p_{b}$ and $W T A=\Delta b_{a} * p_{b}$, meaning that WATP equals WTA if and only if $\Delta b_{p}=\Delta b_{a}$. That would be a most unusual situation. As illustrated by Figure 9 (for a different consumer than considered above), it can occur. To construct Figure 9, $U^{\prime}$ had to be drawn as a vertical translation of $U_{0}$, that is, $A D$ and $B C$ must have the same length. This implies that the income effect of the fall in the price of apples on the demand for apples, which is the motion from $B$ to $C$, is exactly zero ( $C$ lies exactly vertically above $B) .{ }^{88}$ Utility functions of this special type are called "quasilinear." In this graph, $\Delta b_{p}$ is equal to $B C$, and $\Delta b_{a}$ is equal to $A D$; accordingly, since $A D$ and $B C$ have the same length, $\Delta b_{p}=\Delta b_{a}$, which, as we saw above, implies that WATP is equal to WTA.

\footnotetext{
${ }^{88}$ In a model with more than two goods, all the goods except for one would have zero income effects on demand.
} 


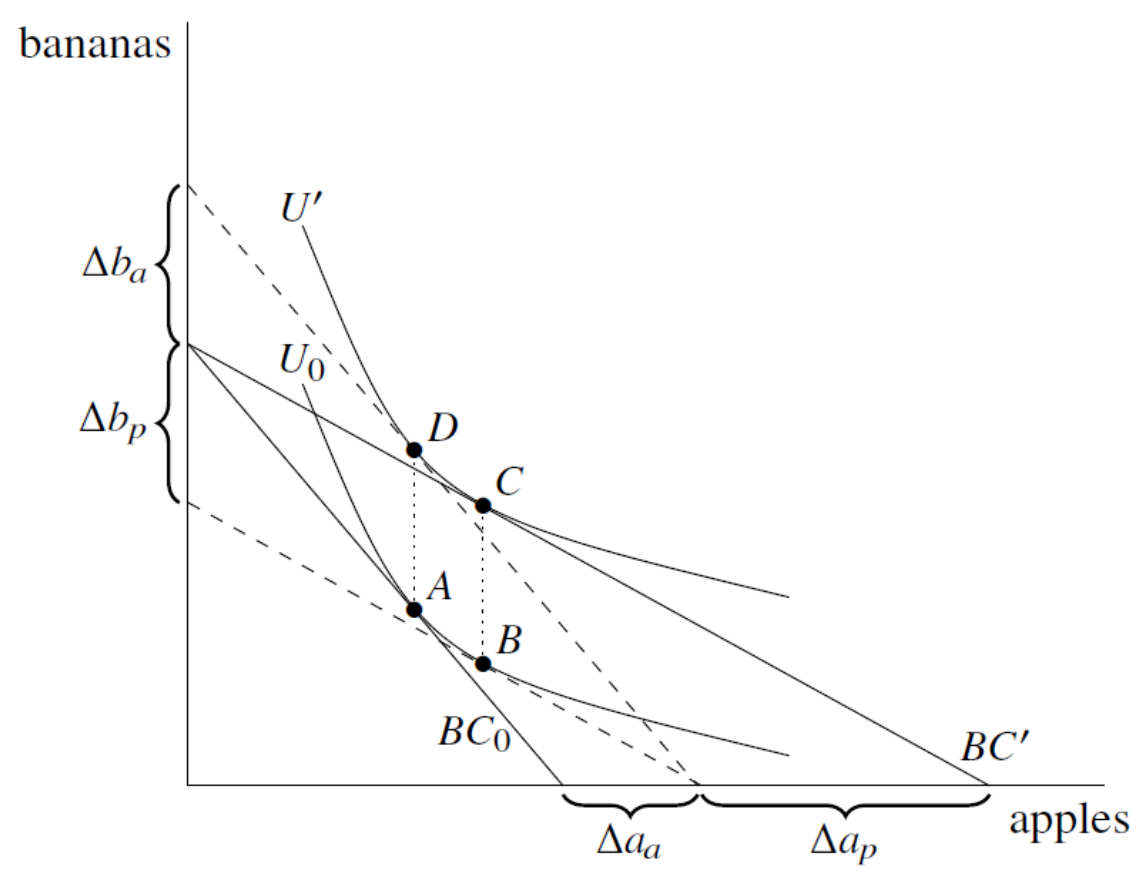

Figure 9. An example in which WTA $=$ WATP in Setting P $i$.

We saw that WATP and WTA could be undefined in Setting Qq; this can also occur in Setting Pi. In Figure 10 it is not possible to define WATP because $U_{0}$ is steeper everywhere than $B C^{\prime}$; one can see this by comparing $U_{0}$ to the dashed line, which is parallel to $B C^{\prime}$. (In this case, it is also impossible to divide the motion from $A$ to $C$ into an income effect and a substitution effect.) 


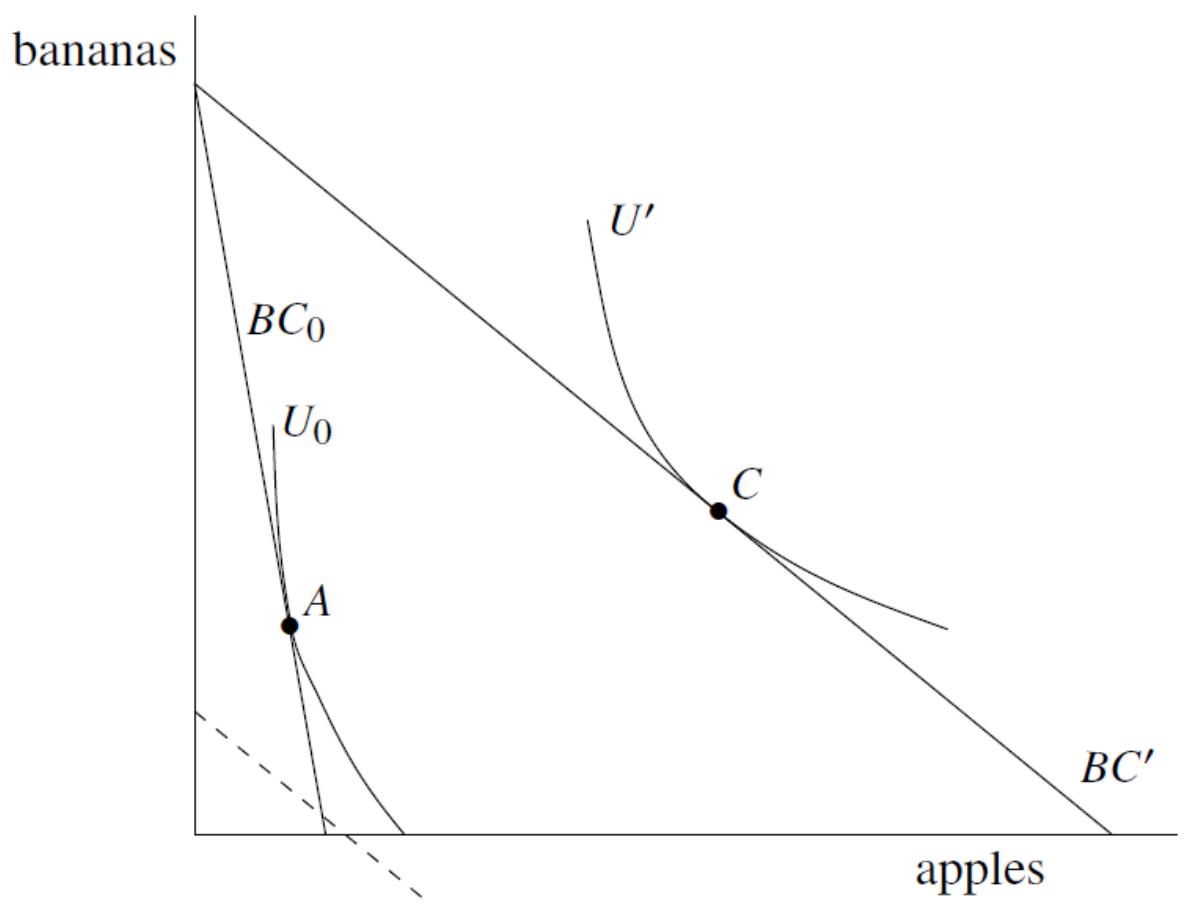

Figure 10. An example with no WATP in Setting Pi.

Similarly, in Setting Pi's Figure 11, it is not possible to define WTA (or the income and substitution effects) because $U^{\prime}$ is flatter everywhere than $B C_{0}$, as can be seen by comparing $U^{\prime}$ to the dashed line, which is parallel to $B C_{0}$.

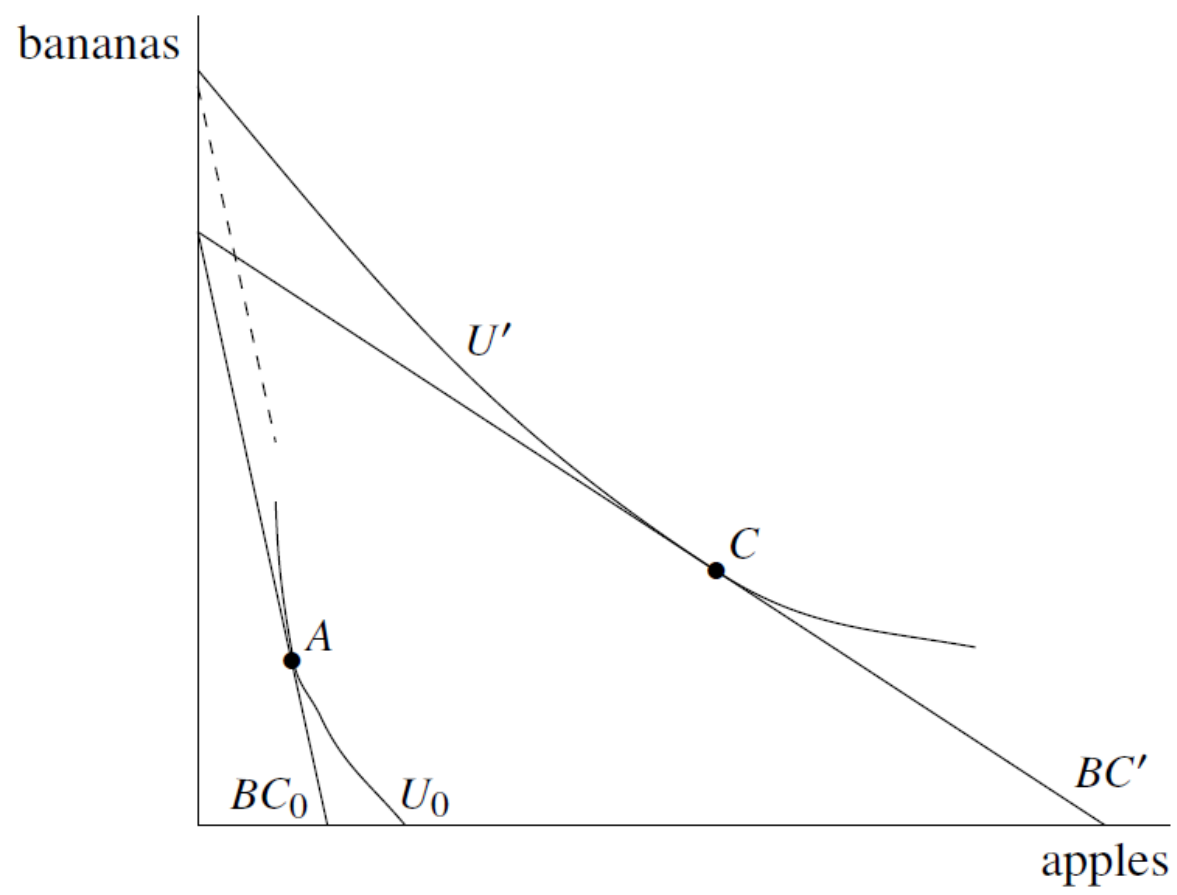

Figure 11. An example with no WTA in Setting Pi. 


\section{The General Inequality of WATP and WTA}

In both Settings Qq and Pi, then, neoclassical economic theory predicts - under its usual assumptions of a "rational" consumer maximizing a utility function subject to a budget constraint - that WATP will not be equal to WTA except under a highly restrictive further assumption. ${ }^{89}$ The "highly restrictive further assumption" is, in Setting Pi, exactly the one we have encountered before: Part III.G.1(d)'s assumption that "demand curves do not depend upon income" (there used in discussing the Coase Theorem). ${ }^{90}$ In Setting Qq, the "highly restrictive further assumption" is that indifference curves are linear and parallel.

Before undertaking the next steps in the analysis, we need to define more terminology and introduce additional techniques.

\section{Compensating and Equivalent Variation}

Consider a pure exchange economy (that is, an economy with no production, only exchange) with Ms. Smith and Mr. Jones as the only two people, and apples and bananas as the only two goods, and no prices. Consider the following original position and two possible policies that propose moving from that position:

Original position: Smith has 6 apples and 5 bananas. Jones has 4 apples and 1 banana.

Policy 1: Give 4 of Smith's bananas to Jones, leaving Smith with 1 banana (hence the name "Policy 1").

Policy 3: Give 2 of Smith's bananas to Jones, leaving Smith with 3 bananas (hence the name "Policy 3").

Both Policy 1 and Policy 3 would help Jones and hurt Smith. Both would transfer bananas. There are two versions of "Willingness and Ability to Pay" and "Willingness to Accept." The first version is defined by the answers to the following two questions:

If we adopt the policy, how many apples would Jones be willing and able to pay ("WATP") to make him as well off as if we had not adopted the policy?

If we adopt the policy, how many apples would Smith be willing to accept ("WTA") to make her as well off as if we had not adopted the policy?

This "if we adopt" version is due to Kaldor. The second version of "Willingness and Ability to Pay" and "Willingness to Accept" is defined by the answers to the following two questions:

\footnotetext{
${ }^{89}$ The inequality of WATP and WTA is not quite the same as the "phenomena known variously as loss aversion, the endowment effect, or status quo bias. [...] The essence of these phenomena is that individuals weigh losses more heavily than comparable gains. The evidence comes from experiments in which researchers have elicited values for changes in an item like $q$. However, the changes are different from those considered so far. Up to now, I have compared the WTP for some particular change in $q$ to the WTA for the same change in $q$. By contrast, many of the empirical experiments compare the WTP for an increase in $q$ with the WTA for a comparable decrease in $q$. As I now show, this is a somewhat different matter." W. Michael Hanemann, The Economic Theory of WTP and WTA, in Ian J. Bateman and Kenneth G. Willis, eds, Valuing environmental preferences: Theory and practice of the contingent valuation method in the US, EU, and developing countries 66 (Oxford University Press 1999).

${ }^{90}$ For the corresponding preferences see supra note 69.
} 
If we do not adopt the policy, how much would Jones be willing to accept ("WTA") to make him as well off as if we had adopted the policy?

If we do not adopt the policy, how much would Smith be willing and able to pay ("WATP") to make her as well off as if we had adopted the policy?

This "if we do not adopt" version is due to Hicks.

Kaldor did not use WATP and WTA but used the related concept of "compensating variation" ("CV"). Denote the winner of a policy by "W" and the loser of a policy by "L." When faced with Kaldor's "if we adopt" scenario, W would be willing to pay for the policy to be adopted and $\mathrm{L}$ would require compensation in order to accept the policy. Hence in Kaldor's scenario, W has a WATP and L has a WTA. It can be shown that W's WATP is equal to W's CV and L's WTA is equal to negative one times L's CV. ${ }^{91}$

Hicks did not use WATP and WTA but the related concept of "equivalent variation" ("EV"). Again, denoting the winner of a policy by "W" and the loser of a policy by "L," when faced with Hicks's "if we do not adopt" scenario, L would be "willing to pay" for the policy not to be adopted and $\mathrm{W}$ would require compensation in order to accept non-adoption of the policy. Hence weighing the policy using Hicks's question, L has a WATP and W has a WTA, whereas weighing the same policy using Kaldor's question, it was W who had a WATP and L who had a WTA. (To repeat, since this is a point completely missing from any of the numerous L\&E textbooks surveyed in Appendix 1: one policy; two different evaluations of it by W (one a WATP and one a WTA); and two different evaluations of it by L (one a WATP and one a

\footnotetext{
${ }^{91}$ To explain the relationships between Kaldor's CV, on the one hand, and WATP and WTA, on the other hand, consider Policy 1 above. If Jones's utility function is $u_{J}$ (apples, bananas) then Jones's WATP for Policy 1 obeys the relationship $u_{J}(8,1)=u_{J}(8-W A T P, 5)$ because the left-hand side is how well off Jones is if we do not adopt Policy 1 and the right-hand side is how well off Jones is if we adopt Policy 1, giving Jones four more bananas, if Jones were to give up WATP apples in return. Utility here is understood in its ordinal sense because if we instead measured Jones's utility using a transformation $f\left(u_{J}\right)$ instead of using $u_{J}$, the same WATP would satisfy relationship $f\left(u_{J}(8,1)\right)=f\left(u_{J}(8-W A T P, 5)\right)$. Since Jones cannot be said to possess a negative number of apples, $8-W A T P$ needs to be greater than or equal to zero, so WATP needs to be less than or equal to 8 , illustrating the point we made above that "WATP" indeed is limited by a person's ability to pay. If Smith's utility function is $u_{S}$ (apples, bananas) then Smith's WTA for Policy 1 obeys the relationship $u_{S}(2,5)=$ $u_{S}(2+W T A, 1)$ because the left-hand side is how well off Smith is if we do not adopt Policy 1 and the right-hand side is how well off Smith is if we adopt Policy 1, taking away from Smith four bananas, if Smith were to be given WTA apples in return. For either person, "compensating variation" ("CV") is defined to obey the relationship $u$ (original apples, original bananas) $=u$ (original apples $-C V$, new bananas). This makes Jones's WATP equal to Jones's CV and makes Smith's WTA equal to negative one times Smith's CV.
} 
WTA).) It can be shown that W's WTA is equal to W's EV and L's WATP is equal to negative one times L's EV. ${ }^{92,93}$

Setting Hicks/EV/“if we do not adopt" aside for a few paragraphs, in the context of Kaldor's "if we adopt" question and Setting Qq, it is possible to graphically illustrate in an Edgeworth Box Jones's WATP (Jones's CV) and Smith's WTA (Smith's CV) for a policy resembling Policy 1. Construct an Edgeworth Box in which apples $a$ are measured horizontally and bananas $b$ are measured vertically. Both Policies 1 and 3 involve a transfer of bananas from Smith to Jones. A generic transfer of some number of bananas from Smith to Jones can be represented by a movement in an Edgeworth Box from $o$ ("old") to $n$ ("new") in the two graphs of Figure 12:

\footnotetext{
92 To explain the relationships between Hicks's EV, on the one hand, and WATP and WTA, on the other hand, consider Policy 1 above. If as before we represent Jones's utility function as $u_{J}$ (apples, bananas) then the EV version of Jones's WTA for Policy 1 obeys the relationship $u_{J}(8,5)=u_{J}(8+W T A, 1)$ because the left-hand side is how well off Jones is if we adopt Policy 1 and the right-hand side is how well off Jones is if we do not adopt Policy 1, which would have given Jones four more bananas and gave Jones "WTA" apples instead. Similarly, the EV version of Smith's WATP for Policy 1 obeys the relationship $u_{S}(2,1)=u_{S}(2-W A T P, 5)$ because the lefthand side is how well off Smith is if we adopt Policy 1 and the right-hand side is how well off Smith is if we do not adopt Policy 1, which would have taken four bananas away from Smith if Smith were willing to give up "WATP" apples instead. For either person, "equivalent variation" ("EV") is defined to obey the relationship $u$ (original apples, new bananas $)=u$ (original apples $+E V$, original bananas $)$. This makes Jones's WTA equal to Jones's EV and it makes Smith's WATP equal to negative one times Smith's EV.
}

${ }^{93} \mathrm{CV}$ and EV are much older terms than WATP and WTA (perhaps three decades older) and are the terms Kaldor and Hicks used. Hicks, supra note 80 at 35-6, used the terms "quantity-equivalent variation" and "quantitycompensating variation" for EV and CV in Setting Qi, and the terms "price-equivalent variation" and "pricecompensating variation" for EV and CV in Setting Pi. Since "quantity-equivalent variation" and "quantitycompensating variation" are from Setting Qi, they are not identical to the EV and CV in our Setting Qq, but they resemble the EV and CV of Setting Qq more than "price-equivalent variation" and "price-compensating variation" resemble EV and CV in Setting Qq. "Price-equivalent variation" and "price-compensating variation" are by far the most commonly used EV and CV in economics because Setting Pi is used much more than Frames Qi and Qq.

"Quantity-equivalent variation" is sometimes called "equivalent surplus" ("ES") and "quantity-compensating variation" is sometimes called "compensating surplus" ("CS") but we will not use those terms in this paper. See A. Myrick Freeman III, Joseph A. Herriges, and Catherine L. Kling, The Measurement of Environmental and Resource Values: Theory and Methods 66 (in Chapter 3, "Welfare Measures: Definitions and Concepts")

(Resources for the Future Press $3^{\text {rd }}$ ed 2014). Also, in Environmental Economics the acronym "CV" is often used to denote not compensating variation but Contingent Valuation, a survey method that can be used to measure either equivalent variation or compensating variation. 
Jones

Jones
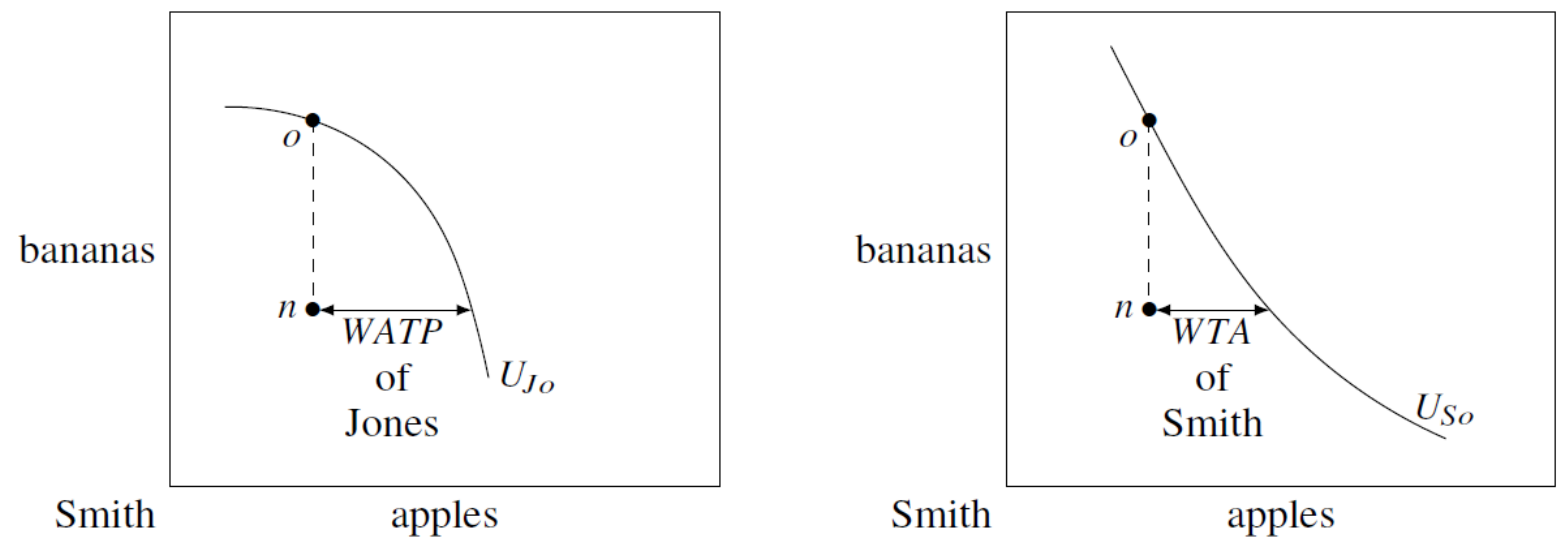

Figure 12. Setting $Q q$ 's compensating-variation WATP and WTA for a move from $\mathrm{o}$ to $\mathrm{n}$ in an Edgeworth Box.

Left-hand graph: "WATP of Jones" shows how many apples Jones is willing to pay in return for receiving bananas from Smith via the move from $o$ to $n$. If Jones were asked to pay his WATP after moving from $o$ to $n$, he would go from $n$ to the right until he reached his original indifference curve (making him as well off as he was at $o$ ). If in exchange for his vertical gain in bananas he had to pay any more apples than his WATP, he would end up on a lower indifference curve than he started out at.

Right-hand graph: "WTA of Smith" shows how many apples Smith would require to fully compensate Smith for having bananas taken away from her and given to Jones via the move from $o$ to $n$. If Smith were given her WTA after moving from $o$ to $n$, she would go from $n$ to the right until she reached her original indifference curve (making her as well off as she was at $o$ ). If in exchange for her vertical loss in bananas she was given any fewer apples than her WTA, she would end up on a lower indifference curve than she started out at.

These graphs showed a transfer of a generic quantity of bananas from Smith to Jones. Figure 13 is a graph using the specific numbers of Policy 1 ( $o$ to $\left.n_{1}\right)$ and Policy 3 ( $o$ to $n_{3}$ ). Over the next several sections we will methodically build up an explanation for all of Figure 13. For now, only consider the right-hand side of Figure 13, which shows one possible relative orientation of the indifference curves passing through $o$ for Smith (the "Loser" if one moved down from $o$ ), called $U_{L o}$, and for Jones (the "Winner" if one moved down from $o$ ), called $U_{W o}$. To the right of $n_{3}$ we see Loser Smith's $W T A_{L 3}$ and Winner Jones's $W A T P_{W 3}$, and to the right of $n_{1}$ we see Loser Smith's $W T A_{L 1}$ and Winner Jones's $W A T P_{W 1}$. 


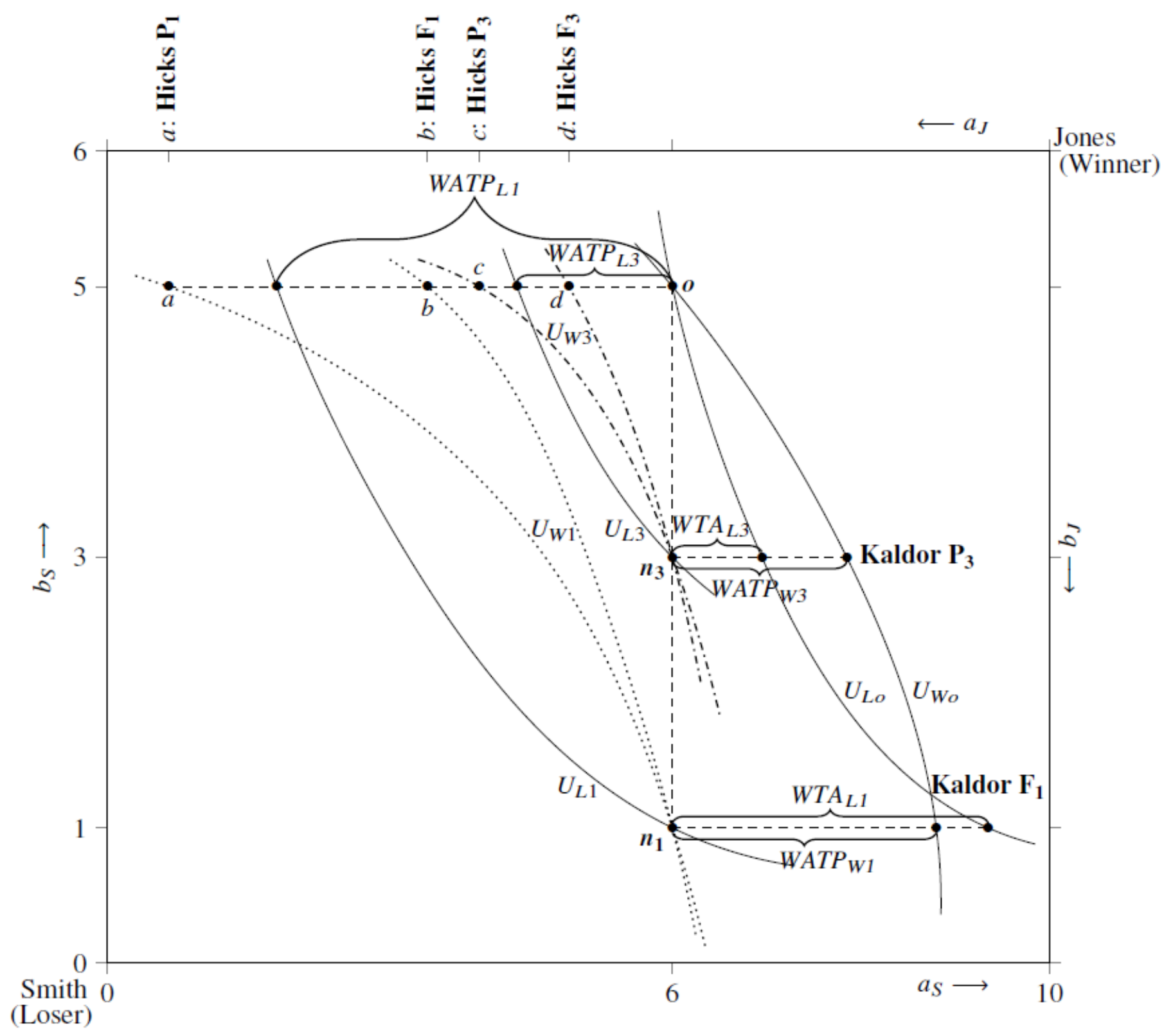

Figure 13. The Hicks and Kaldor WTA and WATP for Policy 3 (o to $\mathrm{n}_{3}$ ) and for Policy 1 (o to $n_{1}$ ). Two alternative positions are shown for $U_{W 1}$ and two alternative positions are shown for $U_{W 3}$.

These measurements of WATP and WTA so far have been the "CV" versions of Kaldor, and have always used the original indifference curves and the new point $n$. One could use these definitions to graph the CV versions of WATP and WTA for policies which, unlike Policies 1 and 3, involve moves other than "taking bananas away from Smith and giving them to Jones." Graphs showing policies such as "taking bananas away from Jones and giving them to Smith," "taking apples away from Smith and giving them to Jones," and "taking apples away from Jones and giving them to Smith" will have WATP and WTA that look different from the graphs above, but as long as they illustrate the CV versions of WATP and WTA, they will always 
reflect moving from the new point to the original indifference curve in a direction perpendicular to the direction of the policy whose WTA or WATP one is trying to measure.

As with Kaldor's CV, we can use elementary Edgeworth Boxes to illustrate Hicks's EV in Setting Qq; consider a policy of moving from $o$ to $n$ in Figure 14.

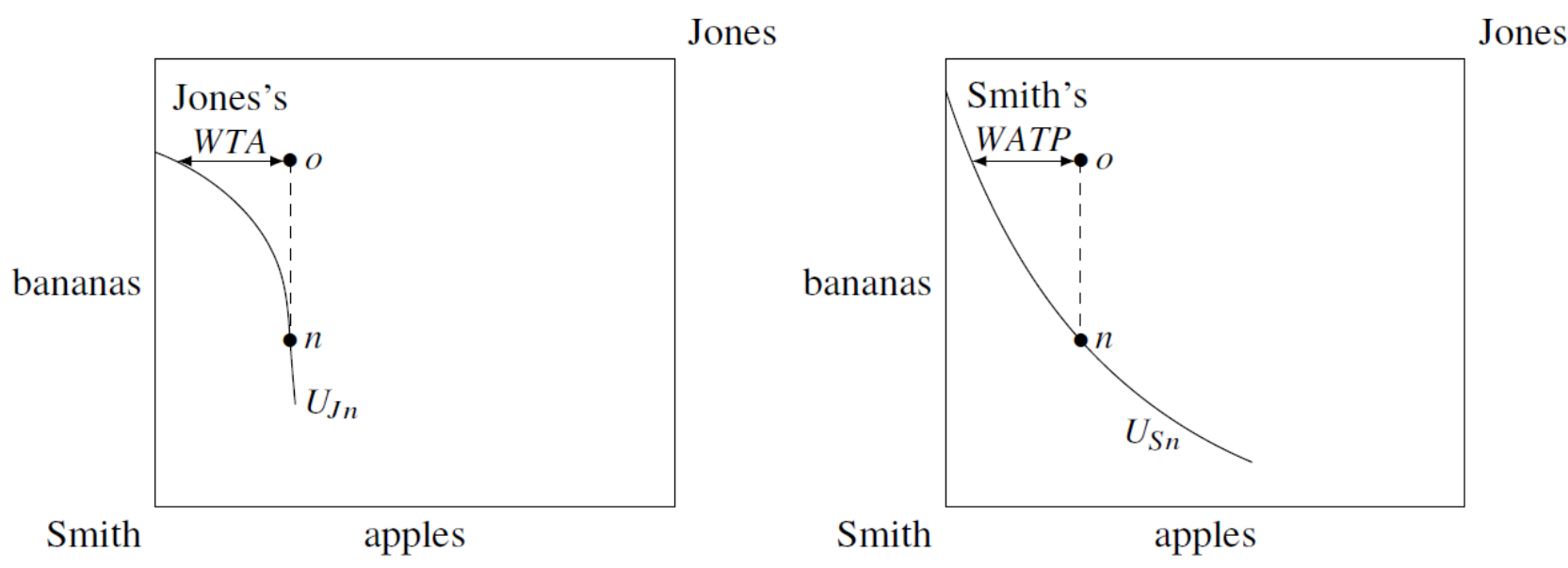

Figure 14: Setting Qq's equivalent-variation WTA and WATP for a move from $\mathrm{o}$ to $\mathrm{n}$ in an Edgeworth Box. This move from $\mathrm{o}$ to $\mathrm{n}$ is the same move which is illustrated in Figure 12.

Left-hand graph: Jones's WTA shows how many apples Jones would require to fully compensate him in return for not having bananas taken away from Smith and given to him via the move from $o$ to $n$. If Jones were given his WTA instead of being able to move from $o$ to $n$, he would go from $o$ to the left until he reached his indifference curve passing through $n$. If in exchange for not obtaining his vertical gain in bananas he was given fewer apples than his WTA, he would end up on a lower indifference curve than he would have had at $n$.

Right-hand graph: Smith's WATP shows how many apples Smith would be willing to pay in return for not having bananas taken away from her and given to Jones via the move from $o$ to $n$. If Smith paid her WATP instead of being forced to move from $o$ to $n$, she would go from $o$ to the left until she reached her indifference curve passing through $n$. If in exchange for not being forced to undergo her vertical loss in bananas she had to pay any more apples than her WATP, she would end up on a lower indifference curve than she would have had at $n$.

Thus, Hicks's EV is always measured using the new indifference curves and the original point. (Recall that Kaldor's CV uses the original indifference curves and the new point.) One can use this principle to graph the EV versions of WATP and WTA for policies which, unlike Policies 1 and 3, involve moves other than "taking bananas away from Smith and giving them to Jones." Graphs showing policies like "taking bananas away from Jones and giving them to Smith," "taking apples away from Smith and giving them to Jones," and "taking apples away from Jones and giving them to Smith" will have graphs of WATP and WTA that look different from the graphs above, but they will always reflect moving from the original point to the new indifference curve in a direction perpendicular to the direction of the policy whose WTA or WATP one is trying to measure.

The left-hand side of Figure 13 shows indifference curves passing through $n_{3}$ and through $n_{1}$ for Smith (the "Loser" if one moved down from $o$ ), $U_{L 3}$ and $U_{L 1}$. Immediately to the left of $o$ 
we see Loser Smith's $W A T P_{L 3}$, and further to the left of $o$ we see Loser Smith's $W A T P_{L 1}$. In addition, the left-hand side of Figure 13 shows, as dotted curves, two mutually incompatible possible locations for an indifference curve passing through $n_{1}$ for Jones (the "Winner" if one moved down from $o$ ), $U_{W 1}$, one passing through point $a$ and the other passing through $b$. With $a$, Jones's $W T A_{W 1}=a o$, while with $b$, Jones's $W T A_{W 1}=b o$. Also shown, as dash-dotted curves, are two mutually incompatible possible locations for an indifference curve passing through $n_{3}$ for Jones, $U_{W 3}$, one passing through point $c$ and the other passing through $d$. With $c$, Jones's $W T A_{W 3}=c o$, while with $d$, Jones's $W T A_{W 3}=d o$.

Most economists will only be familiar with CV and EV expressed in terms of Setting Pi, that is in terms of money and income, rather than in terms of a commodity such as apples in Setting Qq. In applying CV and EV to Setting Qq, we are merely following the logic of applying WATP and WTA to Setting Qq, as explained above.

Section IV.A.4's point about the general inequality of WATP and WTA can be illustrated in Figure 13. Consider Policy 3 for example. Winner Jones's WTA (EV) is $W T A_{W 3}=c o$; this will in general be different from Jones's WATP $(\mathrm{CV}), W A T P_{W 3}$, which is the distance from point $n_{3}$ right to $U_{W o}$. Similarly, Smith's $W A T P_{L 1}$ is not equal to her $W T A_{L 1}$, and her $W A T P_{L 3}$ is not equal to her $W T A_{L 3} \cdot{ }^{94}$

\section{Nonexistent WATPs and Infeasible WTAs in Edgeworth Boxes}

In Figure 12, Figure 13, and Figure 14, there were no problems defining WATP and WTA, but we pointed out in Section IV.A.2 that such is not always the case. Figure 15 shows examples of such problems in an Edgeworth Box (Setting Qq). Consider first Figure 15's right-hand side, which, for the motion from $o$ to $n$, would usually show the compensating variation (Kaldor) WATP of the winner (Jones) and the WTA of the loser (Smith). In Figure 15 it is not possible to define WATP for Jones because $U_{J o}$ intersects the $b_{J}$ vertical axis before it reaches the line $n m$. It is not possible to extend $U_{J o}$ to the right, beyond that vertical axis, because that would correspond to Jones consuming a negative number of apples. The increase in Jones's bananas caused by the movement from $o$ to $n$ benefits Jones so much that he does not possess enough apples to be "willing and able to pay" apples to the extent necessary to bring him back to his original level of utility. On the left-hand side of Figure 15, analogous remarks apply to the equivalent variation (Hicks) WATP of Smith: the decrease in Smith's bananas caused by the movement from $o$ to $n$ hurts Smith so much that she does not possess sufficient apples to be "willing and able to pay" apples to avoid moving from $o$ to $n$ and enjoy no worse utility than at $n$.

\footnotetext{
94 This inequality of one agent's EV and CV was known by the inventors of the terms EV and CV, but the equivalent inequality of one agent's WATP and WTA was not known by all of the early users of the terms WTP (our WATP) and WTA, who thought WATP and WTA would be equal for rational agents. Even modern texts sometimes ascribe some of the difference between WATP and WTA to consumers' irrationality, which while it might be true is superfluous, since as we have shown, rational agents' WATP and WTA can differ greatly. For an example of such a "modern text" see Thomas H. Tietenberg and Lynne Lewis, Environmental and Natural Resource Economics 81 (Routledge 11 $11^{\text {th }}$ ed 2018): "Economic theory suggests that differences between WTP and WTA should be small, but experimental findings both in environmental economics and in other microeconomic studies have found large differences. Why? Some economists have attributed the discrepancy to a psychological endowment effect...." Occam's Razor simply ascribes the difference between WATP and WTA to income effects, to which Tietenberg and Lewis devote a mere one sentence (ibid).
} 


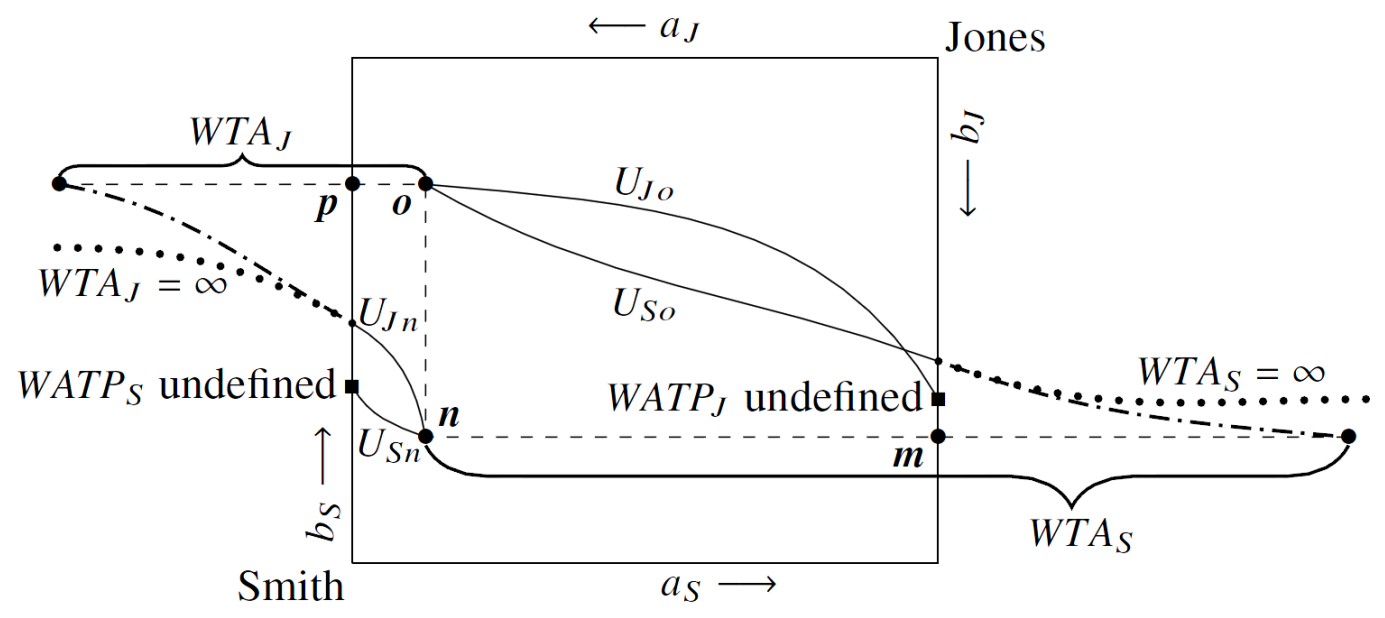

Figure 15. Nonexistent WATP and infeasible WTA in Setting Qq.

The potential problems with WTA are not as severe as the nonexistence problems with WATP. On the right-hand side of Figure 15 (CV/Kaldor), again studying the motion from $o$ to $n$, Smith's WTA cannot be defined as it was in Figure 12 because $U_{S o}$ intersects the $b_{J}$ axis before reaching the line $\mathrm{nm}$. However, $U_{S o}$ can be extended to the right beyond the $b_{J}$ axis: such an extension is into regions of apples and bananas greater than what this economy has, but Smith can certainly have preferences in that region. We show two possibilities for the way the extension of $U_{S o}$ might look, one depicted with dots and the other with a dash-dot pattern. If the extension of $U_{S o}$ looks like the dash-dot curve, Smith's WTA is as shown. It would be infeasible to give Smith her WTA, but there is no problem defining it. If the extension of $U_{S o}$ looks like the dotted curve, which will never intersect with a line extended right from $\mathrm{nm}$, then Smith's WTA would be infinite. On the left-hand side of Figure 15 (EV/Hicks), analogous remarks apply to Jones's willingness to accept compensation in return for foregoing the movement from $o$ to $n$, where again, dots or a dash-dot pattern are used to indicate two possible extensions of $U_{J n}$ left of the $b_{S}$ axis.

\section{Consensual Uses of WATP/WTA/CV}

So far nothing we have said in this Section has pertained to normative social decision-making; we have mostly been concerned merely with explaining the positive point that individuals value commodities in a dual sense. In Section IV.B, however, our focus shifts to using WATP/WTA in L\&E's coercive social decision-making context, but to help ensure that the reputation of WATP/WTA is not sullied by the use which that "Potential Pareto" approach will make of them, we want to point out that there are consensual, non-controversial uses of WATP/WTA as well. Suppose an economist or mediator is trying to design a policy that could be joined to Policy 3, which gives two of Smith's bananas to Jones and goes from $o$ to $n_{3}$ in Figure 13, to make the joined policy a Pareto Improvement. If Policy 3 is joined to a second policy, "transfer from Jones to Smith a number of apples strictly between Figure 13's $W T A_{L 3}$ and $W A T P_{W 3}$," then the final point ends up being to the right of $n_{3}$ in a position that makes both people would be better off than they were at $o$. 
B. The Potential-Pareto/Kaldor-Hicks/Cost-Benefit-Analysis Criterion for Making Coercive Social Decisions

Obviously, not all societal or government decisions have been designed to result in no one being made worse off. Indeed, as noted above, nearly all judicial determinations result in winners and losers. So, how do these alternative "efficiency" measures fare in such circumstances?

Consider a "social" or "governmental" policy having two parts:

- $\quad$ take an action that makes Person L worse off and Person W better off ("L" for "loser" and "W" for "winner"); together with

- $\quad$ require Person W to give to Person L some amount of money or some amount of some commodity that was not involved in the first part's action to compensate for the loss suffered by L.

Suppose that this joint policy is a Pareto Improvement (i.e., no one is left worse off). Clearly, having the State use its coercive powers to enact the first part of the policy without the second would not be a Pareto Improvement because Person L would not be compensated for his loss. For example, if one strikes a two-part deal with an automobile seller that you will get his automobile (the first part) and you will give him a certain amount of money (the second part), that is a Pareto Improvement; but if the State allows you to perform only the first part (taking the car) but not perform the second part (the money transfer), the result is not a Pareto Improvement, or anything like a Pareto Improvement; the result would be a clear property-right violation. Yet, Kaldor astonishingly would endorse the State seizing the car from the dealer without compensation and giving it to you (ignoring any perversion of future incentives), as reflected in this passage:

"... since in all such cases it is possible to make everybody better off than before, or at any rate to make some people better off without making anybody worse off. There is no need for the economist to prove-as indeed he never could prove - that as a result of the adoption of a certain measure nobody in the community is going to suffer. In order to establish his case, it is quite sufficient for him to show that even if all those who suffer as a result are fully compensated for their loss, the rest of the community will still be better off than before. Whether the landlords, in the free-trade case, should in fact be given compensation or not, is a political question on which the economist, qua economist, could hardly pronounce an opinion. ${ }^{95}$

In other words, Kaldor claims that if a two-part policy is a Pareto Improvement, the first part of the policy should be adopted even if the second part is not adopted, because the second part could have been adopted. This is known as the "Potential Pareto" criterion: the first part of a policy should be adopted even if the second part is not, if adopting the second part would (together with the first part) have resulted in a Pareto Improvement.

${ }^{95}$ Nicholas Kaldor, supra note 63 at 550. 
It is difficult to see why anyone should take the Potential Pareto criterion seriously. Varian ${ }^{96}$ says "An allocation that is potentially Pareto preferred to the current allocation has potentially higher welfare. But one might well argue that actual welfare is what is relevant." Coleman ${ }^{97}$ trenchantly points out that there is absolutely no reason to think that people would consent to a policy that harms them "in virtue of its potential to be something other than it is." We agree with Chipman and Moore ${ }^{98}$ that an economist taking Kaldor's advice wants "to wash one's hands of the responsibility for one's own actions."

A possible reason for the criterion's popularity among some economists is that it was couched, not in terms of a pure-exchange economy, but in terms of an economy with production. The first part of the policy, in making Person L worse off and Person W better off, was also assumed to increase the amount of goods produced. However, that is no comfort to Person L. Moreover, a policy that increases the amount of goods produced is not any more virtuous than a policy like the two-part automobile trade, which increases the utility of both parties. Increasing utility is the goal of economic policy; increasing the amount of goods produced, per se, is not. Privileging "productive" activities over those that only increase joint utility via exchange (without new production) fetishizes commodities, which is an old mistake in economics.

We conclude this portion of our argument with one more example. The canonical neoclassical argument in favor of free trade is that the following two-part policy is Pareto Improving: (a) remove barriers to trade; (b) compensate people who lose because the trade barriers were removed. (Proof that (a) combined with (b) is a Pareto Improvement can be found in any textbook on international trade theory.) The Kaldor "Potential Pareto" criterion then says that "(a) without (b)" is also an improvement. The alleged reason for this is the Separation Hypothesis (debunked in Section III.G.1(c) above), that "(b) is about distribution, not efficiency, and is outside the scope of economics; besides, distribution can be taken care of with lump-sum income transfers." However, (b) is not "just" about distribution-(b)'s redistribution is fully half of what makes the joint policy of "(a) and (b)" an efficiency improvement. Accordingly, this "Potential Pareto" criterion makes no sense. However, it is presumably the reason why U.S. presidents of both political parties from the 1980's to 2016 pursued (a) without (b), leading to deindustrialization and an epidemic of "deaths of despair"99" among the policy's losers. Clearly, then, the "Potential Pareto" criterion has none of the moral appeal of the Pareto Criterion.

On the very next page after Kaldor drafted the passage quoted above, he wrote the first argument in favor of the Separation Hypothesis cited in supra note 63. The "Potential Pareto" criterion is closely related to the Separation Hypothesis because Kaldor sees the first part of the policy, making W better off and L worse off, as an "efficiency improving" question, while the second part, compensating L for the loss, he views a "political question" of "distribution." Sections III.G.1(c) and III.G.1(d) have shown that the Separation Hypothesis is unsound.

\footnotetext{
${ }^{96}$ Hal R. Varian, supra note 53 at 409.

${ }^{97}$ Jules L. Coleman, supra note 62 at note 62.

${ }^{98}$ John S. Chipman and James C. Moore, The New Welfare Economics 1939-1974, 19 International Economic Review 547-584, 580 (1978).

${ }^{99}$ Anne Case and Angus Deaton, Deaths of Despair and the Future of Capitalism (Princeton University Press 2020). Deaton is a Nobel Laureate in Economics.
} 
"Value," "willingness and ability to pay," and concepts like "efficiency improvements" that follow from value and WATP, all depend on distribution. Posner ${ }^{100}$ acknowledged this:

Willingness to pay is in turn a function of the existing distribution of income and wealth in the society. Were income and wealth distributed in a different pattern, the pattern of demands might also be different and efficiency would require a different deployment of our economic resources.

To see an example of how this plays out, suppose it is impractical for wealthy automobile drivers to engage in Coasian bargaining with impoverished pedestrians over which group should have the "property rights" (the right-of-way) over a roadway crosswalk. If bargaining were possible, suppose (as is likely) the result would be automobile drivers having the right-ofway, either buying it from the pedestrians, if pedestrians had the original property right, or simply exercising it, if the drivers had the original property right. Applying the Potential Pareto criterion (Kaldor-Hicks efficiency) directs judges to give those property rights to the motorists without compensation to the pedestrians because the motorists could have paid the pedestrians for the right and made both parties better off. But such a judgment leaves the pedestrians worse off than if they had gotten the right-of-way, and leaves advocates of the Potential Pareto judgment on extremely weak footing, defending this judgment by arguing that "there exists $a$ different judgment (the first part of which gives the motorists the right-of-way and the second part of which requires the motorists handing over money to the pedestrians) that would have made both parties better off." Yet, it is obvious why the wealthy motorists would want to make this argument, weak though it is. They benefit from judicial adherence to Kaldor-Hicks efficiency in a way they would not if the criterion were Pareto efficiency and the pedestrians initially had the right-of-way. Section III.G.1(c) showed that original distributions ("endowments") determine what moves are Pareto efficiency improvements. In turn, what determines the endowments are property rights, contract rights, and other legal rules and entitlements. The Potential-Pareto/Kaldor-Hicks/Cost-Benefit-Analysis argument that wealthy drivers rather than impoverished pedestrians should be given the "property rights" over a roadway crosswalk is completely driven (no pun intended) by the ex ante large property rights of the drivers and small property rights of the pedestrians, not by a "distribution-free, objective notion of Pareto efficiency" - there being no such thing. Property rights determine Paretoefficiency improvements, not vice versa. Accordingly, it is impossible to have a "Paretoefficient allocation of property rights," ${ }^{101}$ but (as the wealthy motorists in our example know) it is possible to have "a Potential-Pareto-efficient allocation of property rights." 102

\footnotetext{
${ }^{100}$ Richard A. Posner, supra note 33.

${ }^{101}$ Warren J. Samuels, The Coase Theorem and the Study of Law and Economics 14 Natural Resources J. 1-33, 24 (1974), points out: “...there is no unique Pareto optimal result, only results specific to the power structure; and when the very act of legislating (through statute or court decision) liability rules (through the joint rights determination process discussed above) will also govern the rights and power structure and thereby the Pareto optimal result..." Samuels concluded: "Rights specify efficiency, efficiency does not specify rights. [...] To evaluate costs and benefits in terms of the maximized value of production is to reason circularly to give effect to already extant costs and the rights reflected or given effect therein. [...] For all practical purposes, the Coasian analysis is power-thought, with evocative qualities more akin to ideology than to science." Samuels, id. at 9, 17, and 27.

102 As put by Robert Ashford, Socioeconomics and Professional Responsibilities in Teaching Law-Related Economic Issues, 41 San Diego Law Review 133-176, 157 (2004): “As a positive matter of economics, however,
} 
The above shows the flawed nature of the "Potential Pareto" criterion. There are further flaws in the "Potential Pareto" approach, but they can only be revealed by investigating them in more technical detail and discussing the Kaldor Test separately from the Hicks Test. In the next several sections, we demonstrate, for example, that the "Potential Pareto" criterion does not even completely solve the problem it was supposed to solve-overcoming the Pareto Principle's inability to rank all social states - because it turns out that the Potential Pareto Principle likewise cannot rank all social states. Moreover, the Potential Pareto Principle sometimes ranks State A strictly above State B and ranks State B strictly above State A, an inconsistency not present with the Pareto Principle, nor with applications (such as the one in Section IV.A.7) that put WATP and WTA to the service of the Pareto Principle.

\section{The Kaldor Test (CV Measured as a Quantity)}

A policy that has a winner "W" and a loser " $\mathrm{L}$ " is said to "pass the Kaldor Test" if and only if W's WATP for the policy to be adopted is greater than L's WTA for that same policy. This is because, if this inequality holds, then it seems that W could "potentially" compensate $\mathrm{L}$ and still be better off. (We say "it seems that W could" rather than "W could" because of the caveats in Section IV.E.1.)

As explained in Section IV.A.5, for a policy having a winner "W" and a loser "L," W's WATP is equal to W's CV and L's WTA is equal to negative one times L's CV. Therefore, in symbols:

Kaldor Pass: W's CV = W's WATP > L's WTA $=(-1)$ * L's CV.

It follows that "a policy passes the Kaldor Test if and only if the sum of the CVs is positive." Similarly,

Kaldor Fail: W's CV $=$ W's WATP $<$ L's WTA $=(-1) *$ L's CV

and "a policy fails the Kaldor Test if and only if the sum of the CVs is negative."

As an example, consider the right-hand part of the Edgeworth Box of Figure 13. With its indifference curves $U_{L o}$ and $U_{W o}$, Policy 3 passes the Kaldor Test because $W A T P_{W 3}$ of the Winner (Jones) is greater than $W T A_{L 3}$ of the Loser (Smith). This is what the figure's "Kaldor $\mathrm{P}_{3}$ " signifies. On the other hand, Policy 1 fails the Kaldor Test because $W A T P_{W 1}$ of the Winner (Jones) is less than $W T A_{L 1}$ of the Loser (Smith). This is what the figure's "Kaldor $F_{1}$ " signifies.

D. The Hicks Test (EV Measured as a Quantity)

A policy that has a winner "W" and a loser "L" is said to "fail the Hicks Test" if and only if W's WTA for the policy not being adopted is smaller than L's WATP for rejection of that same policy. This is because if this inequality holds then it seems - not always correctly, as we will see in Section IV.E. 1 - that L could "potentially" pay W compensation for the failure to adopt the policy and still be better off than if the policy had been adopted.

the same logic that holds that prices determine distribution also holds that distribution determines prices. No standard of efficiency is or can be distributively neutral. Even when transactions costs can be assumed to be zero and externalities are negligible or nonexistent, the assignment of property rights nevertheless affects prices and the allocation of resources." 
As explained in Section IV.A.5, for a policy having a winner "W" and a loser "L," W's WTA is equal to W's EV and L's WATP is equal to negative one times L's EV. Therefore, in symbols:

Hicks Fail: W's EV = W's WTA < L's WATP $=(-1) *$ L's EV.

Thus, it follows that "a policy fails the Hicks Test if and only if the sum of the EVs is negative." Similarly,

Hicks Pass: W's EV = W's WTA > L's WATP $=(-1) *$ L's EV

and "a policy passes the Hicks Test if and only if the sum of the EVs is positive."

As an example, consider the Edgeworth Box of Figure 13. With its indifference curves $U_{L 3}$ and " $U_{W 3}$ through $c$," Policy 3 passes the Hicks Test because $c o=W T A_{W 3}$ of the Winner (Jones) is greater than $W A T P_{L 3}$ of the Loser (Smith). This is what the figure's " $c$ : Hicks $\mathrm{P}_{3}$ " signifies. Similarly, Policy 1, with its indifference curves $U_{L 1}$ and " $U_{W 1}$ through $b$," fails the Hicks Test because $b o=W T A_{W 1}$ of the Winner (Jones) is less than $W A T P_{L 1}$ of the Loser (Smith). This is what the figure's " $b$ : Hicks $F_{1}$ ” signifies.

This concludes our explanation of the Kaldor and Hicks Tests in Setting Qq. Armed with this knowledge, we can now begin to explain what is wrong with them. Section IV.E deals with their positive shortcomings and the sections that follow deal with their normative shortcomings.

E. Positive Problems with CV \& EV Measured as Quantities

\section{Potential Pareto Moves that Are Not, In Fact, Potentially Pareto Efficient}

One deeply troubling feature of the Hicks Test can be demonstrated even at this early stage of our critique. However, because it concerns confusing language, this feature is literally difficult to talk about; great precision in defining terms is required.

As is conventional, we have and will continue to define "potential Pareto" moves as "those which pass either the Kaldor Test or the Hicks Test." Set aside any other meaning of "potential Pareto" for now.

Next, define a new term, "potentially Pareto," as moves "for which it must be possible for the winners to be better off even after fully compensating the losers." Even though the definitions of the Kaldor and Hicks Tests seem to imply that there is no difference between "potential Pareto" moves and "potentially Pareto" moves, this section and Section IV.E.3 will show that this is not in fact the case.

The Hicks Test is applied without regard to the characteristics of the original indifference curves. This can be seen in Figure 16, which shows a policy moving from original point $o$ to new point $n$. Ignore the dotted lines for the moment. The policy passes the Hicks Test because Loser Smith's WATP, op, is less than Winner Jones's WTA, oc. Accordingly, the policy of moving from $o$ to $n$ is, by definition, a "potential Pareto" move. But is it necessarily a "potentially Pareto" move? 


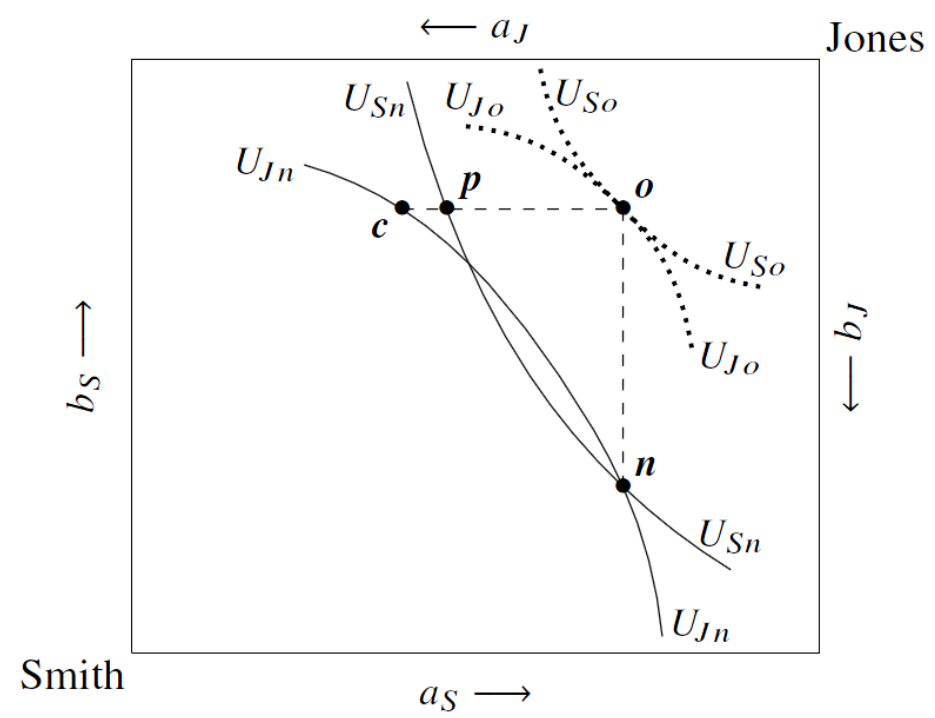

Figure 16: A move which passes the Hicks Test, and so is a Potential Pareto improvement, but is not potentially Pareto improving.

We have concluded that the policy passes the Hicks Test without regard to the shape of any indifference curves passing through the original point $o$. Because the shapes of those original indifference curves do not matter for the Hicks Test, we could draw them with any shape, and, in particular, we could draw them as shown by the dotted lines in Figure 16, namely as original indifference curves $U_{S o}$ and $U_{J o}$ that are tangent to each other at $o$. However, drawing them in this way means that the original point $o$ is already a Pareto Optimal point. By definition, for a point to be Pareto Optimal, there can exist no Pareto-improving moves away from that point. (If there were Pareto-improving moves away from $o$, then $o$ would not be Pareto Optimal.) Therefore, the move from $o$ to $n$ cannot be a "potentially Pareto" move.

We conclude that the move from $o$ to $n$ in Figure 16 is a "potential Pareto" move (because it passes the Hicks Test) but it is not a "potentially Pareto Efficient" move (because it is not possible to make both persons better off by moving away from $o$ ).

This in turn undercuts the entire "Potential Pareto Improvement" basis for thinking that passing the Hicks Test is socially desirable in the first place. The Hicks Test is thereby undermined, at least as a general indicator of socially-desirable changes.

Although this shows that the Hicks Test can lead to fallacious conclusions, in the following sections we will proceed as if we had not already proven this.

\section{Incompleteness Due to Inconsistencies and Reversals}

In Setting Pi, the possibility of inconsistencies between the Kaldor and Hicks Tests has been one of the most important criticisms of the Potential Pareto approach since Scitovsky pointed out in 1941 that such inconsistencies can occur. ${ }^{103}$ In this Section we demonstrate that similar criticisms apply to Setting Qq,

\footnotetext{
${ }^{103}$ See Tibor Scitovsky, A Note on Welfare Propositions in Economics, 9 The Review of Economic Studies 77-88
} (1941). The author's last name is also spelled "de Scitovszky." 
When judging Policies 1 and 3, application of the Kaldor Test turns on the shapes of the original indifference curves to the right of the original point $o$ whereas application of the Hicks Test turns on the shapes of the new indifference curves to the left of $o$. But these geometries are largely independent of each other. Therefore, it makes sense that there can be cases in which the two tests give conflicting policy advice, thereby undermining the usefulness of both. In those cases, the Kaldor-Hicks Criteria, if taken together, cannot rank the social states. The combined Kaldor-Hicks Criteria's lack of ability to rank some social states is ironic because the reason L\&E abandoned Pareto Efficiency and adopted the Kaldor-Hicks Criteria was that Pareto Efficiency cannot rank all social states. However, the irony is lessened because KaldorHicks can rank more states than Pareto can, and may be able to rank all of them, depending on the particular consumer preferences involved.

We will study inconsistencies by filling out Table 1, which is based on Figure 13. To begin, ignore the rows labeled "Reverse of Policy 3" and "Reverse of Policy 1." We fill out the "All alternatives" column, "Policy 3" and "Policy 1" rows, using the results of Section IV.C: Policy 3 has a "Kaldor pass" and Policy 1 has a "Kaldor fail." Next, Section IV.D explained Figure 13's " $c$ : Hicks $\mathrm{P}_{3}$ " label, which lets us fill out the Table's " $c$ " column, "Policy 3" row; and Section IV.D explained Figure 13's " $b$ : Hicks $F_{1}$ " label, which lets us fill out the Table's " $b$ " column, "Policy 1" row. To fill out the " $a$ " column, suppose $U_{W 1}$ switches from being the dotted curve through $b$ to being the dotted curve through $a$. In that case, Jones's $W T A_{W 1}$ is $a o$, which is greater than Smith's WATP $P_{L 1}$, and Policy 1 passes the Hicks Test. This explains the graph's label "a: Hicks $P_{1}$ " and the Table's column " $a$," "Policy 1 " row (ignore the "double" references here and elsewhere in the Table for now). Finally, we can fill out the " $d$ " column of the Table by looking at the case in which $U_{W 3}$ switches from the dash-dotted curve through $c$ to the dash-dotted curve through $d$. In that case, Jones's $W T A_{W 3}$ is $d o$, which is less than Smith's WATP $_{L 3}$, and Policy 3 fails the Hicks Test. That explains the graph's label " $d$ : Hicks $F_{3}$ " and the Table's column " $d$," "Policy 3 " row.

\begin{tabular}{|c|c|c|c|c|c|}
\hline & $\begin{array}{c}\text { All } \\
\text { alternatives }\end{array}$ & $c$ & $d$ & $a$ & $b$ \\
\hline Policy 3 & Kaldor $\mathrm{P}_{3}$ & Hicks $\mathrm{P}_{3}$ & $\begin{array}{c}\text { Hicks } F_{3} \\
(\mathrm{H} \text { double } \mathrm{F})\end{array}$ & & \\
\hline $\begin{array}{c}\text { Reverse of } \\
\text { Policy } 3 \\
\end{array}$ & Hicks $F_{r 3}$ & Kaldor $F_{r 3}$ & $\begin{array}{c}\text { Kaldor } \mathrm{P}_{\mathrm{r} 3} \\
(\mathrm{~K} \text { double } \mathrm{P})\end{array}$ & & \\
\hline Policy 1 & Kaldor $\mathrm{F}_{1}$ & & & $\begin{array}{c}\text { Hicks } \mathrm{P}_{1} \\
(\mathrm{H} \text { double } \mathrm{P})\end{array}$ & Hicks $F_{1}$ \\
\hline $\begin{array}{r}\text { Reverse of } \\
\text { Policy } 1\end{array}$ & Hicks $P_{r 1}$ & & & $\begin{array}{c}\text { Kaldor } \mathrm{F}_{\mathrm{r} 1} \\
(\mathrm{~K} \text { double } \mathrm{F})\end{array}$ & Kaldor $\mathrm{P}_{\mathrm{r} 1}$ \\
\hline
\end{tabular}

Table 1: Contradictions between the Kaldor and Hicks Tests occur in columns $\mathrm{d}$ and a but not in columns a or b. ("P" denotes "pass" and " $F$ " denotes "fail.") 
Table 1's "Policy 3" row has a Kaldor pass; in column $c$, a Hicks pass, so no inconsistency; but in column $d$, a Hicks fail, and so an inconsistency between the Kaldor and Hicks Tests in that situation. Table 1's "Policy 1" row has a Kaldor fail; in column $a$, a Hicks pass, and so an inconsistency between the Kaldor and Hicks Tests; but in column $b$, a Hicks fail, and so no inconsistency.

To obtain more insight into the nature of the contradictions shown in Table 1 we need to explain the Table's "Reverse of Policy 3" and "Reverse of Policy 1" rows. To do so, we must show that, as a general principle, the Hicks Test for a policy passes if and only if the Kaldor Test for the reverse of that policy fails; or, equivalently, a person's EV for a policy is negative one times that person's CV for the reverse of that policy. (The reader uninterested in the proof is invited to skip to the paragraph after next.) To prove this result, first consider that in Figure 17, the policy " $o$ to $n$ " passes the Kaldor Test because, with Smith the Loser and Jones the Winner,

Kaldor Pass: Jones's CV $=n d=$ Jones's WATP $>$ Smith's WTA $=n c=(-1) *$ Smith's CV.

(This is equivalent to the sum of the CV's being positive.) The reverse of policy " $o$ to $n$ " is the policy of " $n$ to $o$." That reverse policy " $n$ to $o$ " fails the Hicks Test because, with Smith the Winner and Jones the Loser,

Hicks Fail: Smith's EV $=n c=$ Smith's WTA $<$ Jones's WATP $=n d=(-1) *$ Jones's EV.

(This is equivalent to the sum of the EV's being negative.) In other words, the Kaldor Test for " $o$ to $n$ " passes, and the Hicks Test for " $n$ to $o$ " fails, if and only if $n d$ is larger than $n c$. Also, $n d$ is both Jones's CV for " $o$ to $n$ " and is negative one times Jones's EV for " $n$ to $o$," and $n c$ is both negative one times Smith's CV for " $o$ to $n$ " and is Smith's EV for " $n$ to $o$."

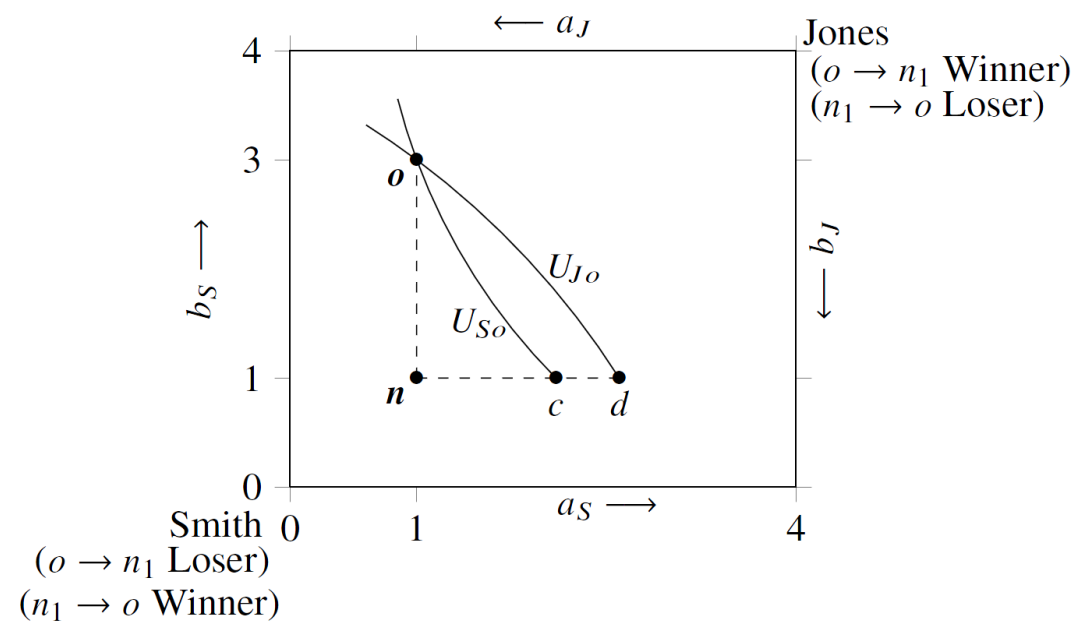

Figure 17. Kaldor Tests of a policy yield the opposite judgments of Hicks Tests of the reverse policy.

Similarly, if the indifference curves in Figure 17 changed so that they intersected again below point $o$ and above point $n$, so that $c$ lay to the right of $d$, then " $o$ to $n$ " would fail the Kaldor Test and " $n$ to $o$ " would pass the Hicks Test. The general principle is that a policy passing or failing one Test (either Kaldor or Hicks) implies that the reverse of that policy fails or passes the other Test (either Hicks or Kaldor, respectively). This enables us to fill in the "Reverse of Policy 3" and "Reverse of Policy 1" rows of Table 1: if a policy gets a "Hicks Pass," then its 
reverse gets a "Kaldor Fail;" if a policy gets a "Kaldor Pass," then its reverse gets a "Hicks Fail;", and so forth.

Thus extended, we can obtain additional insight into Table 1's "Policy 1"/“column $a$ " inconsistency between "Kaldor $\mathrm{F}_{1}$ " and "Hicks $\mathrm{P}_{1}$." In Table 1's "all alternatives" column we see that "Reverse of Policy 1" has "Hicks P P" (the "r1" subscript means "reverse of Policy 1"). With column $a$, then, we have both "Hicks $\mathrm{P}_{1}$ " and "Hicks $\mathrm{P}_{\mathrm{r} 1}$ ": both Policy 1 and the Reverse of Policy 1 pass the Hicks Test. That is the meaning of "H double $\mathrm{P}$ " for the "Policy 1 " row, " $a$ " column. In other words, application of the Hicks Test recommends that Policy 1 be adopted, but if it is adopted, the Hicks Test then recommends that the reverse of Policy 1 be adopted. This is like saying "the grass is always greener on the other side of the fence" regardless of which side of the fence one is on. Following this pair of recommendations would clearly be an absurd way to conduct public policy, forever cycling between adopting Policy 1 and reversing that adoption. ${ }^{104}$

Table 1 also shows, in its "All alternatives" and " $a$ " columns, that both Policy 1 and the Reverse of Policy 1 fail the Kaldor Test (Kaldor $F_{1}$ and Kaldor $F_{r 1}$ ) - i.e., precisely the opposite result of the Hicks test. That is the meaning of "K double F" for the "Reverse of Policy 1" row, " $a$ " column. In other words, application of the Kaldor Test recommends that Policy 1 not be adopted, but if it is adopted, the Kaldor Test then recommends that Policy 1 not be reversed. This is like saying "the grass is always greener on this side of the fence" regardless of which side of the fence one is on. While not as bad as the "column $a$ " Hicks Test "the grass is always greener on the other side of the fence" conclusion, which gave rise to constant cycling, this Kaldor Test result is nevertheless a self-contradictory way of making social decisions.

This demonstrates the futility of responding to "the Kaldor Test contradicts the Hicks Test" conundrum by simply ignoring the Hicks Tests in favor of the Kaldor Test, or vice versa. In "column $a$," if one only applies Kaldor Tests and no Hicks Tests, both Policy 1 and its reverse fail the Kaldor Test (a Kaldor double fail), so it is still not clear which social decision to make. Similarly, if in that column one only applies Hicks Tests and no Kaldor Tests, both Policy 1 and its reverse pass the Hicks Test (a Hicks double pass), rendering it equally unclear which social decision to make.

As column $d$ of Table 1 shows, its "Policy 3" contradiction between the Kaldor and Hicks Tests is in some sense a mirror image of column $a$ 's "Policy 1" contradiction between the Kaldor and Hicks Tests. In column $d$, both Policy 3 and the Reverse of Policy 3 pass the Kaldor Test (we have Kaldor $\mathrm{P}_{3}$ and Kaldor $\mathrm{P}_{\mathrm{r} 3}$ ). This is the meaning of " $\mathrm{K}$ double P" for column $d$. In other words, application of the Kaldor Test recommends that Policy 3 be adopted, but if it is adopted, the Kaldor Test then recommends that the reverse of Policy 3 be adopted. That is, again, like saying "the grass is always greener on the other side of the fence" regardless

\footnotetext{
104 This situation resembles what in Setting Pi is called a "Scitovsky Reversal." See Tibor Scitovsky, supra note 103. Scitovsky proposed a solution to these technical problems with the Kaldor Test and the Hicks Test: adopt a policy if and only if it passes both Tests. This "Scitvosky Double Criterion" eliminates some difficulties but there are situations (not necessarily in Frames Qq or *i) in which it does not eliminate contradictions between more than two policies because it could rank $x$ below $y, y$ below $z, z$ below $w$, but $w$ below $x$. See Hayashi, supra note 140 at 24; also see Figure 3 of Kotaro Suzumura, Paretian Welfare Judgements and Bergsonian Social Choice," 109 The Economic J. 204-220 (1999), and W. M. Gorman, The Intransitivity of Certain Criteria used in Welfare Economics, 7 Oxford Economic Papers (new series) 25-35 (1955).
} 
of which side of the fence one is on. Following this pair of recommendations would lead to forever cycling between adopting Policy 3 and reversing that adoption. Column $d$ of Table 1 also shows that both Policy 3 and the Reverse of Policy 3 fail the Hicks Test (we have Hicks $\mathrm{F}_{3}$ and Hicks $\mathrm{F}_{\mathrm{r} 3}$ ). That is the meaning of "H double F" for column $d$. Accordingly, application of the Hicks Test recommends that Policy 3 not be adopted, but if it is adopted, the Hicks Test then recommends that Policy 3 not be reversed. This is again like saying "the grass is always greener on this side of the fence" regardless of which side of the fence one is on.

Neither the "forever cycling" recommendation ("double pass") nor the "do not change, but if you do change, do not reverse the change" recommendation ("double fail") can be avoided by choosing to ignore the Hicks Tests in favor of the Kaldor Test, or vice versa. This is because the "double pass" resulted from the Hicks Test in column $a$ and from the Kaldor Test in column $d$, while the "double fail" resulted from the Kaldor Test in column $a$ and from the Hicks Test in column $d$. To summarize: whenever there is a conflict between the Hicks Test and the Kaldor Test, one of them - which one will vary depending on the situation - is going to make a "forever cycle" recommendation, and the other one is going to make a "do not change, but if you do change, do not reverse the change" recommendation.

If one took column $d$ for Policy 3 with column $a$ for Policy 1 one would have the worst of both worlds, with Kaldor-vs.-Hicks contradictions both for Policy 3 and for Policy 1. If one took column $c$ for Policy 3 with column $b$ for Policy 1 one would have the best of both worlds, with Kaldor-vs.-Hicks contradictions neither for Policy 3 nor for Policy 1. Taking column $c$ for Policy 3 with column $a$ for Policy 1 generates a contradiction for Policy 1 and no contradiction for Policy 3, while taking column $d$ for Policy 3 with column $b$ for Policy 1 generates a contradiction for Policy 3 and no contradiction for Policy 1. There is no apparent reason why the unproblematic case, columns $c$ with $b$, should be any more or less likely to occur than the three problematic cases $c$ with $a, d$ with $a$, and $d$ with $b$. After all, the cases are quite similar to each other, only differing in slight repositionings of $U_{W 1}$ and $U_{W 3} \cdot{ }^{105}$

The upshot of all of this is quite simple: application of the Kaldor-Hicks criteria can lead to contradictory results and therefore, like the Pareto Approach it is designed to replace, it can fail to provide a ranking some social states.

\section{Incompleteness Due to Nonexistence of WATP or Infeasibility of WTA}

In Section IV.E.2 the Potential Pareto approach was often incomplete because the Kaldor Test and Hicks Test contradicted each other for half of the situations depicted in Table 1, but at least the Kaldor Test and the Hicks Test considered individually, rather than together, were capable of ranking policies. We show in this section that that is not always true, thereby further undermining the usefulness of the Potential Pareto approach.

\footnotetext{
${ }^{105}$ The Kaldor Test presumes the policy is adopted, so we may not want to apply it when the prospective policy fails the Kaldor Test. The Hicks Test presumes the policy is not adopted, so we may not want to apply it when the prospective policy passes the Hicks Test. However, deleting the "Kaldor F" and "Hicks P" entries in Table 1 would mean that in column $a$, Policy 1 would be subject to neither the Hicks Test nor the Kaldor Test, and in column $a$, the Reverse of Policy 1 would also be subject to neither the Hicks Test nor the Kaldor Test. That would make the Potential Pareto approach completely unable to say anything about column $a$. The social decisions for the other three columns $c, d$, and $b$ would be unaffected. So this attempt to lessen contradictions by selectively dropping one or the other of the Tests does not appear to be helpful.
} 
One of the two problems discussed in Section IV.A.6 was nonexistent WATPs. If WATP does not exist, as in Figure 15, it is obvious that the corresponding Kaldor or Hicks Test cannot be carried out.

The other problem discussed in Section IV.A.6 was infeasible WTAs (again, see Figure 15 for examples). Infeasible WTAs pose no problem for the Potential Pareto approach of the Kaldor and Hicks Tests because those tests only concern hypothetical, not actual, compensation: hypothetical compensation with infeasible apples or bananas seems unproblematic because, for example, if a Kaldor Test loser's WTA were 10 apples and the economy only has 6 apples, the infeasibility of paying the loser 10 apples in compensation is irrelevant because in the Potential Pareto approach the loser is actually not going to be getting any compensation at all. The Potential Pareto's unwillingness to pay the loser any apples makes its inability to pay the loser 10 apples irrelevant. ${ }^{106}$

This completes our discussion of the positive problems of the Potential Pareto approach. While L\&E advocates resort to the Kaldor and Hicks Tests to overcome the incompleteness of the Pareto criterion, Sections IV.E.1, IV.E.2, and IV.E.3 have shown that those Tests have incompleteness problems of their own (albeit less pervasive). They therefore fail to provide a reliable theoretical foundation for L\&E. In the next section we will see that in return for the Potential Pareto's only modest improvement over the Pareto approach as far as its positive ability to rank policies, the Potential Pareto approach carries with it serious normative problems that the Pareto approach does not have.

F. Normative Problems with CV \& EV Measured as Quantities

\section{Potential Pareto Moves that Are not Potentially Pareto Efficient Moves}

The Hicks and Kaldor tests suffer not only from positive problems but also from normative ones. Our hypothetical Policies 1 and 3 both involve State confiscation of bananas from Smith and the transfer of the confiscated bananas to Jones. The main moral ground justifying using the Kaldor or Hicks Tests to decide whether to carry out such confiscation is that they identify "potentially Pareto" moves - that is, moves that make some better off without harming others. However, as we demonstrated in Section IV.E.1, that a prospective policy move satisfies the Hicks Test is no guarantee that the move is, in fact, "potentially Pareto" (satisfying the Kaldor or Hicks Test merely means the move is "potential Pareto"). Moves that are not "potentially Pareto" have no normative justification, by which we mean not only that we cannot think of a normative justification for such moves, but also that we have not found any other authors who have attempted to give a normative justification for them. To be concrete, in Figure 16, the move from $o$ to $n$ passes the Hicks Test, but lacks normative justification of any kind.

\footnotetext{
${ }^{106}$ One might think that an infeasible WTA would mean that a policy passing the Potential Pareto Kaldor Test might fail to be "potentially Pareto" because it would not be feasible to provide the required compensation to the loser. However, infeasible WTAs are infeasibly large, and therefore larger than a WATP could be, making it impossible for the Kaldor Test to pass in the first place. Similarly, one might think that an infeasible WTA would mean that a policy failing a Hicks Test would not be compelling because it would not be feasible to provide the required compensation to the winner in return for foregoing the policy. However, since again infeasible WTAs are infeasibly large, in this situation it would be impossible for the Hicks Test to fail in the first place. Therefore, the phenomenon of infeasible WTAs does not supply additional examples of potential Pareto moves that are not potentially Pareto; the only such example remains the one illustrated in Section IV.E.1.
} 
Having dispensed with that case, the remaining subsections of this Section IV.F address only potential Pareto moves that are, in addition, potentially Pareto Efficient. One way to frame these subsections is as a response to a defense against our argument in Section IV.B (before introducing the Kaldor and Hicks Tests) that the Potential Pareto Criterion was ethically indefensible. This defense is: despite the possibility of being on the losing side of a KaldorHicks-based decision, someone in a state of Rawlsian uncertainty ${ }^{107}$ might assent to society's use of Kaldor-Hicks anyway because using Kaldor-Hicks is better for society as a whole. But, as we demonstrate in the remaining subsections of Section IV.F, there is no basis for concluding that "using Kaldor-Hicks is better for society as a whole." Advocates for that position may not realize how devastating it could be to end up on the losing side of a KaldorHicks-based decision, and, correspondingly, how unequal societies using Kaldor-Hicks could be. They also may not realize that who wins and who loses in a world using Kaldor-Hicks criteria can depend merely on who is able to propose policies first. Our task is to illustrate these points.

\section{Complete Inequality Can Be an Efficient Outcome Under the Kaldor Test}

Consider the set of indifference curves in the bottom part of Figure 18, namely $S_{1}, J_{1}, S_{0}$, and $J_{0}$. The move from $o$ to $n_{1}$, which reduces Smith's bananas to zero, passes the Kaldor Test because Jones's WATP for that move is larger than Smith's WTA for that move. (The geometry to the right of $n_{1}$ is the same as the geometry to the right of the " $n_{3}$ " of Figure 13 , where the associated Policy 3 passed the Kaldor Test.)

\footnotetext{
107 This refers to operating under the "veil of ignorance," also called the "original position," in John Rawls' 1971 book $A$ Theory of Justice. See https://en.wikipedia.org/wiki/Original position.
} 


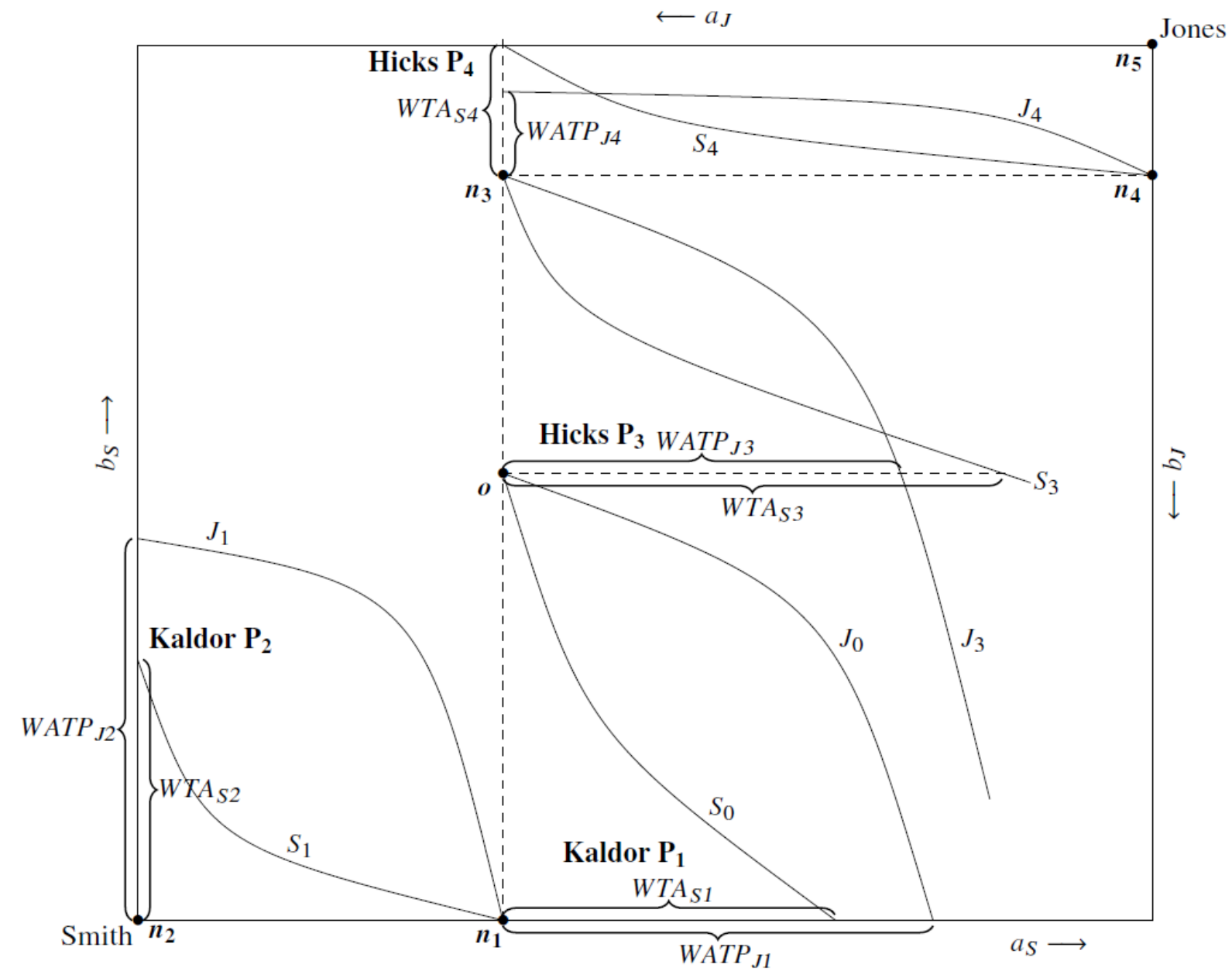

Figure 18. The Kaldor Test or Hicks Test sometimes can lead to very great inequality, in either direction.

Now consider the further move from $n_{1}$ to $n_{2}$. Such a move further reduces Smith's welfare, by also reducing her number of apples to zero. Smith's WTA compensation, in the form of bananas, for the move from $n_{1}$ to $n_{2}$ is shown by $W T A_{S 2}$. Jones's WATP, in the form of bananas, for the move from $n_{1}$ to $n_{2}$ is shown by $W T P_{J 2}$. Since $W A T P_{J 2}>W T A_{S 2}$, the move from $n_{1}$ to $n_{2}$ passes the Kaldor Test and leaves Smith with neither apples nor bananas, the position of maximum unfairness to Smith. In conclusion, Jones can use two applications of the Kaldor Test to justify moving from $o$ to $n_{1}$ to $n_{2}$, resulting in complete inequality.

3. Almost-Complete Inequality Can Be an Efficient Outcome Under the Hicks Test

Next, consider the set of indifference curves in the upper part of Figure 18's Edgeworth Box, namely $S_{3}, J_{3}, S_{4}$, and $J_{4}$. The move from $o$ to $n_{3}$ passes the Hicks Test because Loser Jones's $W A T P_{J 3}$ to avoid that move is less than the $W T A_{S 3}$ that Winner Smith would require to forego that move. The move from $n_{3}$ to $n_{4}$ passes the Hicks Test because Loser Jones's WAT $P_{J 4}$ to avoid that move is less than the $W T A_{S 4}$ that Winner Smith would require to forego that move. So, Smith can use two applications of the Hicks Test to justify moving from $o$ to $n_{3}$ to $n_{4}$, resulting in very great, but not complete, inequality vis-à-vis Jones. 
It is not possible to use the Hicks Test on a movement from $n_{4}$ to $n_{5}$ because the WTA and WATP would both be beyond the right-hand edge of the Edgeworth Box.

One could argue that the situation will likely not remain quite as bad for Jones as point $n_{4}$ would suggest. After arriving at $n_{4}$, Smith and Jones might begin to bargain again, and end up making a Pareto-improving move from $n_{4}$ to some point on the contract curve. This would make Jones somewhat better off, but not much better off (in the sense of not giving him very many more apples, while he loses bananas). Alternatively, after arriving at $n_{4}$, Smith and Jones could be presented with market equilibrium prices that would induce them to buy and sell apples and bananas, also moving them to a point on the contract curve, and thereby also making Jones a bit better off than he is at $n_{4}$ but still not much. ${ }^{108}$

\section{Application of the Kaldor and Hicks Criteria Can Result in Arbitrary Outcomes}

While Sections IV.F.2 and IV.F.3 show how Kaldor-Hicks decision-making can result in confiscations that neutral observers would almost certainly deem unjust, it is also the case that Kaldor-Hicks decisions can be arbitrary. In Figure 18, moves from $o$ to $n_{1}$ and then to $n_{2}$ can be justified by Jones using the Kaldor Test, as we saw in Section IV.F.2. However, moves from $o$ to $n_{3}$ and then to $n_{4}$ can be justified by Smith using the Hicks Test, as we saw in Section IV.F.3. If Jones can set the State's agenda, Jones can convince the Kaldor/Hicks/CostBenefit-using State to confiscate all of Smith's goods and give them to Jones (ending up at $n_{2}$ ), but if Smith can set the agenda, then Smith can convince the State to confiscate many goods from Jones and give them to Smith (ending up at $n_{4}$ ). The actions of this hypothetical State clearly do not reflect any genuine concern for social welfare; instead, the State is merely a tool of whichever social faction can set the State's agenda. ${ }^{109}$

If moves from $o$ to points as divergent as $n_{2}$ and $n_{4}$ can both be justified by applications of the Kaldor-Hicks Tests, one wonders just how broad the set of "potential Pareto Improvements" from $o$ is. This set at least includes all the points between $o$ and $n_{1}$, between $n_{1}$ and $n_{2}$, and between $o$ and $n_{3}$, and between $n_{3}$ and $n_{4}$; but depending on the shape of other indifference curves, it could contain many other points as well. As a practical issue it seems as if almost any transfer, in any direction, could be justified when applied to some not-outlandish hypothetical indifference curve map. As a theoretical issue, while it is easy to describe the set of all Pareto Efficient points in an Edgeworth Box (i.e., the contract curve), and the set of all Pareto improvements from a particular endowment point (e.g., in Figure 1, if the initial endowment is at Point F, the points that lie neither in the "Smith Veto" hatched area nor in the "Jones Veto" hatched area), it is unclear how to come up with a list of all Potential Pareto points, nor a list of all points that, given a particular endowment point, would pass either the Kaldor Test or the Hicks Test.

\footnotetext{
${ }^{108}$ In this latter situation, even though the framework we are using is Setting Qq, a price system would exist; it however only comes into play after the quantity changes to the endowments (which set all the changes into motion) have been made.

${ }^{109}$ A party disadvantaged by the Kaldor Test might be able to appeal to the Hicks Test for protection, and a party disadvantaged by the Hicks Test might be able to appeal to the Kaldor Test for protection, but those appeals might fail, depending on the position of the indifference curves.
} 
The normative concern of all this is that, if social decision-makers use the Kaldor or Hicks Tests to make decisions, the agent with the political power to propose policies to those decision-makers and the economic power to commission cost-benefit analyses supporting their position could, through this process (assuming the indifference curve map has, or could be argued to have, the right geometry), justify the confiscation of much or all of every other agents' wealth. But what if the indifference curve map has the wrong geometry? More fundamentally, how does one even determine what the indifference curve map looks like? That is a question of econometrics, to which we now turn.

\section{G. Econometrics and Political Power}

We have seen in the graphs of the last few sections that whether one can use a Kaldor or Hicks Test to justify having the State confiscate goods from other people and give those goods to oneself depends on the shapes of the indifference curves. Up until now we have assumed those shapes are known, but in the real world those shapes are not known. Instead, those shapes, and the resulting sizes of WATP and WTA that drive all social decisions made under the KaldorHicks Criteria, must be indirectly inferred, using statistical techniques (and sometime survey techniques) that are themselves imperfect and potentially subject to manipulation.

Fears that statistical methods give misleading answers are always greater when the statistician or econometrician is forced to extrapolate rather than being able to interpolate, because under extrapolation one is attempting to infer consumer or firm behavior under circumstances that the consumers or firms have never experienced. As is shown in Figure 12 and Figure 14, the size of WATP and WTA sometimes depends on indifference curve shapes in regions of the Edgeworth box located away, and sometimes far away, from the initial point $o$. Since economists will typically have data only for points near $o$, far-away parts of the Box are a terra incognita (unless by coincidence those parts have been visited in the past and therefore are part of the historical record). As a result, econometric estimates of WATP and WTA will often be extrapolations, inheriting the fundamental uncertainties and inaccuracies of all extrapolations.

In addition to being imperfect, statistical estimates of WATP and WTA are potentially subject to manipulation because, unlike professions such as medicine and law, the economics profession has no universal code of ethics, let alone a licensing board tasked with enforcing ethical conduct. Already some decades ago mathematical economist and polymath Nicholas Georgescu-Roegen observed, "in many an econometrician's shop...we see him selecting his tools with a single purpose in mind: to cut the log on his workbench in such a way that he may be able at the end to exclaim triumphantly, 'I told you that inside that log there was a beautifully carved Madonna!""110 In other words, we cannot actually know for sure what anyone's indifference curve map looks like, and the fear is that our econometric efforts to estimate how it looks might be subject to prejudiced manipulation that could only be detected by conversely-motivated but similarly-compensated consultants, necessitating a comparably well-heeled opponent. In a nutshell, the concern is that the Kaldor/Hicks/Cost-Benefit approach can readily be manipulated by the powerful to convince the State to confiscate goods from the powerless and transfer them to the powerful.

\footnotetext{
${ }^{110}$ Nicholas Georgescu-Roegen, Further Thoughts on Corrado Gini's "Delusioni dell'Econometrica," in Nicholas Georgescu-Roegen, ed, Energy and Economic Myths: Institutional and Analytical Economic Essays 266-7 (Pergamon 1976).
} 
Our discussion so far has largely relied on Section IV.A.2's Setting Qq, as suggested by the mention of "quantity" rather than price in the titles of Sections IV.C, IV.D, IV.E, and IV.F. While this has allowed us to identify several ethical problems with the Potential-Pareto/KaldorHicks/Cost-Benefit-Analysis Criterion without using much mathematics, beyond our brief comments in this section, working in Setting Qq has not allowed us to say much about the advantages that Kaldor-Hicks decision-making gives to wealthy people (because it is not easy to explicitly study wealth in Edgeworth Boxes). We change settings in the next two sections to better investigate the effect of wealth on WATP and WTA.

\section{H. Positive Economic and Normative Problems with CV \& EV Measured in Dollars}

Setting Pi (a Setting much more familiar to economists than Setting Qq) allows us to better study the power that use of the Kaldor-Hicks Criteria bestows on people of wealth. This is important because it will allow us to answer the conundrum of why L\&E advocates, who are most often associated with conservative political philosophies, would embrace such an active governmental tool as the Kaldor-Hicks Criteria. After all, Kaldor-Hicks is applied to determine when to give permission for the State to use its coercive power to confiscate property and rights from individual citizens, so an observer who naïvely believed the rhetoric of conservatives would predict that L\&E proponents of "small government" and the tiny "night watchman" State would roundly reject Kaldor-Hicks. Describing and investigating Setting Pi will equip us with the tools to make the following argument: To understand why conservatives do not reject Kaldor-Hicks requires seeing through conservatives' "small government" rhetoric. L\&E does not actually advocate small government at all. Modern neoliberals advocate a very powerful State able to wield Kaldor-Hicks to confiscate property and rights from one group (usually the poor, or at least the poorer of the conflicting groups) and transfer that property and rights to another group (usually wealthy individuals or firms). ${ }^{111}$

In Setting Pi, compensating variation $(\mathrm{CV})^{112}$ is defined as the amount of money that could be taken away from the consumer in the new situation to make the consumer as well off as he/she was in the old situation. If the policy change makes the consumer worse off, then CV is equal to negative one times WTA; and if the policy change makes the consumer better off, then CV is equal to the consumer's WATP. Hence the relationships between $\mathrm{CV}$, on the one hand, and WATP and WTA, on the other hand, are formally the same as in Setting Qq, even though in Setting Pi, CV, WATP, and WTA are all measured in monetary, rather than physical, quantities. Similarly, in this new setting, equivalent variation $(\mathrm{EV})^{113}$ is defined as the extra amount of money the consumer would have to be given in the old situation to make the consumer as well off as he would be in the new situation. If the policy change makes the consumer worse off, then EV is equal to negative one times WATP; and if the policy change makes the consumer better off, then EV is equal to the consumer's WTA.

A significant generalization of Setting Pi is what we will call "Setting *i," where the asterisk stands for a policy that could simultaneously change one or more prices, one or more quantities, or a consumer's income, or all of these. The " $i$ " signifies that we measure the value

\footnotetext{
${ }^{111}$ Neoliberals realized that a strong state was necessary to dismantle the New Deal consensus. See Philip Mirowski and Dieter Plehwe, supra note 10 at 161.

112 As note 93 points out, in the language of Hicks supra note 80, this is "price-compensating variation."

113 As note 93 points out, in the language of Hicks supra note 80, this is "price-equivalent variation."
} 
of such policies using income changes, so that CV and EV are defined in Setting $*_{i}$ the same as in the preceding paragraph.

The properties of EV and CV have been the subject of careful study for several decades in Setting Pi and generalizations of it, mostly using advanced mathematics not Edgeworth Boxes. A classic reference and survey paper of Setting *i is Blackorby and Donaldson's The Case against the Use of the Sum of Compensating Variations in Cost-Benefit Analysis. While their title only refers to compensating variations, they assert that "These criticisms apply with minor changes to the sum of equivalent variations." 114 Their title faithfully conveys their disapproval of the Kaldor-Hicks Criteria. Within the non-mathematical confines of this paper, we will focus on explaining the main conclusions of their work. We use the abbreviation "BD" for the authors' names.

In Section IV.E.1. we used Figure 16 to show that in Setting Qq, a policy can pass the Hicks (EV) test, and thus be a "potential Pareto" move by definition, but not be a "potentially" Pareto Improvement because the initial position was already Pareto Efficient. In Section IV.D, we noted that "a policy passes the Hicks Test if and only if the sum of the EVs is positive." Applying both of these statements, the lesson of Figure 16 can be reworded as being that "a positive sum of EVs is not sufficient for a "potentially' Pareto Improvement to occur." BD concluded that the same wedge between CV and "potentially" Pareto Improvements exists in Setting *i (where BD use the phrase "Potential Pareto Principle" to describe what we mean "potentially Pareto"):

A positive sum of compensating variations is not the same thing as an improvement according to the Potential Pareto Principle. [...] Although a positive sum of compensating variations is necessary for an improvement according to the Potential Pareto Principle (when lump-sum transfers are feasible), it is not sufficient. ${ }^{115}$

A second BD conclusion echoes our Setting Qq discussion in Section IV.E.2, on incompleteness and reversals. BD's conclusion is stronger than ours in at least one respect, however, because, in accordance with the preceding paragraph, they distinguish between "the sum of the CVs" ("potential Pareto") and "the Potential Pareto Principle" ("potentially Pareto"):

Neither the sum of compensating variations nor the potential Pareto Principle ranks social alternatives in a reasonable way. In order to eliminate intransitivities over consumption-efficient allocations, all households must be assumed to have quasi-homothetic preferences that are identical at the margin. ${ }^{116}$

Preferences are "quasi-homothetic and identical at the margin" when a one dollar increase in anyone's income is spent - for example, 5 cents on "apples," 8 cents on "bananas," etc.-in

\footnotetext{
${ }^{114}$ Charles Blackorby and David Donaldson, The Case against the Use of the Sum of Compensating Variations in Cost-Benefit Analysis, 23 The Canadian J. of Economics 471-494, 492, 493 (1990).

${ }^{115} I d$. at $472-3$.

${ }^{116} I d$. at 473 .
} 
exactly the same way by everyone in the economy. ${ }^{117}$ These are obviously very special preferences, much narrower than Arrow-Debreu preferences, ${ }^{118}$ and resemble in their implausibility the Setting Qq requirement that indifference curves be parallel lines. In the real world, preferences are not like this, so using the sum of CV or the Potential Pareto Principle can result in intransitivities (or, in other words, incompleteness and reversals).

A third BD conclusion is that "these criticisms apply with minor changes to the sum of equivalent variations;" "119 that is, to the Hicks Test as well as to the Kaldor Test.

Thus, many of the same positive problems we identified with the Kaldor-Hicks Criteria in Setting Qq (Section IV.E) also apply, with some mathematical refinements, to the KaldorHicks Criteria in Setting *i.

Finally, consider BD’s Setting *i normative conclusions:

1. "A notion of efficiency that is independent of the distribution of income - an idea that makes no sense in real-world economies," only in economies in which there is only one commodity. ${ }^{120}$

2. "The ethical judgments implied by the compensating-variation test are not defensible. It treats increases in income as equally socially valuable no matter who receives them. Social judgments — revealed by government policy — and the overwhelming majority of individual judgments are not consistent with this indifference toward inequality." 121

3. Disagreement over "the appropriate level of inequality-aversion" in no way logically justifies economists ignoring inequality, but rather suggests that they should use "criteria that exhibit various degrees of inequality aversion." 122

Not surprisingly, these conclusions conform well with ours above: Point (1) is coextensive with our discussion of the Separation Hypothesis (Section III.G.1(c)) and Point (2) echoes points we made in Setting Qq. Point (3) recommends that instead of using Kaldor-Hicks, other criteria that transparently incorporate inequality aversion should be used to make social decisions; BD go on to gives examples of such alternatives. ${ }^{123}$

\footnotetext{
117 See John S. Chipman and James C. Moore, supra note 98 at 551, and BD, supra note 114 at 473, 487. Quasihomothetic preferences are also called Gorman Form preferences. Also see Varian, supra note 53 at 153.

118 Preferences that are "quasi-homothetic and identical at the margin" are not, however, as special as the quasilinear, "demand curves do not depend on income" preferences needed to support the Coase Theorem in supra Section III.G.1(d), needed to make WATP equal to WTA in supra Section IV.A, and needed in infra Section V.C to make consumer surplus exact. On the other hand, for this result of BD to hold, besides having these preferences, all agents also have to face identical prices; and as BD point out (supra note 114 at 489), "In many standard cost-benefit exercises, however, the existence of public goods, semi-public goods, and different labour qualities rules out identical prices. The impossibility of consistent ordering of alternatives in such cases should count (we believe) very strongly against the compensating-variation (willingness-to-pay) test."

${ }^{119}$ Blackorby and Donaldson, supra note 114 at 473.

${ }^{120} I d$. at 490.

${ }^{121} I d$. at 472 .

122 Id. at 491.

${ }^{123} \mathrm{Id}$. at 492: "We have investigated other methods for performing distributionally sensitive cost-benefit analysis. One is the employment of welfare ratios (ratios of household incomes to the household's poverty lines) as indexes
} 
BD's position on the Kaldor-Hicks Criteria is shared by other social welfare theorists working in Setting *i. In Section IV.J we cite Hammond and Fleurbaey making an ethical argument agreeing with BD; and in Section IV.B we quoted the criticism of Kaldor by Chipman and Moore, who, we add here, flatly conclude that Kaldor and Hicks's "New Welfare Economics must be considered a failure." 124

Overall, then, analysis under both Settings Qq and *i send a similar message about the Potential-Pareto/Kaldor-Hicks/Cost-Benefit-Analysis approach: it has serious positive problems and disqualifying normative problems.

\section{WATP Justifies Results that Favor the Wealthy (Positive Theory)}

As to Setting Pi, Section IV.A.3. showed that WATP had to be less than wealth, so certainly WATP is related to wealth. In particular, WATP depends on wealth exactly like any other demand curve (like any other "willingness to pay"); moreover, in the typical case of normal goods, WATP is an increasing function of wealth. ${ }^{125}$ We alluded to this in connection with our example of Bill Gates's WATP to reduce air pollution near where he lives in contrast to a less wealthy individual; namely, that a simple sum of WATP's or WTA's weights people more the wealthier they are. This "preference for the wealthy"126 is an inherent, anti-egalitarian, antidemocratic feature of the Potential Pareto approach.

It has been argued that despite this preference for the wealthy, the Potential Pareto approach is still unproblematic because ${ }^{127}$ "If each policy had different winners and losers so that in the long run everyone were a winner as often as he or she were a loser, the unfairness of individual policies taken separately might wash out." Wonnell ${ }^{128}$ refers to this argument as "Package Paretianism": people, perhaps but not necessarily in a state of Rawlsian uncertainty, will support systematic application of the Potential Pareto criterion because, while they will "win" in some decisions and "lose" in others, on average - that is, seen as a "package" of many decisions - they will, overall, win. A more accurate name for this argument would be "Package Potential Paretianism." But our common experience tells us this is not true: the poor,

of well-being (Blackorby and Donaldson 1987). Another is the employment of household equivalence scales in estimated utility functions (Blackorby and Donaldson 1988c). The latter method has been used by Jorgenson and Slesnick (1984a, 1984b).”

${ }^{124}$ John S. Chipman and James C. Moore, supra note 98 at 548.

${ }^{125}$ C. Edwin Baker, supra note 69 at 17, points out that as income rises, the WATP for "inferior goods" such as "cat food bought for human consumption" would fall.

Flores and Carson (in N.E. Flores and R.T. Carson, (1997). The relationship between the income elasticities of demand and willingness to pay, 33 J. of Environmental Economics and Management 287-295) point out that, as Carson and Hanemann put it, "the income elasticity of WTP" is actually not the same as "the income elasticity of demand” (Richard T. Carson and W. Michael Hanemann, “Contingent Valuation,” in Karl-Göran Mäler and Jeffrey R. Vincent, eds, Handbook of Environmental Economics, Vol. 2 "Valuing Environmental Changes" 909 (North-Holland Elsevier 2005). A certain amount of caution in these matters is therefore prudent.

Another caveat is that it is not particularly clear how to illustrate a bias toward the wealthy in FrameQq.

${ }^{126} \mathrm{Cf}$. "the preferential option for the poor" in the social teaching of the Roman Catholic church, as described in for example https://en.wikipedia.org/wiki/Option for the poor.

${ }^{127}$ Daniel M. Hausman and Michael S. McPherson, supra note 90 at 247.

${ }^{128}$ Christopher T. Wonnell, Efficiency and Conservatism, 80 Neb. L. Rev. 660 (2001). 
almost by definition, rarely come out on top. Hausman and McPherson explain why this argument is fallacious:

But the bias built into cost-benefit analysis against the preferences of the poor suggests that the unfairness will not wash out. Exactly those people whom policy makers should be most concerned to protect are those who are most likely to be harmed.

Similarly, "the consent argument ... for the assignment of common-law entitlements according to the wealth maximization criterion" is rejected by Bebchuk ${ }^{129}$ because of "the bias of the WMC [wealth maximization criterion] against the poor." 130 Moreover, the Potential Pareto approach exacerbates this bias over time because a rich person, having benefitted from one public policy decision decided by the Potential Pareto approach, has become even richer, and thus 131 "is progressively more likely to be favored in the next case." Whether this bias is bad or not depends on one's point of view, which is the topic of the next section.

\section{J. WATP Justifies Results that Favor the Wealthy (Normative Theory)}

One may ask, is WATP's bias in favor of the wealthy ethically a bad thing? As with all normative questions, the answer depends on whom one asks. Clearly it is in the eyes of, for example, the authors of some Bible passages. ${ }^{132}$ And special concern for the poor is indicated by Islam's practice of almsgiving ("Zakat"), one of that religion's "pillars."

There certainly are economists critical of Cost-Benefit Analysis's bias in favor of the wealthy. Posner was not among them; he wrote ${ }^{133}$ that objections to assigning a "quantity of pituitary extract" not to the low bidder, "a poor family whose child will be a dwarf unless he gets the extract," but rather to the high bidder, "a wealthy dilettante who wants to use the extract to grow a giant gerbil," "may be superficial" objections - because such objections ignore the existence of private charity, and because "in the long run, there may be more and cheaper pituitary extract, and fewer dwarves, if the society does not try to allocate the product to those who will derive the greatest happiness from it." However, Posner immediately undermined the "charity" argument, admitting that charity usually generates positive externalities and thus is under-supplied under laissez faire. What remains of Posner's argument is extremely speculative, involving three hypotheticals: critics' arguments may be superficial because there

\footnotetext{
${ }^{129}$ Lucian A. Bebchuk, The Pursuit of a Bigger Pie: Can Everyone Expect a Bigger Slice? 8 Hofstra Law Review 671-709, 671-2 (1980).

${ }^{130}$ A more recent article discussing the bias of Cost-Benefit Analysis in favor of the wealthy is Zachary Liscow, supra note 86.

${ }^{131}$ C. Edwin Baker, supra note 69 at 9.

${ }^{132}$ See 1 Timothy 6 ("But those who want to get rich fall into temptation and a snare and many foolish and harmful desires which plunge men into ruin and destruction. For the love of money is a root of the evils"); Ecclesiastes 5 ("Whoever loves money never has enough;/ whoever loves wealth is never satisfied with their income./ This too is meaningless./ As goods increase, so do those who consume them./ And what benefit are they to the owners except to feast their eyes on them?/ [...] I have seen a grievous evil under the sun: wealth hoarded to the harm of its owners..."). The pithy admonition "you cannot serve both God and Mammon" actually appears twice, in Matthew 6:24 and in Luke 16:13. "It is easier for a camel to go through the eye of a needle than for a rich man to enter the kingdom of God" says Mark 10:25.

${ }^{133}$ Richard A. Posner, Wealth Maximization Revisited, 2 Notre Dame J.L. Ethics \& Pub. Pol'y 85-105, 96 (1985).
} 
may be more pituitary extract in the long run under Cost-Benefit Analysis, and that increased supply of pituitary extract may result in fewer people with dwarfism (rather than merely resulting in more wealthy dilettantes growing more giant gerbils). Contrast the weakness of Posner's argument on this fundamental point with the straightforward, non-speculative argument by critics of Cost-Benefit Analysis, represented here by welfare economics theorists Hammond and Fleurbaey ${ }^{134}$ :

At this stage, many economists of the so-called "Chicago school", following Harberger (1971) in particular, succumb to the temptation of just adding different individuals' monetary measures. "A dollar is a dollar", they might say, regardless of how deserving is the recipient. Implicitly, they attach equal value to the extra dollar a rich man will spend on a slightly better bottle of wine and to the dollar a poor woman needs to spend on life-saving medicine for her child. Of course, any such judgement is a value judgement, even an interpersonal comparison, which lacks scientific foundation. [...] Thus, the "surplus economists" who just add monetary measures, often of consumer surplus ${ }^{135}$ rather than individual welfare, make their own value judgements and their own interpersonal comparisons. Moreover, their comparisons not only lack scientific content, but most people - especially non-economists - also find them totally unacceptable from an ethical point of view. Surely it is better to avoid interpersonal comparisons altogether rather than make them in such a biased way.

Blackorby and Donaldson ${ }^{136}$ similarly write, "The other side of the compensating-variation test is the ethical judgment that 'a dollar is a dollar'-income-inequality is ignored" and that "there is near unanimity about the undesirability of such ethics."

\section{K. The Complete Failure of Potential Pareto in a General Pure-Exchange Economy}

So far, we have only considered in detail Settings Qq and Pi, and in neither of those settings were we able to answer the questions "what are all the policies that pass the Kaldor Test?" or "what are all the policies that pass the Hicks Test?" In this section we show that we can answer these questions using what in Section IV.A we called Setting QQqq, that is, the setting in which the initial change could be a change in both apples and bananas, and the final change could also be a change in both apples and bananas. Setting QQqq clearly generalizes Setting Qq, but it also captures all the utility changes that could come about in Setting $*_{\mathrm{i}}$, because prices and income only affect consumers' utility indirectly, while the only thing that affects consumers' utility directly is their consumption. As Chris Jones writes, "ultimately, welfare changes are determined by changes in final consumption because that is what enters the utility functions of

\footnotetext{
${ }^{134}$ Marc Fleurbaey and Peter J. Hammond, Interpersonally Comparable Utility, in Salvador Barberà, Peter J. Hammond, and Christian Seidl, eds, Handbook of Utility Theory, Volume 2 Extensions 15 (Kluwer Academic 2010).

${ }^{135}$ See Section V.D.

${ }^{136}$ Blackorby and Donaldson, supra note 114 at 492, 493.
} 
consumers." 137 For every policy in Setting *i there is a policy with the same outcome in Setting QQqq. Hence Setting QQqq is the most general setting. ${ }^{138}$

In Setting QQqq, the definition of a Hicks improvement is given by Hayashi. ${ }^{139}$ For changes confined to a single Edgeworth Box — that is, a pure-exchange economy — parsing Hayashi's definition (as done in footnote 139) yields: " $y$ is a Hicks-improvement over $x$ if $y$ is Pareto efficient." The intuition is that if $y$ were not Pareto efficient, then a rearrangement of the initial allocation $x$ could Pareto-dominate $y$, thwarting the move to $y$. In turn, this implies: "Any policy ending on the contract curve passes the Hicks Test."

We can use Figure 13 and its "Policy 1" to develop more intuition for this. In Setting QQqq, Policy 1 will fail the Hicks Test if there is any point, not just "to the left of $o$," but instead "in the entire Box," that can Pareto-improve upon $n_{1}$ (that is, a point that is better for Smith than $U_{L 1}$ and is better for Jones than $\left.U_{W 1}\right)$. This will be true if there exists any lens-shaped area between $U_{L 1}$ and $U_{W 1}$, which is true unless $n_{1}$ is already Pareto optimal (which dispenses with any need for WATP, WTA, CV, or EV). Accordingly, the only policies that pass the Hicks Test are those that end up on a Pareto optimal point. Hence, in Setting QQqq, within a single Edgeworth Box, we have been able to answer the question "what are all the policies that pass the Hicks Test?" Furthermore, if we define a point as being "Hicks-efficient" if there is no point that is a Hicks-improvement over it, then there are no Hicks-efficient points.

Referring back to Figure 1, this means for example that $\mathrm{S}$ is a Hicks-improvement over $\mathrm{F}$, and that $\mathrm{J}$ is also a Hicks-improvement over $\mathrm{F}$. This confirms the worst fears of the arbitrariness of the Hicks Test because $\mathrm{S}$ is also a Hicks-improvement over $\mathrm{J}$ and $\mathrm{J}$ is a Hicks-improvement over S; in fact, $\mathrm{S}$ is even a Hicks-improvement over itself, and every point on the contract curve is a Hicks-improvement over itself. This clearly does not constitute a serious method for making policy decisions.

Recall that the entire reason for resorting to the Potential Pareto approach was that the Pareto approach could not rank all points. In Figure 1, with an initial location at F, the Pareto approach concluded that the points on the contract curve between I and $\mathrm{H}$ were better than any other point in the Edgeworth Box, but it could not rank the points on the contract curve between I and $\mathrm{H}$ vis-à-vis each other. What we now see is that the Hicks Test, in Figure 1 with an initial location at F, ranks the entire contract curve, between $\mathrm{S}$ and $\mathrm{J}$, as improving upon $\mathrm{F}$; but saying that it "ranks" S above $\mathrm{J}$ and $\mathrm{J}$ above $\mathrm{F}$ is equally as useless as criteria, such as Pareto, that do not claim to rank that pair. The hope of the Hicks Test was that it would narrow

\footnotetext{
${ }^{137}$ Chris Jones, Applied Welfare Economics 8 (Oxford University Press 2005).

${ }^{138}$ A more formal treatment of the material in the rest of this section appears in a working paper by Gabriel A. Lozada available at https://content.csbs.utah.edu/ lozada/Research/CBA_Generalized.pdf.

${ }^{139}$ Takashi Hayashi, supra note 82 at 22, Definition 2.5 says (replacing his typographical error $y_{i}^{\prime}$ with $x_{i}^{\prime}$ ), where the symbol $\succsim_{i}$ means "is preferred by person $i$ " and the symbol $>_{i}$ means "is strictly preferred by person $i$ ": "An allocation $y=\left(y_{1}, y_{2}, \ldots, y_{n}\right)$ is a Hicks-improvement of $x=\left(x_{1}, x_{2}, \ldots, x_{n}\right)$ if there exists no allocation $x^{\prime}=$ $\left(x_{1}^{\prime}, x_{2}^{\prime}, \ldots, x_{n}^{\prime}\right)$ with $\sum_{i=1}^{n} x_{i}^{\prime}=\sum_{i=1}^{n} x_{i}$ such that it holds $x_{i}^{\prime} \gtrsim_{i} y_{i}$ for all $i$ and $x_{i}^{\prime}>_{i} y_{i}$ for at least one $i$." This is equivalent to: "An allocation $y$ is a Hicks-improvement of $x$ if there exists no allocation $x^{\prime}$ with $\sum_{i=1}^{n} x_{i}^{\prime}=\sum_{i=1}^{n} x_{i}$ such that $x^{\prime}$ is a Pareto improvement over $y$." If $y$ and $x^{\prime}$ are in the same Edgeworth Box, then this is equivalent to: "An allocation $y$ is a Hicks-improvement of $x$ if $y$ is Pareto efficient." (Note that the move from $o$ to $n$ in Figure 16 passes the conventional Hicks Test but fails Hayashi's version of the Hicks Test.)
} 
the range of recommended points down from "the contract curve between I and H," but it has actually expanded the range instead, to "the entire contract curve." This is an utter failure of the Hicks Test to accomplish what it set out to do. Moreover, if society is on the contract curve, any policy moving to a different point on the contract curve would pass the Hicks Test, with no mechanism for judging between such points. Indeed, since there are no Hicks-efficient points, this is a recipe for never-ending movement.

Thus, the Hicks Test does not rank, in any useful way, more points than the Pareto criterion and, as proven above, it is normatively more objectionable than the Pareto criterion as well. On both positive and normative grounds, therefore, the Hicks Test loses to the Pareto criterion and should be abandoned.

Hayashi also supplies a Setting QQqq definition of the Kaldor Test, ${ }^{140}$ and the Kaldor Test turns out to fare even worse than the Hicks Test. The footnote's parsing of it yields, for changes confined to one Edgeworth Box: " $y$ is a Kaldor-improvement over $x$ if $x$ is not Pareto efficient." To see the intuition for this, consider the diagonal move from $\mathrm{F}$ to $\mathrm{S}$ in Figure 1. (Such a move is in Setting QQqq not in Setting Qq because the initial change is a change in both apples and bananas and the final change might also be a change in both apples and bananas.) The policy proposing a diagonal move from $\mathrm{F}$ to $\mathrm{S}$ passes the Kaldor test because, from $\mathrm{S}$, one could potentially move (diagonally again) to $\mathrm{R}$, making both parties better off than they were at F. For that matter, if Smith were to gain political power, she could propose a move from $\mathrm{F}$ to $\mathrm{J}$, and it too would pass the Kaldor test because, from J, one could potentially move (diagonally) to R, making both parties better off than they were at F. In turn, this implies: "Any policy starting away from the contract curve passes the Kaldor Test."

We can again use Figure 13 and its "Policy 1" scenario to develop more intuition for this. In Setting QQqq, a policy will pass the Kaldor Test if there is any point, not just "to the right of $n_{1}$," but instead "in the entire box," that can Pareto-improve upon $o$ (that is, a point that is better for Smith than $U_{L o}$ and is better for Jones than $U_{W o}$ ). This will be true if there exists any lens-shaped area between $U_{L o}$ and $U_{W o}$, which is true unless $o$ is Pareto optimal (again divorcing the Potential Pareto approach from WATP, WTA, CV, or EV). Accordingly, every policy will pass the Kaldor Test unless it begins at a Pareto Optimal point. This also implies that if we define a point as being "Kaldor-efficient" if there is no point that is a Kaldor-

\footnotetext{
${ }^{140}$ Takashi Hayashi supra note 82 at 18-19, Definition 2.4 says: "An allocation $y=\left(y_{1}, y_{2}, \ldots, y_{n}\right)$ is a Kaldorimprovement of $x=\left(x_{1}, x_{2}, \ldots, x_{n}\right)$ if there exists an allocation $y^{\prime}=\left(y_{1}^{\prime}, y_{2}^{\prime}, \ldots, y_{n}^{\prime}\right)$ with $\sum_{i=1}^{n} y_{i}^{\prime}=\sum_{i=1}^{n} y_{i}$ such that it holds $y_{i}^{\prime} \gtrsim_{i} x_{i}$ for all $i$ and $y_{i}^{\prime} \succ_{i} x_{i}$ for at least one $i$." This is equivalent to: "An allocation $y$ is a Kaldorimprovement of $x$ if there exists an allocation $y^{\prime}$ with $\sum_{i=1}^{n} y_{i}^{\prime}=\sum_{i=1}^{n} y_{i}$ such that $y^{\prime}$ is a Pareto improvement over $x$." If $y$ and $x$ are in the same Edgeworth Box, then this is equivalent to: "An allocation $y$ is a Kaldor-improvement of $x$ if there exists a point which is a Pareto improvement over $x$."

Another way to rephrase this definition is that an allocation $y$ is a Kaldor-improvement over an allocation $x$ if there exists an allocation $y^{\prime}$ located in the same Edgeworth Box as $x$ and $y$ such that no one prefers $x$ to $y^{\prime}$ and at least one person prefers $y^{\prime}$ to $x$. Substituting $\mathrm{S}$ for $y, \mathrm{~F}$ for $x$, and $\mathrm{R}$ for $y^{\prime}: \mathrm{S}$ is a Kaldor-improvement over $\mathrm{F}$ if there exists an allocation $\mathrm{R}$ located in the same Edgeworth Box as $\mathrm{F}$ and $\mathrm{S}$ such that no one prefers $\mathrm{F}$ to $\mathrm{R}$ and at least one person prefers $\mathrm{R}$ to $\mathrm{F}$.
} 
improvement over it, then the set of Kaldor-efficient points is equal to the set of Pareto-efficient points. ${ }^{141}$

In Figure 1, the Hicks Test would not rank $\mathrm{C}$ above $\mathrm{F}$ (because $\mathrm{C}$ is not Pareto efficient), but the Kaldor Test does (because once one moves from $\mathrm{F}$ to $\mathrm{C}$, one could then move to R, making both parties better off than at F). Indeed, given an initial point F, the Kaldor Test ranks every point in the Edgeworth Box above F. It gets worse, however: not only is any point a Kaldorimprovement over $\mathrm{F}$, but $\mathrm{F}$ is also a Kaldor-improvement over any point not on the contract curve. Such a test is clearly useless because it would justify any policy move away from $\mathrm{F}$ and most moves towards F.

Recall that the hope was that the Kaldor Test would narrow down the Pareto Criterion's "better than F" points to a set smaller than "the contract curve between I and H," but now we see that the Kaldor Test has actually vastly expanded the range instead, to "the entire Edgeworth Box" (except for point F). The failure of the Kaldor Test to accomplish what it set out to do is even more dramatic than the failure of the Hicks Test. On both positive and normative grounds, the Kaldor Test unquestionably loses to the Pareto criterion and should be abandoned.

To expand on the normative point: Setting QQqq in a pure-exchange economy reveals the Kaldor Test's normative defects in their rawest form. The Kaldor Test is not based on a Utilitarian ethic that there is some greater good (perhaps "utility" or "wealth" or "surplus") that is maximized when adoption of a policy causes losses to some people. There is no "greater good" function that is maximized at every point other than F in the Edgeworth Box. But what the Kaldor Test does do is to legitimize theft. Literally any theft of goods by Jones from Smith or by Smith from Jones in Figure 1 is justified by the Setting QQqq Kaldor Test so long as the thief throws none of the stolen goods away (and the original point was not on the contract curve). In a world governed by a Setting QQqq Kaldor Test, no one is safe. How much comfort does the victim really obtain, as they lie dying from starvation, from the thought that if the apple and banana thief wished, the thief could restore some of the stolen goods (and even more) in such a way that the victim and the thief would then be better off than in their original situation?

In a world governed by a Setting QQqq Hicks Test, the normative situation is hardly less grim. In it, how much comfort does the victim really obtain, as they lie dying from starvation, from the thought that there would be no way to make him better off without hurting the thief?

So far, we have been confined to policies within a single Edgeworth Box, that is, to a pureexchange economy. Extending the positive analysis to an economy with production is not straightforward, but we can easily extend the normative analysis to an economy with production. In an economy with production, enslavement of one person by the other, if it decreased output of no commodity and increased output of at least one commodity, would pass the Kaldor Test, even if its accompanying allocation decreased the welfare of both the slave

\footnotetext{
${ }^{141}$ Also, any policy starting away from the contract curve and ending on the contract curve would pass supra note 104's Scitovsky Double Criterion. Paul Samuelson, supra note 76, explicitly denounced the normative implications of such a criterion.
} 
and the enslaver, because there is an alternative allocation that would increase both persons' utility if the economy moved to it, which it will not. ${ }^{142}$

Because if a policy passes the Kaldor Test then its reverse fails the Hicks Test, we can use this example to say something about the normative features of the Hicks Test in an economy with production. In an economy with production, abolition of slavery, if it increased output of no commodity and decreased output of at least one commodity, would fail the Hicks Test, even if the accompanying allocation increased the welfare of both the former slave and the former enslaver. The intuition is that in the society with slavery and higher output, there is a reallocation of the goods that could make both persons better off than in the slavery-free society; this suffices to block the move to end slavery, even if the "reallocation" will never be done.

Why then does the Potential Pareto Test have supporters, when, by advocating a move from $\mathrm{F}$ to any other point in the Edgeworth Box (Kaldor) or to any point on the contract curve (Hicks), it fails every potential theory of justice? Perhaps some supporters are under the delusion that the purpose of an economy is to create commodities instead of to satisfy human desires or utility. Such people applaud when "dead matter comes forth from the factory ennobled, while men there are corrupted and degraded." 143 No well-trained modern economist would admit to being sympathetic to such a position. Other supporters, one suspects, have the utilities only of certain people in mind, such as the allegedly productive people. The Potential Pareto approach supports any policy, assuming the initial point is not Pareto efficient (Kaldor), or any policy moving to any Pareto efficient point (Hicks), so long as output does not fall. With either the Kaldor or Hicks Test in Setting QQqq, whoever can submit their proposal first reaps large rewards because the first proposal will pass the Kaldor Test regardless of its content (so long as it does not cause output to fall and the initial point is not Pareto efficient), or will pass the Hicks Test regardless of its content (so long as the new position is on the contract curve), and it can cleverly preempt any second proposal by someone else simply by terminating at a maximum-inequality Pareto Efficient point (such as Figure 1's S or J).

Before leaving this Part, we need to revisit Section III.G.1(c)'s question of the relationship between efficiency and distribution. That section showed that improvements in Pareto efficiency were determined by distribution: the Separation Hypothesis between distribution and Pareto efficiency is false. For example, in Figure 1, moving from $\mathrm{F}$ to $\mathrm{R}$ is an improvement of Pareto efficiency (i.e., is "a Pareto improvement") but moving from $\mathrm{C}$ to $\mathrm{R}$ is not. The questions "what is the relationship between distribution and Kaldor-efficiency?" and "what is the relationship between distribution and Hicks-efficiency?" are not usually asked because

\footnotetext{
${ }^{142}$ Consider Figure 1 and a similar figure which is slightly larger in one or both directions. The new figure has the same origin for Smith, and so the same indifference curves for Smith, but a shifted origin, and hence shifted indifference curves, for Jones. However, Jones's indifference curves will not shift much if the second Edgeworth Box is only slightly bigger than the first. Consider a move from $G$ in the first Box to "a point close to F" in the second Box. This plausibly decreases the utility of both persons but would pass the Kaldor Test because of the possibility of increasing the utility of both persons.

${ }^{143}$ Pope Pius XI, Quadragesimo Anno (1931). Available at http://www.vatican.va/content/piusxi/en/encyclicals/documents/hf p-xi enc 19310515 quadragesimo-anno.html. Cited in E. F. Schumacher, The Age of Plenty: A Christian View, in Herman E. Daly and Kenneth N. Townsend, eds, Valuing the Earth: Economics, Ecology, Ethics 165 (MIT Press 1993).
} 
most economists consider "efficiency" only to be Pareto efficiency (Section III.C), but we now raise them.

In Setting QQqq in an Edgeworth Box, the set of Hicks-improving points is any point on the contract curve, irrespective of initial distribution. Thus, the Separation Hypothesis is true between distribution and Hicks efficiency improvements.

In an Edgeworth Box, if the initial point is not Pareto-efficient, the set of Kaldor-improving points is every point except for the initial point. In this case, changing the initial point from Pareto-inefficient point $\mathrm{F}$ to Pareto-inefficient point $\mathrm{R}$ changes the set of Kaldor-improving points from "all points except F" to "all points except R." Technically, the Separation Hypothesis fails in this case, but almost every point belongs to both "all points except F" and "all points except R" so as a practical matter, the Separation Hypothesis is true between distribution and Kaldor efficiency improvements when the initial distribution is Paretoinefficient. ${ }^{144}$ If on the other hand the initial distribution is Pareto-efficient, the set of Kaldorimproving distributions is only the initial distribution (because it cannot be Pareto-improved upon). Therefore, the Separation Hypothesis is false between distribution and Kaldor efficiency improvements if the initial distribution is Pareto-efficient.

Accordingly, the Separation Hypothesis between distribution and efficiency is false as regards Pareto Efficiency, true as regards Hicks-efficiency, and mostly true as regards Kaldorefficiency-but Hicks- and Kaldor-efficiency are much less compelling than Pareto efficiency. For the same reason, the "pie" analogy, which is false as regards Pareto Efficiency, is true or mostly true in the Potential Pareto approach.

Part IV has been long. However, our overall conclusion from it is that given the positive and normative flaws of the Cost-Benefit/Kaldor-Hicks/“Potential Pareto" approach, only those who have a "preference for the wealthy" (wealthy individuals or firms) and can control the agenda of the State-for example, by hiring lawyers and economists and filing lawsuits before other people do- have a reason to use it. ${ }^{145}$

\section{CONSUMER SURPlus/CONSUMER WELFARE: COERCION, WITH LESS JUSTIFICATION}

In 1966, Robert Bork argued that the "consumer welfare standard" should be the sole goal of antitrust law, and that such was what Congress intended when it passed the Sherman Act in

\footnotetext{
${ }^{144}$ In mathematical language, the measure of the difference between "the set of Kaldor-improvements over F" and "the set of Kaldor-improvements over R" is zero.

${ }^{145}$ While the positive problems with the Potential Pareto approach appear to be insuperable when they occur, they do not always occur; and Potential Pareto's normative problems might be partially solved by econometrically estimating $\mathrm{CV}$ and $\mathrm{EV}$ to obtain an income-adjusted CV and EV. It would remain problematic, however, to obtain the $\mathrm{CV}$ and $\mathrm{EV}$ of future generations, particularly if their income will change depending on the decision currently under debate (for example, climate change policy). Furthermore, removing the approach's "preference for the wealthy" would remove its attraction for some of its current proponents.

For a use of CV and EV outside of the Potential Pareto framework, illustrating dividing the data into income quantiles, see Abdeldrim Araar and Paolo Verme, Prices and Welfare, Policy Research Working Paper 7566, Poverty and Equity Global Practice Group, World Bank Group (February 2016), https://openknowledge.worldbank.org/bitstream/handle/10986/23897/Prices0and0welfare.pdf?sequence=1\&isAllo wed=y
} 
1890. ${ }^{146}$ In his influential book The Antitrust Paradox, Judge Bork made clear that his term "consumer welfare" was simply a rebranding of the concept of consumer surplus. ${ }^{147}$ The movement caught on so swiftly that, during the 1980s, other traditional antitrust goals such as dispersion of economic power ${ }^{148}$ and protection of small business ${ }^{149}$ were swept away as neoliberal policy began to dominate the antitrust agencies. Today, the domination of the "consumer welfare" standard, that is, consumer surplus, in antitrust law is complete.

Consumer surplus is a measure of welfare, just like WATP and WTA (equivalently, just like compensating variation and equivalent variation). Using consumer surplus (or, more generally, social surplus) is an alternative to using the Kaldor-Hicks/Cost-Benefit Analysis/Potential Pareto approach. Furthermore, the most surprising result of our review of L\&E textbooks in Appendix 1 (Part Appendix 1:) is that while most L\&E textbooks say they use the KaldorHicks approach, what they actually use is the surplus approach. ${ }^{150}$ Applied economists sometimes use the surplus approach and sometimes use Cost-Benefit Analysis, often but not always depending on which approach is traditionally used in their subdiscipline (surplus in industrial organization and Cost-Benefit Analysis in environmental economics). Clearly it is important to decide which is better, the surplus approach or the Potential Pareto approach.

The Potential Pareto Approach, flawed as shown in Part IV, is at least built upon the noncontroversial and useful foundation of WATP, WTA, EV, and CV. Those concepts are so noncontroversial that in Section IV.A.7 we even discussed potential consensual uses for them. Consumer surplus is normatively very similar to the Potential Pareto Approach (and so has all of the latter's normative flaws). However, we will show in this Part that the positive foundation of consumer surplus, while an improvement over early nineteenth-century ideas, is inferior to the twentieth-century positive foundation of Potential Pareto. This means that consumer surplus is an inferior basis on which to make social decisions than Potential Pareto.

However, consumer surplus has three attractions for anyone who has a "preference for the wealthy." First, like the Potential Pareto approach, it reflects such a preference. Second, it is so simple that it is easily taught to undergraduates, unlike EV/CV; and it is taught to every undergraduate economics major, and to many students who only take a single undergraduate economics course. Third, its description of consumer behavior is so incorrect that it masks what is otherwise readily apparent - that "value" has a dual nature. Thus, consumer surplus theory functions like proverbial rose-colored glasses, hiding the messiness of EV not equaling $\mathrm{CV}$, and the inconsistencies and incompleteness and arbitrariness which that causes, behind lenses tinted so strongly that none of those problems can be perceived.

\footnotetext{
146 Robert Bork, Legislative Intent and the Policy of the Sherman Act, 9 J.L.\& Econ 7 (1966).

${ }^{147}$ Robert Bork, The Antitrust Paradox: A Policy at War with Itself Ch. 4 (Basic Books 1978). For affirmation that today "consumer welfare [is] equivalent to consumer surplus" see Kenneth Heyer, "Consumer Welfare and the Legacy of Robert Bork," 57 J. Law and Econ. S19-S32, S20 (2014).

${ }^{148}$ Harlan Blake and William Jones, In Defense of Antitrust, 65 Columbia L. Rev. 377-400 (1965).

${ }^{149}$ Kenneth Elzinga, The Goals of Antitrust Other Than Competition and Efficiency, What Else Counts? 125 U. Penn. L. R. 1191-1213, 1191 (1977).

${ }^{150}$ As discussed in Appendix 1 (Part Appendix 1:), only the four texts of Cole and Grossman, Hirsch, Friedman, and Polinsky deviate in various ways from the pattern of "claiming to use Kaldor-Hicks but not using it."
} 
To understand why consumer surplus theory is inferior to the Potential Pareto approach, one must first understand its origins and prior uses.

\section{A. Consumer Surplus: An Advance Over the Expenditure Approach}

We begin by explaining how consumer surplus is an advance over an even more mistaken view, the view that the total expenditure on a good is a credible measure of its value.

Suppose Figure 19 shows the demand curve for a commodity like diamonds, $D_{d}$, and for a commodity like water, $D_{w}$, and their corresponding supply curves, $S_{d}$ and $S_{w}$. A straightforward, but misleading, way to answer the question "what is the value of diamonds?" is the expenditure on diamonds, the rectangle $p_{d} Q_{d}$. According to this "Expenditure Approach"-it could also be called the "Total Revenue" Approach since the buyer's spending is the seller's receipts - the value of water would similarly be $p_{w} Q_{w}$. Since the rectangle $p_{d} Q_{d}$ is larger than the rectangle $p_{w} Q_{w}$, this results in the conclusion that diamonds are more valuable than water. This answer is paradoxical because water is a requirement for life while diamonds are mostly merely used as decoration and adornment. This is called "the diamondwater paradox," and it shows why the Expenditure Approach to value is flawed. (Replace water with a free commodity, air, for an even more dramatic example.)

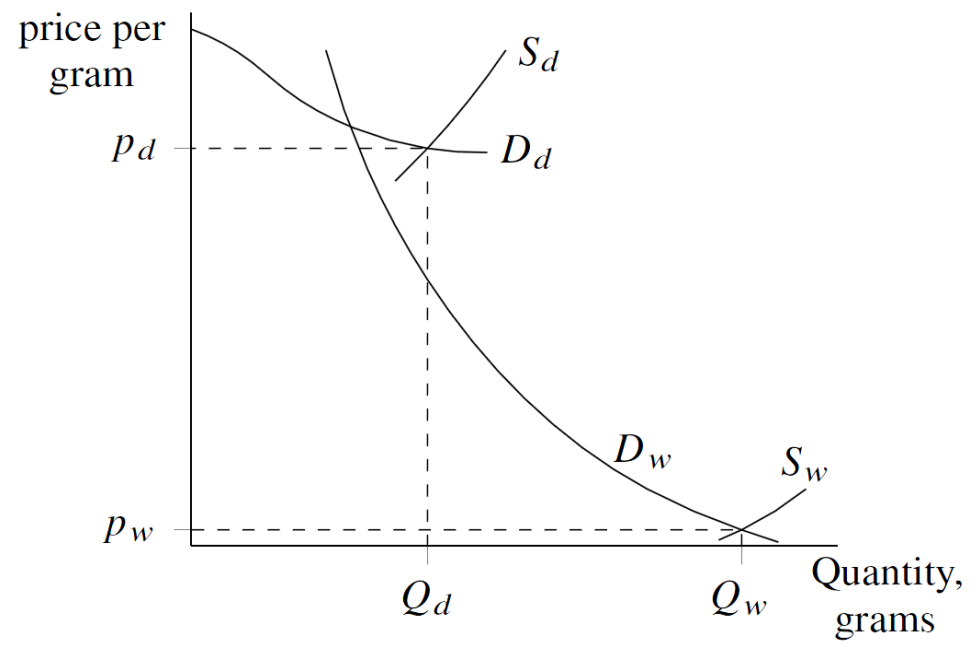

Figure 19. The Diamond-Water Paradox.

To see how the "Consumer Surplus" approach to value improves on the Expenditure Approach, refer to Figure 20, showing the demand curve for a commodity, and consider this way of thinking through how to answer the question "what is the value of $Q_{1}$ "? Suppose first that the consumer only had access to the good at a price of $p_{a}$. In that case, as reflected in Figure 20, the consumer would be willing and able to pay for $Q_{a}$ units of the good-hence paying $p_{a} Q_{a}$ in total for those units. Geometrically, this is the area under line $p_{a} A$. Having bought $Q_{a}$ units of the good, suppose the consumer is offered additional units of the good at a new, lower price of $p_{b}$. He is then willing and able to buy an additional $Q_{b}-Q_{a}$ units of the good at this lower price, resulting in a total payment of $p_{b} *\left(Q_{b}-Q_{a}\right)$ for those units, i.e., the area under line $G B$. Having bought $Q_{b}$ units of the good in total, suppose the consumer is offered additional units of the good at a new, even lower price of $p_{c}$. He is willing and able to buy $Q_{c}-Q_{b}$ units 
of the good, resulting in a total payment of $p_{c} *\left(Q_{c}-Q_{b}\right)$ for those units, i.e., the area under line $H C$.

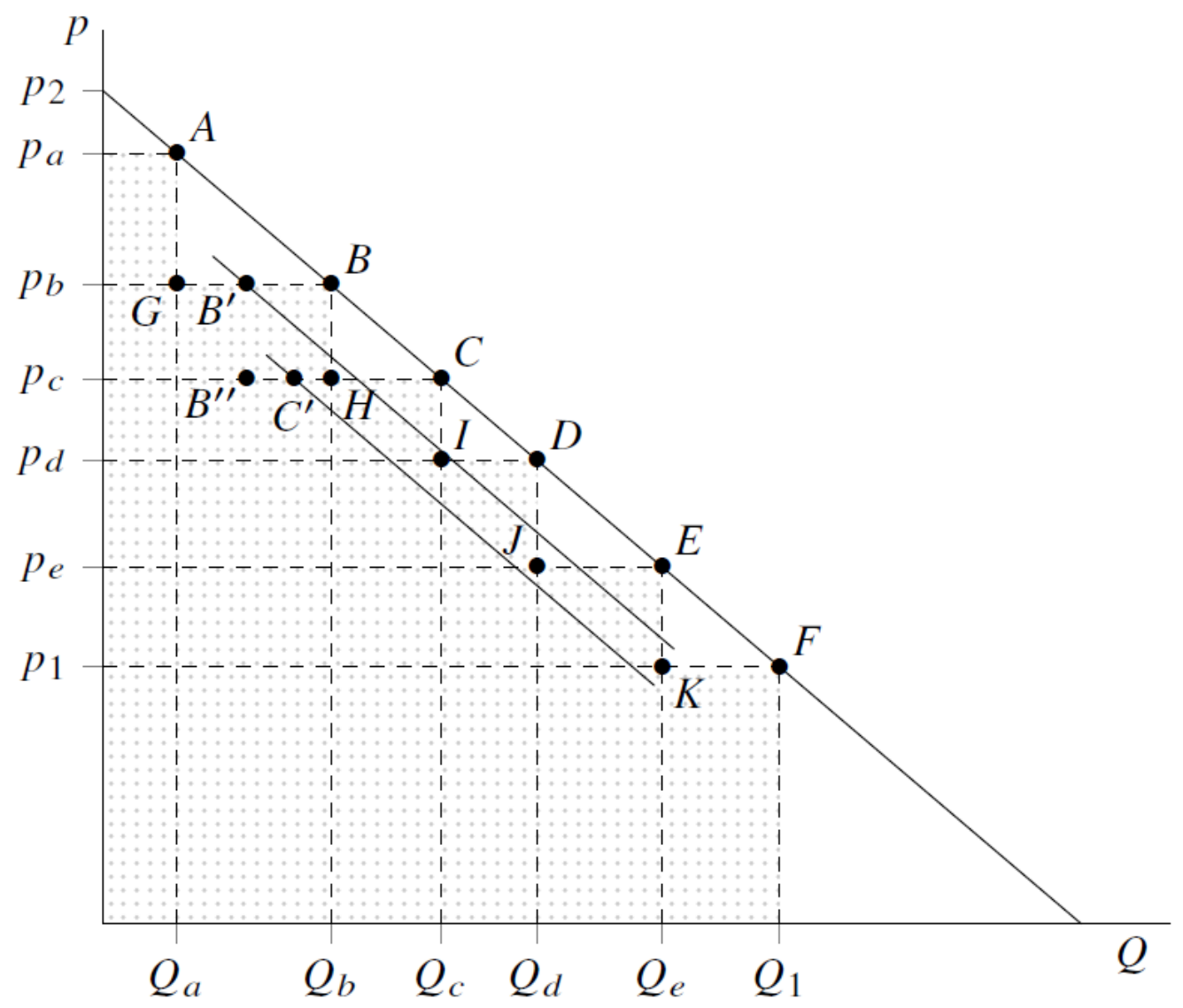

Figure 20. Problems in the derivation of Consumer Surplus.

In a similar manner, the consumer's willingness and ability to pay for $Q_{1}$ will include the area under the lines $I D, J E$, and $K F$. The consumer's willingness and ability to pay will be, in total, the sum of the areas under the lines $p_{a} A, G B, H C, I D, J E$, and $K F$. If the distance from $p_{2}$ to $p_{1}$ had been divided into more intermediate prices, the consumer's willingness and ability to pay would converge to the area under the line $p_{2} F$. "Consumer surplus" is this area minus the consumer's $p_{1} Q_{1}$ outlay for $Q_{1}$, so consumer surplus is the triangle $p_{2} F p_{1}$. (If the demand curve is not a straight line, consumer surplus is not a triangle, strictly speaking, but instead is a triangle-like shape with one leg curved not straight.). Thus we see that the Expenditure Approach is wrong to think that the value of $Q_{1}$ is only $p_{1} Q_{1}$; instead, a better answer is that the value of $Q_{1}$ is $p_{1} Q_{1}$ plus the consumer surplus. ${ }^{151}$ The Consumer Surplus approach resolves the Diamond-Water Paradox because, as is evident in Figure 19, the area under the

151 This insight is due to work by Dupuit in 1844; see R. W. Houghton, A Note on the Early History of Consumer's Surplus, 25 Economica (New Series) 49-57 (1958). In some sense, though, the idea goes back to Aristotle: Herman E. Daly's Steady-State Economics: Second Edition with New Essays 186 (Island Press 1991) reminds us that "Marx, and Aristotle before him, pointed out that the danger of money fetishism arises when society shifts its focus from use value to exchange value." Aristotle's distinction is between oikonomia and chrematistike in The Nichomachean Ethics Book I Chapter 5 and in Politics Book I Parts VIII, IX, and X. 
diamond demand curve is smaller than the area under the water demand curve, making $Q_{d}$ diamonds "less valuable" than $Q_{w}$ water.

The success of the consumer surplus approach in explaining the Diamond-Water Paradox turned out to be the apex of its influence on economics. As we describe in Section V.C, by the early twentieth century, shortcomings of the consumer surplus approach became apparent, and in the opinion of most economic theorists, Kaldor and Hicks's development of EV and CV should have spelled the end of consumer surplus. However, before we continue with our narrative in Section V.C, we take a detour to address a mistake in the L\&E treatment of surplus and "wealth."

\section{B. Consumer Surplus is Not Part of Wealth}

In Section V.A, we criticized the Expenditure Approach because it was not a good measure of the value a consumer gains from a commodity, and we demonstrated that adding consumer surplus to expenditure provides a better measure. By "the value a consumer gains from a commodity"- "value" for short - we are trying to describe how the commodity affects the consumer's "utility," which cannot be measured directly, which is ordinal, and which is what we are ultimately concerned with. We sometimes refer to the consumer's utility as the consumer's "welfare"- but not in the same sense as Bork's "consumer welfare," which is cardinal and means "consumer surplus" or "producer and consumer surplus." While utility, as manifest in the form of (many) graphs of indifference curves, underlay everything we did in this paper's "Potential Pareto" Part IV - and while Part III, on Pareto Optimality, was even more directly about utility - we did not mention utility or indifference curves once in Section V.A. That is not a promising sign for consumer surplus as a measure of welfare/utility, and Section V.C will show that, as its title says, "consumer surplus is not a credible measure of welfare."

Posner criticized the Expenditure Approach in 1981, not on the grounds that we used - that it is a bad measure of utility/welfare - but instead on the grounds that it is a bad measure of "wealth." In this section we explain why the "bad measure of utility/welfare" criticism is different from the "bad measure of wealth" criticism, in so far as the word "wealth" is used by economists. Once we show that "wealth" is not welfare/utility, it will be clear that "wealth" is irrelevant to the subject of this paper; yet Posner has been strongly advocating "wealth maximization" to lawyers since the 1970 's,${ }^{152}$ as has Robert Bork. ${ }^{153}$ Accordingly, it is important to expend some effort bringing clarity to its definition.

What Posner wrote in 1981 was: ${ }^{154}$

Coleman and Korhauser argue that wealth maximization cannot be an ethically attractive system because it depends on prices. The wealth of society (in their view) is the sum of the outputs of all goods and services, weighted by their

\footnotetext{
152 Richard A. Posner, Utilitarianism, Economics, and Legal Theory, 8 J. Legal Studies 103-140, 119 (1979))

${ }^{153}$ Robert H. Bork, The Antitrust Paradox 90 (Basic Books 1978): "Consumer welfare, in this sense, is merely another term for the wealth of the nation."

${ }^{154}$ Richard A. Posner, A Reply to Some Recent Criticisms of the Efficiency Theory of the Common Law, 9 Hofstra L. Rev. 775-794, 786 (1981).
} 
prices. [...] But their definition of social wealth is incorrect. It leaves out consumer and producer surplus. When these are included, as they are whenever economists talk about the wealth of the society, it becomes clear that [....]

Accordingly, we need to clarify what macroeconomists mean when they "talk about the wealth of society," and then we need to clarify what microeconomists mean when they talk about the wealth of an individual.

When macroeconomists talk about "wealth," they mean that term in the context of National Income Accounting. In "supply and demand" graphs like Figure 19, the quantity on the horizontal axis is assumed to be purchased during a defined period of time, such as one month. Therefore expenditure, such as $P_{w} Q_{w}$, is best understood as a flow (e.g., dollars per month). The sum of expenditures on all the goods produced in the economy would be the sum over all goods $i$ of $P_{i} Q_{i}$. This is roughly how Gross Domestic Product ("GDP") is defined; GDP is often interpreted as "the value of final goods and services produced in [a country]"155 during a particular period of time, typically one year. GDP is equal to "Gross Domestic Income."156 "National Wealth," on the other hand, is not a flow but a stock; one way to confirm this is that National Wealth is measured in dollars, not in dollars per a unit of time. ${ }^{157}$ There is, however, a relationship between total expenditure (GDP) and wealth: GDP minus depreciation is equal to consumption plus the change in national wealth. ${ }^{158}$ By contrast, there is no relationship or equation in the System of National Accounts that involves "surplus." Accordingly, in macroeconomics, surplus is not part of wealth.

Microeconomists have a different definition of "wealth." Mas-Colell, Whinston, and Green write: ${ }^{159}$ "The consumption bundle $[\ldots]$ is affordable if its total cost does not exceed the consumer's wealth level $w$, that is, if [footnote reference] $p \cdot x=p_{1} x_{1}+\cdots+p_{L} x_{L} \leq w$." Their footnote reads: "Often, this constraint is described in the literature as requiring that the cost of planned purchases not exceed the consumer's income. In either case, the idea is that the cost of purchases not exceed the consumer's available resources. We use the wealth terminology to emphasize that the consumer's actual problem may be intertemporal, with the commodities involving purchases over time, and the resource constraint being one of lifetime income (i.e., wealth) [...]." The mathematics makes it clear that "wealth" in microeconomics is a sum of expenditures, which directly contradicts Posner's statement that surplus is "included whenever economists talk about the wealth of the society."

Just because the Expenditure Approach is the correct way to measure "wealth" (which it is in microeconomics) or "income" (which it is in macroeconomics) does not mean it is a good way

\footnotetext{
155 See https://www.bea.gov/data/gdp/gross-domestic-product.

156 Stephanie H. McCulla and Shelly Smith, Measuring the Economy: A Primer on GDP and the National Income and Product Accounts 4 (Bureau of Economic Analysis, U.S. Department of Commerce 2015). Available at https://www.bea.gov/sites/default/files/methodologies/nipa primer.pdf.

${ }^{157}$ European Communities, International Monetary Fund, Organisation for Economic Co-operation and Development, United Nations and World Bank, System of National Accounts 2008257 (2008). For the general distinction between stocks and flows, see https://en.wikipedia.org/wiki/Stock and flow.

158 Supra note 156 at 4.

159 Supra note 55 at 20-21.
} 
to measure what we (and, we hope, Posner) are interested in, which is welfare/utility. What Posner should have said is that "expenditure plus consumer and producer surplus" is a better measure of welfare/utility than "expenditure" alone is. That is a true statement. It does not go very far at all, as Section V.C. will show, but at least it is true. Relating such things to "wealth," however, was a serious mistake on Posner's part.

Posner's quotation mentions "producer surplus." In much the same way as a consumer would be willing to pay more for $Q_{1}$ than he "needs to if the price is uniform at $p_{1}$," a firm with a rising supply curve would be willing to supply $Q_{1}$ upon being paid less than "it is actually paid if the price is uniform at $p_{1}$." The argument is the analog of Figure 20's: if offered a very low price $p_{z}$, the firm might produce $Q_{a}$, receiving $p_{z} Q_{a}$ in revenue; but if it is later offered a slightly higher price $p_{y}$ the firm might produce an additional quantity $Q_{b}-Q_{a}$, receiving $p_{y} *$ $\left(Q_{b}-Q_{a}\right)$ in additional revenue; and so forth. "Producer surplus" is the difference between what the firm receives when facing a uniform price in contrast to facing the nonuniform prices. L\&E authors usually include producer surplus with consumer surplus as part of their measure of value. ${ }^{160}$ What L\&E authors almost never mention, however, is that "social surplus" is not only the sum of consumer and producer surplus, but should also include the surpluses generated in input markets, such as the market for labor. Input markets, if characterized by a uniform price for the input, generate surpluses for the input demander and the input supplier in a completely analogous way to the consumer and producer surpluses generated in output markets. The surplus accruing to an input supplier even has its own name: "economic rent." "Social surplus," thus, properly includes all of the surpluses. (A completely correct analysis considers the effect of any policy change on everyone who is affected, not only those affected through the market and who thus have or could have a surplus - workers, other input suppliers, owners, and customers; competing and complementary firms' workers, other input suppliers, owners, and customers; and anyone engaged in commerce with any of these people - but also those affected outside of the market, such as family members of those affected through the market, and people experiencing negative or positive externalities from any of the affected firms, including people in future generations.)

\section{Consumer Surplus is Not a Credible Measure of Welfare}

However much of an improvement consumer surplus was over the Expenditure Approach in measuring welfare/utility/value, consumer surplus (added to expenditure) cannot literally be the correct answer to the question "what is the value of $Q_{1}$ " because, as we already saw in Part IV.A, that question has not one answer ("the consumer surplus plus expenditure") but two. ${ }^{161}$

\footnotetext{
${ }^{160}$ See Heyer, supra note 147 at S20: "Bork's use of the term 'consumer welfare' is unfortunate and confusing in this context. It is clear, as will be demonstrated below, that by consumer welfare Bork meant total welfare [....] To avoid confusion, I use the term "total welfare" to mean just that: total welfare (equivalent to consumer plus producer surplus and economic efficiency)." Our point is to show that L\&E now values producer surplus as much as consumer surplus, not to endorse the rest of Heyer's definition. Heyer presents this as a not-entirely-settled point; his Section 4, "Current Scholarly Debates," begins with Section 4.1, "Consumer Welfare versus Total Welfare." He writes, "Although economic efficiency is frequently equated with total wealth, Salop observes that business conduct that increases total wealth does not necessarily increase total welfare. So long as any individual is left worse off, total utility could fall" (id. at S27). That is more properly viewed as a complaint about using any kind of surplus as a measure of utility.

${ }^{161}$ Realizing this is difficult even for non-specialist professional economists because Ph.D.-level textbooks such as Varian (supra note 53, Chapter 13 “Competitive Analysis" Section 7 "Welfare Analysis” p. 222 ff.) and Mas-
} 
The flaw in Section IV.A's argument is easy to explain. Recall what we claimed above, concerning Figure 20:

Having bought $Q_{a}$ units of the good, suppose the consumer is offered additional units of the good at a new, lower price of $p_{b}$. He is willing and able to buy an additional $Q_{b}-Q_{a}$ units of the good at this lower price, resulting in a total payment of $p_{b} *\left(Q_{b}-Q_{a}\right)$ for those units, i.e., the area under line $G B$.

This is actually wrong. It is wrong because the statement that "He is willing and able to buy an additional $Q_{b}-Q_{a}$ units of the good at this lower price" rests on the assumption that the consumer has available his initial level of income, say $I_{1}$, when in actuality the consumer has already spent $p_{a} * Q_{a}$ dollars buying $Q_{a}$, so he has less than $I_{1}$ dollars left over when the new, lower price of $p_{b}$ is offered. If this good is a "normal" good, having less income means demand for it shifts down, for example to $B^{\prime}$ for a price of $p_{b}$. Hence, instead of being "willing and able to pay" $G B$ when the price is $p_{b}$, the consumer is only WATP $G B^{\prime}$ when the price is $p_{b}$. When the price falls to $p_{c}$, the demand curve will have shifted down again, and the amount of money spent when the price is $p_{c}$ would be only $B^{\prime \prime} C^{\prime}$ instead of $H C$. The conclusion is that the actual WATP for $Q_{1}$ will be less than the area under $p_{2} F$. If this good were "inferior" instead of "normal," then the demand curves would shift up rather than down, and the actual WATP for $Q_{1}$ would be more than the area under $p_{2} F{ }^{162}$

The reader will recognize that the flaw in the consumer surplus derivation is the same flaw that invalidated the Coase Theorem (discussed in conjunction with Figure 4 above), because both arguments depend on making a series of steps along a demand curve (the $M E C$ curve in Figure 4 functioning as the demand curve for clean air). The flaw in that Coase Theorem argument was that once money had left the consumers' pockets, the $M E C$ curve did not stay where it was before, but rather shifted in precisely the same way and for precisely the same reason as the demand curve shifts in our discussion in this section.

Colell, Whinston and Green (supra note 55, Chapter 10 "Competitive Markets" Section D "The Fundamental Welfare Theorems in a Partial Equilibrium Context" at $325 \mathrm{ff}$.) repeat a demonstration from undergraduate textbooks that "maximizing consumer surplus plus producer surplus" yields the competitive equilibrium, which is Pareto Optimal, in a partial equilibrium context while dangerously de-emphasizing the fact that this requires assuming consumers have quasilinear preferences, which is an unrealistic, "knife-edge," cardinal assumption of no relevance to the real world, as we have explained before and will revisit in the paragraph after next. Deemphasizing these restrictive assumptions has a long history, the most ironic of which appears in J. R. Hicks, The Rehabilitation of Consumers' Surplus, 8 The Review of Economic Studies 108-116, 109 (1941), in which Hicks calls "a fiddling business, fortunately not likely to be of much importance" the concept which every economics Ph.D. student now actually calls the Hicksian demand curve ("...to adjust the ordinary demand curve so as to allow for the effects of the changes in real income as we pass along the curve").

${ }^{162}$ For a more technical discussion of these points, see Gabriel A. Lozada, supra note 69.

Doubts about consumer surplus along the lines discussed here were raised as early as Bordas in 1847 (see Houghton, supra note 151 at 51). Alfred Marshall, supra note 47, clearly understood these same problems, although he unfortunately downplayed them. Marshall wrote that "In regard to different people allowance may have to be made where necessary for differences of sensibility and for differences of wealth: but it is seldom needed in considering large groups of people" (margin notes for pages 130 and 131, Book III ("On Wants and their Satisfaction") Chapter VI ("Value and Utility") Section 3, id.). 
The curves do not merely shift in our Figures, but also shift in the real world. Only in the theoretically uninteresting and empirically irrelevant "quasilinear preferences" case in which ${ }^{163}$ the good is exactly on the borderline between being normal and being inferior-in which, that is, "demand curves do not depend upon income" as we described in Part III.G.1(d) (on the Coase Theorem) and Part IV.A (on WATP equaling WTA in Setting Pi) - will the demand curve not shift, and will consumer surplus, the area under $p_{2} F$, be exactly equal to WATP for $Q_{1}$. So unlikely is that case that 2015 Economics Nobel laureate Angus Deaton flatly says ${ }^{164}$ "there is no valid theoretical or practical reason for ever integrating under a Marshallian demand curve" (that is, for calculating consumer surplus). We concur. ${ }^{165}$

In the uninteresting case in which the demand curve does not shift, demand does not depend upon income, meaning that even though the "winner" of a policy, when faced with the Kaldor "if the policy is adopted" question, will be richer than if he is instead faced with the Hicks "if we do not adopt the policy" question, his increase in wealth will not affect his answer to the valuation question. In other words, his CV (WATP) will equal his EV (WTA). In Setting Pi, income effects of price changes are what drives a wedge between $\mathrm{CV}$ and $\mathrm{EV}$, so in this case of zero income effects, CV, EV, and consumer surplus all become identical, value's dual nature merges into one nature, and the positive problems of $\mathrm{CV}, \mathrm{EV}$, and consumer surplus all disappear, leaving only their normative problems. Because of this, it is not surprising that some authors have attempted to salvage Consumer Surplus, despite its defects. In the next section we explain why we find these efforts unavailing.

\section{Willig's Claim that Consumer Surplus Approximates EV and CV Does Not Save} Consumer Surplus

In Section V.C we showed that consumer surplus was not an accurate measure of value. In an advanced treatment due to Willig, ${ }^{166}$ consumer surplus earns respectability because in Setting $\mathrm{Pi}$, consumer surplus lies between compensating variation and equivalent variation, thus forming an approximation to both of them. We here explain why Willig's argument does not undermine Deaton's conclusion about consumer surplus.

First, Willig is only able to show that consumer surplus is numerically close to WATP and WTA when WATP and WTA are themselves numerically close to each other, which happens when policy changes are marginal, in the sense of being minor or small. Many other problems we have discussed in this paper would also disappear when policies are small: not only would the gap between WATP and WTA be small, making the dual nature of value less important, but

\footnotetext{
163 Though see supra note 118 on quasi-homothetic preferences.

${ }^{164}$ As quoted in Marco Becht, The Theory and Estimation of Individual and Social Welfare Measures, 9 J. of Economic Surveys 53-87, 77 (1995).

${ }^{165}$ If the area under $p_{2} F$ is not the WATP for $Q_{1}$, is there some way of calculating the WATP for $Q_{1}$ using market demand curves as in Figure 20? Given that the demand curves shift as the figure shows, the answer to this question is likely 'no.' Actually, with sufficiently advanced mathematics, it is possible to take into account the demand curve's shifts and arrive with a numerical value for $Q_{1}$, and the answer turns out to be exactly the same as the WATP or WTA one can arrive at by other means; for the technical proof, see Gabriel A. Lozada, supra note 69. The reader may wonder which value measure, WATP or WTA, is arrived at by this procedure, and the answer is both, depending on whether an "if we do this" or an "if we do not do this" question is asked.

${ }^{166}$ Robert D. Willig, Consumer's Surplus Without Apology, 66 The American Economic Review 589-597 (1976).
} 
it would be impossible for WATP to fail to exist (Figure 10's geometry could not happen), and it would be impossible for WTA to fail to exist (Figure 11's geometry could not happen). ${ }^{167}$ However, many policy changes are not marginal - think of free trade between the USA and China and its dramatic results of industrialization in China, and deindustrialization and "deaths of despair" in the USA. Indeed, it is reasonable to conjecture that when the stakes are big enough to motivate a party to pay economists to calculate consumer surplus and to pay attorneys to bring or defend against a corresponding lawsuit, the policy is not small. (A policy may be "small" to some people, such as customers, and "big" to others, such as competing firm owners forced into bankruptcy, and their employees.) When a policy is not small, WATP and WTA will not generally be numerically close to each other. In that case consumer surplus cannot simultaneously be close to both of them, Willig's argument lacks applicability, and consumer surplus is therefore robbed of importance.

Next, Hausman ${ }^{168}$ showed that if one has the statistical information necessary to estimate consumer surplus, one also has the statistical information necessary to estimate $\mathrm{CV}$ and $\mathrm{EV}$ directly, rendering consumer surplus unnecessary. CV and EV are the exact measure of value change - they have a direct link to utility while consumer surplus does not-so there is no reason to calculate consumer surplus. Furthermore, only by calculating CV and EV can one determine whether there are any inconsistencies between the Kaldor and Hicks Tests.

Another point made in Hausman's paper is that even in situations where consumer surplus is close to both $\mathrm{EV}$ and $\mathrm{CV}$, the change in social surplus as the result of a policy (namely the change in consumer surplus plus the change in firm revenue) may not be a good approximation to the change in social value (EV or $\mathrm{CV}$ plus the change in firm revenue). This is important because it is the change in social value (the so-called "deadweight loss") of a policy, not simply the change in consumer surplus, that economists care about. ${ }^{169}$

Lastly, an additional problem with consumer surplus is that if more than one price change is made, consumer surplus changes troublingly depend on the order in which those price changes are made. ${ }^{170}$ For example, the change in consumer surplus if "the price of apples changes from $\$ 4$ to $\$ 3$ and then the price of bananas changes from $\$ 10$ to $\$ 8$ " is not the same as the change in consumer surplus if "the price of bananas changes from $\$ 10$ to $\$ 8$ and then the price of apples changes from $\$ 4$ to $\$ 3$."

\footnotetext{
${ }^{167}$ For infinitesimally small changes, in Frame Qq value is a single number, the marginal rate of substitution, as referred to in supra note 78; and in Frame Pi, the Slutsky Equation (see generally Hal R. Varian, supra note 53 $\S 8.2$, not the discrete version in §8.10) guarantees that the income effect, and thus WATP and WTA, exist.
}

168 Jerry A. Hausman, Exact Consumer's Surplus and Deadweight Loss, 71 American Economic Review 662-676 (1981).

${ }^{169}$ See also Mas-Colell, Whinston, and Green, supra note 55 at 89-91, where in addition to confirming the above points, the authors exhibit a function which approximates the change in CV better than consumer surplus does.

${ }^{170}$ Hayashi, supra note 140 at 53: "Theorem 3.5: There is no regular preference such that consumer surplus is path-independent when both price vector and income vary." [...] "Theorem 3.6: When income is fixed, consumer surplus is path-independent if and only if the preference is homothetic as well as strongly monotone and strictly convex." Page 54: "Theorem 3.7: When prices of a subset of goods $K$ and income vary, consumer surplus is pathindependent if and only if preference exhibit no income effect on every good in $K$." This problem with consumer surplus was also pointed out by Harold Hotelling, The General Welfare in Relation to Problems of Taxation and of Railway and Utility Rates, 6 Econometrica 242-269 (1938). 
As an aside, Willig's work only applies to Setting Pi, which makes sense because consumer surplus of the sort we have been discussing also only applies to Setting $\mathrm{Pi}^{171}{ }^{171}$ but some observations about the gap between WATP and WTA in Setting Qi seem appropriate. In Setting Qi, numerous empirical studies find large differences between WATP and WTA. Knetsch says that ${ }^{172}$ "in perhaps the earliest report of a large disparity between the measures, bird hunters said they would be willing to pay an average of $\$ 247$ to preserve a marsh area that contributed to the propagation of ducks, but would demand an average of \$1044 to agree to its destruction (Hammack and Brown, 1974)." No Setting Qi approximation could ever simultaneously be "a good approximation to \$247" and "a good approximation to \$1044." Hanemann ${ }^{173}$ pointed out in 1991 that if the policy under consideration were, for example, your own life - as it would be if doing a Cost-Benefit Analysis of positioning a potentially-explosive gas pipeline close to your house - "there is no reason why WTP and WTA could not differ vastly: in the limit, WTP could equal the individual's entire (finite) income, while WTA could be infinite." Since nothing could be a good approximation to both a finite WATP and an infinite WTA, it would be pointless to look for an approximation to both WATP and WTA in Setting Qi, and this reasoning extends to Setting Qq, as we mentioned in connection with Figure 5.

\section{E. Another Problem with "Wealth Maximization"}

Section V.B already showed that the first word in Posner's famous phrase "wealth maximization" is inappropriate, but we can now see that the second word, "maximization," is inappropriate as well, for a completely different reason. In the Kaldor-Hicks approach, value has a dual nature, so it is not a function and, therefore, cannot be maximized, as discussed in Section IV.A.2. Posner's use of "maximization" shows that Posner is not actually following the Kaldor-Hicks approach, but rather the social surplus approach, which falsely holds that value is unitary and hence can be maximized.

It is clear that one of the main characteristics and flaws of the consumer surplus approach is that it represents value by a single number. It is this insistence on a single number that makes it appear that value maximization is possible, even though it is not. The insistence on a single

\footnotetext{
${ }^{171}$ We have been discussing changes in consumer surplus resulting from a price change-Setting Pi, as noted above. Another type of change in consumer surplus results from a quantity change_-Setting Qi. Using Hicks's language as described in supra note 93, Setting Pi consumer surplus is an approximation to Setting Pi "priceequivalent variation" and "price-compensating variation," not to Setting Qi "quantity-equivalent variation" and "quantity-compensating variation."

172 Jack L. Knetsch, Biased valuations, damage assessments, and policy choices: The choice of measure matters, 63 Ecological Economics 684, 685 (2007).

${ }^{173}$ W. Michael Hanemann, supra note 81. See also Mishan, supra note 69 at 19. Also, Richard T. Carson and W. Michael Hanemann, supra note 125 at 907, say that "WTA could be infinity while WTP was a small positive number" and explain further: "Randall and Stoll (1980) were the first to expand Willig's framework to consider the imposed quantity changes but the full import of the differences between the two cases was not clear until Hanemann (1991). The discovery of these differences first found in the context of CV studies, coupled with the initial belief that Willig's results were more widely applicable, caused some researchers to claim the observed CV results violated economic theory. Hanemann (1991), in a standard neo-classical theoretical framework, shows that for imposed quantity changes, WTP and WTA can be infinitely far apart due to interactions between income and substitution effects. Kahneman and Tversky (1979) had earlier put forth an alternative they called 'prospect theory' where losses are valued more highly than gains."
} 
number also, as stated in the introduction to this Part, functions like proverbial rose-colored glasses, hiding the problems of EV not equaling $\mathrm{CV}$, and the attendant inconsistencies, incompleteness, and arbitrariness that follow.

\section{F. Normative Issues in Using Consumer Surplus}

As with the Potential Pareto approach, consumer surplus theory suffers from normative as well as positive problems, and some of those normative problems are almost the same as the normative problems of the Potential Pareto approach. Policy decisions using the consumer surplus standard work by adding up the consumer surpluses of different people, just like policy decisions using the Potential Pareto approach work by adding up the CVs or EVs of different people. This means that, just like the Potential Pareto approach, the consumer surplus approach is coercive, with "winners" and "losers," and approves policies in which, ex post, the winners could in theory give enough surplus (which means enough money) to the losers to make everyone gain in surplus, even if the winners will not actually give any money to the losers. The very serious normative problems arising from adopting a policy which hurts people, based on the existence of a different policy which hurts no one, were well covered in Part IV.

In one important aspect, though, the surplus approach is normatively worse than the Potential Pareto approach. The Potential Pareto approach is built upon CV and EV (WATP and WTA), and even though Potential Pareto puts CV and EV to a bad use, CV and EV themselves are quite useful: they are exact measures of value. CV and EV could even be put to use, by for example a mediator, to construct an actual Pareto-improving policy (as in Section IV.A.7), and it is this "potential" for doing good - though never to be realized under the Potential Pareto approach - that gives the Potential Pareto approach what pitifully little normative attraction it has. The surplus approach does not even have this. A mediator, knowing each person's surplus changes (but not their CV and EV), would not know enough to be able to construct an actual Pareto-improving policy. This is because unlike $\mathrm{CV}$ and $\mathrm{EV}$, which are tightly connected to utility via their links to indifference curves, knowing surplus changes is insufficient to allow one to determine whether a policy has caused the net utility of any individual to go up or down. If the State increases the price of apples from one to two dollars per pound, and if Smith's CV (WTA) for this action is \$5, then we know that giving Smith less than $\$ 5$ will leave her worse off, giving her $\$ 5$ will leave her equally well off, and giving her more than $\$ 5$ will leave her better off than she was originally. But if instead of knowing Smith's WTA, we only knew Smith's loss of surplus - which will not be $\$ 5$ unless there is exactly zero income effect — we would have no way of knowing what payment to Smith would leave her as well off as she was originally. ${ }^{174}$ As Paul Samuelson wrote in 1947, in a book section entitled "Why Consumer's Surplus is Superfluous," any questions one might use

\footnotetext{
${ }^{174}$ If one, in addition, happened to know that the typical but not universal inequality WATP $<$ WTA applied in this case, one could infer that (with "CS" standing for consumer surplus) WATP $<$ CS $<$ WTA from Willig's result, and so would know that WTA > CS, but that would only imply that the payment to Smith which would leave her equally as well off as before was larger than CS; it would not reveal how much larger than CS that payment would have to be. Similarly, if one knew that WATP $>$ WTA then the payment to Smith which would leave her equally as well off as before would be smaller than CS; but it would not be known how much smaller than CS that payment would have to be.
} 
consumer surplus to answer "can more conveniently (and more honestly!) be answered in terms of the consumer's ordinal preference field." 175

Consumer surplus depends on wealth because individual demand curves depend on the individual's wealth; in the typical case of normal goods, consumer surplus is an increasing function of wealth. This is just like WATP. Thus, it follows that the consumer surplus criterion has the same "preference for the wealthy" that the Potential Pareto approach has. When consumer surplus's "preference for the wealthy" is coupled with its positive characteristics - its ability to be maximized, and its lack of consistency problems, both resulting from the fact that it measures value incorrectly-it becomes an attractive tool to promote Neoliberalism (unscrupulously).

With "consumer welfare" we have reached an end of the road, much like we reached with the Kaldor-Hicks Criteria and with Pareto Efficiency: none of these alternative versions of economic efficiency meet either the positive or the normative standards society would want a decision-making method to have.

\section{CONCLUSION}

Economics can undoubtedly make important contributions to legal analysis. For example, econometric techniques can be used to analyze data and draw conclusions about the impact of legal violations. Economics may be able to model the impact of changes in policy or even suggest Pareto efficient settlement structures in mediation. What economics cannot do is offer a scientific method for making legal decisions; yet, this is precisely what the "law and economics movement" purports to do.

L\&E claims to do this by offering a "value-free" decision principle of "efficiency" but those claims are bankrupt.

The Pareto version of efficiency is not value-free, and it cannot rank situations in which there is a loser, which is essentially all situations in U.S. courts.

The Potential Pareto approach of Kaldor and Hicks likewise fails to provide a viable measure of efficiency for the law. In a pure-exchange economy, the Kaldor version of efficiency is value-free but also content-free, and the Hicks version is not much better. And in all economies, the Kaldor and Hicks versions of efficiency raise deeply troubling normative problems.

L\&E's resort to consumer surplus theory is similarly unavailing. The surplus version of efficiency is based on the fallacy that "value does not have a dual nature," which it clearly does.

All of these defects manifest themselves in L\&E textbooks. Their main problem is not that some of them have a crude understanding of normative issues, nor that most of them think they are using the Kaldor-Hicks approach when they are in fact using the surplus approach - though those are certainly problems. The main problem with L\&E textbooks is that they attempt to

\footnotetext{
175 Paul A. Samuelson, Foundations of Economic Analysis 197 (Atheneum 1979; first published by Harvard University Press 1947). Samuelson points out (id. at 198) that he published most of his criticisms of consumer surplus already in 1942 (id. note 20).
} 
give economic efficiency, in any form, a status it should not have. Economic efficiency is not about justice, but the law presumably is. Accordingly, L\&E's obsession with efficiency, whether real or contrived, has little place in the law.

In contrast, economic efficiency definitely has an important, almost indispensable, place if one's view of the law's purpose is not in dispensing justice, but rather in imposing on society the will of the well-to-do. ${ }^{176}$ The well-to-do fare nicely under each of L\&E's efficiency notions: under Pareto efficiency, they cannot be hurt; under surplus efficiency, their desires get heavier weight per capita than the desires of others; and under Kaldor-Hicks efficiency, not only is their "willingness and ability to pay" and usually their "willingness to accept" higher than others', but also their wealth often enables them to set the agenda of the State, giving them large, sometimes insuperable advantages.

Some of our work has been novel, in particular our demonstration of inconsistencies in Setting Qq, our characterization of Hicks-improving and Kaldor-improving policies in a general framework (building on Hayashi), and our discovery that when L\&E authors refer to "KaldorHicks" they almost without exception do not mean what economists understand "KaldorHicks" to mean; rather, the L\&E authors almost always misidentify the surplus approach as "Kaldor-Hicks." But much of what we have done is to weave together the critiques that others have made concerning the various notions of efficiency. Marshall knew about the flaws of the surplus approach a century ago, although he downplayed them (supra note 162). For the Potential Pareto/Kaldor-Hicks/“Cost-Benefit Analysis” approach, we have cited leading welfare economists John Chipman and James Moore. They concluded that:

Unfortunately, as we have seen, the welfare criteria suggested by Kaldor and Hicks, even with the qualifications added by Scitovsky and Kuznets, could not escape the possibility of giving rise to an inconsistent sequence of policy recommendations, unless either the distribution of income and wealth or the forms and degree of dissimilarity of consumers' preferences were assumed to be suitably restricted. [...W]e are forced to come back to Robbins' 1932 position. We cannot make policy recommendations except on the basis of value judgments, and these value judgments should be made explicit. ${ }^{177}$

Most expert economic theorists from the mid-twentieth century to today-authors such as Samuelson, Blackorby, Donaldson, Deaton, Hammond, and Fleurbaey - agree with this assessment. The arguments on the other side have been weak; as the next quotation shows, Kaldor's response to Robbins comes very close to saying that economists should dissemble in

\footnotetext{
176 Similar: "Jurisprudence is but the will of your class made into a law for all." Marx and Engels, The Communist Manifesto, Part II (Progress Publishers 1969 (first published 1848))

(https://www.marxists.org/archive/marx/works/1848/communist-manifesto/ch02.htm). In the original German:

"...euer Recht [ist] nur der zum Gesetz erhobene Wille eurer Klasse...." (https://www.marxists.org/deutsch/archiv/marx-engels/1848/manifest/2-prolkomm.htm).

177 John Chipman and James Moore, supra note 98 at 548, 581. See also renowned welfare economist E. Mishan, "Criteria based on compensation tests have turned out to be untrustworthy, indeed misleading;" in E. Mishan, Introduction to Normative Economics, Oxford (1981) at 368.
} 
order to protect their jobs, ${ }^{178}$ a response so weak that for all intents and purposes it refutes itself:

If the incomparability of utility to different individuals is strictly pressed, not only are the prescriptions of the welfare school ruled out, but all prescriptions whatever. The economist as an adviser is completely stultified, and unless his speculations be regarded as of paramount aesthetic value, he had better be suppressed completely.

If Kaldor's motivation was protecting economists' jobs, it is hard to imagine that none of the participants in the L\&E movement had a grander motivation: to advance a questionable and in our opinion false value judgment - the superiority of the neoliberal free market ideology - by camouflaging it under the cloak of efficiency, the latter presented as a coherent and useful methodology to resolve real-world legal disputes. We have seen that there were voices in legal scholarship who were troubled by L\&E from the start - voices like Coleman, Samuels, Baker, and Hale. But they have been drowned out in L\&E, as voices critical of the Potential Pareto and surplus approaches have been drowned out in some other subdisciplines of economics, by the voices of economists who have convinced many non-economists of the falsehood that economics can solve disputes and controversies in an objective, scientific, just way. We hope to have convinced the reader that this is not true.

Except for a few remarks in infra note 192, we have refrained from discussing where we think L\&E should go from here. L\&E should accept that economic efficiency is an inappropriate goal for society, inappropriate for the reasons the famous economic historian R.H. Tawney pointed out in his 1920 book The Acquisitive Society: ${ }^{179}$ efficiency in wealth acquisition is at most a subsidiary objective because wealth itself ought to be the means to an end, not the end itself. Modern welfare theorists are clear that policy decisions need to have ethical and moral, not economic, concerns as their prime motivations. If we accept Robbins' famous definition of economics as ${ }^{180}$ the "relationship between ends and scarce means which have alternative uses," then ecological economist Herman Daly ${ }^{181}$ makes the illuminating point that the economist's ends-means spectrum consists of ultimate means (scarce natural resources), intermediate means (technology), intermediate ends (being fed, being clothed), and the ultimate end; and so what economic wisdom calls for is employing the first three of these in service of the final one. The reason that Robbins, and later Chipman and Moore, called on us to have "confidence in

\footnotetext{
178 Nicholas Kaldor supra note 63 at 549.

179 Richard Henry Tawney, The Acquisitive Society (Harcourt, Brace \& Co. 1920). Available at https://www.gutenberg.org/files/33741/33741-h/33741-h.htm or

https://books.google.com/books?id=NZ7dbq3GCcUC\&printsec=frontcover\&source=gbs ge summary $\mathrm{r} \& \mathrm{cad}=0 \#$ $\mathrm{v}=$ onepage\&q\&f=false.

${ }^{180}$ Lionel Robbins, An Essay on the Nature and Significance of Economic Science 15 (MacMillan and Co. 1935). Available at https://scholar.google.com/scholar lookup?title=An+Essay+on+the+Nature+and+Significance+of + Economic + Sci ence\&author $=$ L. + Robbins\&publication year $=1935 \&$.

${ }^{181}$ Herman E. Daly, Introduction to Essays toward a Steady-State Economy, in Herman E. Daly and Kenneth N. Townsend, supra note 143.
} 
ultimate values"182 is that that is what is required for each of us to specify what we believe the ultimate end is. Despite such confidence, philosophers, religious leaders, and ordinary people will have many viewpoints as to what the ultimate end is, and thus what proper economic and political policies and judicial philosophies to support. The controversies arising from those conflicting viewpoints are an enduring part of the human condition and as such are never going to be short-circuited by economics, regardless of the genuine value economics has in illuminating the tradeoffs they embody.

182 This phrase comes from Robbins, supra note 49 at 639, which Chipman and Moore, supra note 98, used as an epigraph to their paper: "Was it not only the timidity of an age which had lost all confidence in ultimate values which led us to attempt to claim 'scientific' justifications for attitudes which in the nature of things could not be justified (or refuted) by appeal to laboratory methods?" 


\section{APPENDIX 1: “EFFICIENCY” AS TAUGHT IN LAW \& ECONOMICS TEXTBOOKS}

A reader familiar with the material we have covered so far is well-equipped to uncover the concepts of efficiency presented in L\&E textbooks for what they really are, rather than what they purport to be or what their authors believe them to be.

It would be a gratuitous anachronism to criticize any of these textbooks for failing to incorporate the material in our Section IV.K, which is new; so we will set IV.K's material aside in this Part. As regards the Separation Hypothesis between distribution and "efficiency," and the "pie" analogy between distribution and "efficiency," this does mean setting aside Section IV.K's findings about their validity when "efficiency" is taken in either the Kaldor or the Hicks sense. In Part V we did not investigate their validity when "efficiency" is taken in the surplus sense. In Section III.G.1(c) we determined they were invalid when "efficiency" is taken in the Pareto sense. Below we will point out, without judgment, which authors make use of the Separation Hypothesis or the "pie" analogy.

We begin with the textbook by Posner, whose earlier editions set the background for all the other textbooks.
A.
Posner (2014)

In the ninth (2014) edition of Economic Analysis of Law, ${ }^{183}$ Posner introduces Pareto Efficiency, but quickly writes, ${ }^{184}$ "the conditions for Pareto superiority are rarely encountered in the real world," and then moves to adopt a different notion of efficiency. This patternintroducing Pareto Efficiency, saying its relevance is limited, then dismissing it and moving on to a different definition of efficiency - is a very common approach in the L\&E textbooks we review, and it dates back at least to the third (1986) edition of Posner's book. ${ }^{185}$

Posner writes: ${ }^{186}$

The economic value of a good or service is how much someone is willing to pay for it or, if he has it already, how much money he demands for parting with it. These are not always the same amounts, and this can cause difficulties, which we shall consider later.

In the first sentence, Posner is trying to express WATP and WTA, but his definition is not quite right. WATP and WTA are different ways of valuing the same policy, either gaining "a good or service" or not gaining that same "good or service." Posner instead is defining WATP in the context of gaining the good (say, a policy of going from 3 to 4 bananas) and WTA in the context of losing a good (say, a policy of going from 3 to 2 bananas). This is the error Hanemann describes in supra note 89 . The second sentence is a commendable observation that WATP is not always equal to WTA. Unfortunately, when Posner takes up that issue "later," it is in his section entitled "Irrationality and Hyperrationality: Herein of Behavioral Economics

\footnotetext{
${ }^{183}$ Richard A. Posner, Economic Analysis of Law 14 (Wolters Kluwer $9^{\text {th }}$ ed 2014).

${ }^{184}$ Id. at 14.

185 Richard A. Posner, Economic Analysis of Law 12 (Little, Brown $3^{\text {rd }}$ ed 1986).

${ }^{186}$ Supra note 183 at 13.
} 
and Game Theory," where ${ }^{187}$ he incorrectly suggests that WATP is equal to WTA for rational consumers. ${ }^{188}$ Fortunately, he later backs away from that error and acknowledges wealth effects. ${ }^{189}$

Posner gets into more permanent trouble when explaining the meaning of "the Kaldor-Hicks concept of efficiency." Instead of presenting a definition, he develops it by presenting an example of a transaction that "the concept" would endorse. The example begins, "if A values the wood carving at $\$ 50 \ldots . . .190$ That alone is enough to bring an economist to a dead stop. What does that mean? Is the $\$ 50$ the WTA value that A would accept to give up the wood carving A currently possesses? The WATP value that A would pay to avoid giving up the wood carving A currently possesses? The WATP value that A would pay to re-obtain the wood carving if it has been transferred to B? The WTA value to compensate A for not re-obtaining the wood carving once it has been transferred to B? Posner does not say. In effect, while Posner admits that WATP may not equal WTA, he fails to appreciate the most important consequence of that inequality, which is that "value" has a dual nature.

Posner's cavalier treatment of value is reflected in his equally cavalier use of language. He tells the student he is using "the Kaldor-Hicks concept of efficiency." He also writes about "the value to consumers, as measured by their willingness to pay;" 191 of course, "willingness (and ability) to pay" is one of the main concepts of the Kaldor-Hicks approach. However, the fact that Posner treats value as being unitary instead of dual, and that Posner treats value as something that can be maximized, as in his phrase "wealth maximization", means that despite his claim Posner is not actually following the Kaldor-Hicks approach. (We first pointed this out in Section V.E, based on other writing by Posner.) Kaldor-Hicks acknowledges the dual nature of value - that is actually why the approach bears both names: one aspect of value is illuminated by Kaldor and the other by Hicks. An approach that does not acknowledge the dual nature of value simply is not a Kaldor-Hicks/Cost-Benefit Analysis/“Potential Pareto" approach. The only other approaches are: the Pareto approach, which Posner has rejected; the modern "social welfare function" approach, ${ }^{192}$ which makes ethical positions transparent and

\footnotetext{
${ }^{187}$ Id. at 19.

188 There are texts in environmental economics that come close to making this error; see supra note 94.

189 Supra note 183 at 20.

${ }^{190} I d$. at 14.

${ }^{191} I d$. at 12.

${ }^{192}$ For some properties and examples of using social welfare functions see: Mas-Colell, Whinston, and Green, supra note 55 at Chapter 22; Blackorby and Donaldson, supra note 114 at 492-3 and supra note 123; Daniel L. Slesnick,, Empirical Approaches to the Measurement of Welfare, 36 J. Economic Literature 2108-2165 (1998); the book-length treatment of Marc Fleurbaey and Didier Blanchet, Beyond GDP: Measuring Welfare and Assessing Sustainability (Oxford University Press 2013); and discussions of the Human Development Index, the Index of Sustainable Economic Welfare, the Genuine Progress Indicator (GPI), gross national happiness (GNH), sustainable national income (SNI), for example at https://en.wikipedia.org/wiki/Measures of national income and output. Supra note 145's idea of an incomeadjusted $\mathrm{CV}$ or EV can be thought of as implicitly embodying a social welfare function approach. So is the practice of conducting Cost-Benefit Analysis using “distributional weighting," as described in Matthew D. Adler and Eric A. Posner, Rethinking Cost-Benefit Analysis, 109 Yale Law J. 165-247, 193 and its note 80 (1999). (The "Impossibility Theorem" of Economics Nobel Laureate Kenneth Arrow showed that there is no guaranteed way to make social decisions being sensitive to the opinions of everyone. The "social welfare function" approach does
} 
paramount, and so is antithetical to Posner's point of view; and the social surplus approach, which, by process of elimination, must be what Posner is actually following.

Posner's error of calling the social surplus approach "the Kaldor-Hicks approach" has had a profound influence on L\&E: it is repeated by most of the textbooks that we discuss below. How textbooks have managed to get away with calling the fundamental, unifying concept in all of Law and Economics, its concept of efficiency, by the wrong name is puzzling, but the pedagogical effect is clear: students will have no idea that the real Kaldor and Hicks Tests are actually different from each other and can be inconsistent, nor, equivalently, that economists' actual value measures, EV and CV or WATP and WTA, are different from each other and that that means value has a dual nature and is not something that can be maximized.

The ideological consequence of this error is also clear: in this way, L\&E textbooks guarantee that students are indoctrinated into the simplistic and fallacious "social surplus maximization" dogma, with its false message that it is conceptually easy to measure economic efficiency and theoretically possible to maximize it, and with its "preference for the rich" always present but rarely illuminated by an author - although to be fair, Posner does point out "the preference for the rich," as we discuss in the paragraph after next, and so do Seidenfeld and Barnes \& Stout.

It is useful here to recall the historical context. The social surplus approach is a modern expansion of the consumer surplus approach that Marshall used. Kaldor's idea of CV was $a$ (not "the") correction of that surplus approach, and Hicks's idea of EV is another correction of the surplus approach to value. Critically, Kaldor and Hicks wrote in opposition to the very ideas that Posner is presenting under the "Kaldor-Hicks" name. The effect of this is to protect Posner's approach from deserved criticism because, as we know from Part V, the surplus approach has even more flaws than the approach Kaldor and Hicks actually endorsed-and Part IV showed that the approach Kaldor and Hicks endorsed has flaws aplenty.

Enough about Posner's positive economics. (For more on Posner's positive economics, as reflected not in his textbook but in his scholarly writing, see Appendix 2.) As for Posner's normative economics, he begins in a promising way: ${ }^{193}$

But what if $A$ in our example valued the wood carving at only $\$ 70$ and B at $\$ 120$ not because A likes wood carvings less than B - he may like them much moreand not because there is any appealing concept of deservedness that B might invoke to validate his claim to be able to buy the wood carving, but rather because $\mathrm{A}$ is destitute and has to sell his wood carving in order to eat, while $\mathrm{B}$, rather than being passionate about wood carvings, merely wants to diversify his enormous wealth by holding a variety of collectibles. These circumstances are not inconsistent with the sale's making both A and B better off; on the contrary, they explain why it makes both better off. But the circumstances undermine the moral foundations of a social system oriented to Pareto superiority, let alone potential Pareto superiority, by showing that the pattern of consumption and production is determined by the distribution of wealth. If that distribution is

not try to be sensitive to the opinions of everyone - though it is usually sensitive to the personal utility of everyone - and so is not affected by Arrow's result.)

${ }^{193}$ Id. at 15. 
unjust, the pattern of economic activities derived from it will not have a strong claim to be regarded as just either. And insofar as the distribution of wealth is itself largely determined by the market, the justice of the market cannot be derived from some independent notion of the just distribution.

However, Posner's naïve understanding of value completely derails this train of thought: 194

Because economics cannot tell us whether the existing distribution of income and wealth is good or bad, just or unjust, the economist cannot issue mandatory prescriptions for social change. Yet this turns out to be less of a handicap to the normative use of economics than might appear. Economists can usually appeal to a generally accepted goal, such as maximizing the value of output, rather than having to defend the goal.

We know from Section III.G.1(c) that "the value of output" reflects the existing distribution of wealth, so choosing this goal is not value-neutral. This goal probably is, we regret to admit, "generally accepted"; however, it is so only in the sense that it is consistent with the preferences of those at the top of the income distribution, who usually "call the shots." We also agree with Posner that "economists"- meaning Kaldor and Hicks and Harberger but not Blackorby or Donaldson or Hammond or Chipman or Moore or Paul Samuelson - rarely in practice have to "defend the goal," even though we think they ought to be forced to do so; rather, the State usually defends the goal on behalf of the politically powerful. "The State" obviously includes the courts (whom Posner is implicitly instructing to "defend the goal"). With this flimsy reasoning, Posner unfortunately retreats from the conclusion he earlier came to, that the Potential Pareto approach "will not have a strong claim to be regarded as just." (As we pointed out earlier, what Posner thinks of as the potential Pareto approach is really a surplus approach, so the topic is the justice of a surplus approach, not the justice of the actual potential Pareto approach; but the surplus approach inherits all the normative problems of the Potential Pareto approach, as discussed in Section V.F.)

B. Harrison and Theeuwes (2008)

Jeffrey Harrison and Jules Theeuwes ${ }^{195}$ begin by teaching the "social surplus" approach to value. They write, ${ }^{196}$ "the point is that when economists speak in terms of social welfare, they mean the sum of both consumer and producer surplus," though of course experts in welfare economics such as Blackorby, Donaldson, Hammond, and Deaton do not mean this, because of all the problems with the "surplus" approach we discussed in Part V.

Later, Harrison and Theeuwes discuss Pareto, "Kaldor-Hicks," and "wealth maximization" in a way common to L\&E textbooks ${ }^{197}$ and hewing roughly to the pattern in the third edition of Posner's textbook: they introduce Pareto Efficiency; dismiss it because it cannot rank all choices; introduce "The Kaldor-Hicks Criterion" as a replacement for Pareto Efficiency; define it using an example (here, an autographed copy of Crime and Punishment instead of Posner's

\footnotetext{
${ }^{194} I d$. at 16.

${ }^{195}$ Jeffrey Harrison and Jules Theeuwes, Law and Economics (WW Norton 2008).

${ }^{196} I d$. at 25 .

${ }^{197} I d$. at $26-29$.
} 
wood carving); and give the process of applying the "Kaldor-Hicks Criterion" the synonym "wealth maximization"- both "wealth" and "maximization" being words that are deeply problematic for the different reasons discussed in Sections V.B and V.E.

Harrison and Theeuwes do specify, when discussing "the Kaldor-Hicks Criterion," that they wish to compare the WTA of the book's owner and the WATP of a new potential owner of the book with regard to a single policy: transferring the book from its current owner to a new owner. This precision is an improvement over Posner's treatment. However, there is also the possibility of the book's owner being willing and able to pay the potential new owner not to take the book, and the potential new owner's WTA not to take it, and Harrison and Theeuwes do not consider these WATP and WTA. In short, they ask Kaldor's question but not Hicks's.

Also, Harrison and Theeuwes attempt to analyze "wealth maximization" as literal maximization of something called "wealth"; 198 that only sows confusion because the Potential Pareto approach does not literally maximize anything, only surplus approaches do that.

Turning to Harrison and Theeuwes' normative treatment, we find it quite a bit inferior to Posner's. They write, speaking about Hicks: ${ }^{199}$

He [Hicks] also tackled the question of whether the hypothetical transfers ought to actually take place when a policy is enacted. He admits there is no decent answer, as the question is distributive and is based on moral and political concerns. Mainly, he points out that distributive questions should not hamper policies that clearly increase efficiency.

The second sentence is exactly what Chipman and Moore had in mind when they criticized proponents of the Potential Pareto approach for wanting "to wash one's hands of the responsibility for one's own actions" (supra Section IV.B and note 98). (In this respect the Potential Pareto and surplus approaches share identical normative positions.) Such proponents advocate State confiscation of private property as beneficial to the "welfare of the members of society" (when the Kaldor or Hicks Tests are passed); but when asked whether the losers should be compensated, they say that the welfare of those members of society is, on the contrary, none of their business - a response as illogical as it is cowardly. Recall Chipman and Moore's echo of Robbins's call for "confidence in ultimate values" instead of "timidity" (supra note 182), and for that matter see all the normative criticisms of the Potential Pareto approach in Sections IV.B, IV.F, IV.H, IV.J, and IV.K, and the very similar normative criticisms of the surplus approach in Section V.F.

The third sentence in Harrison and Theeuwes' quote is the Separation Hypothesis, the idea that distribution is separate from efficiency, disproven as regards Pareto efficiency in Section III.G.1(c). The fourth sentence links the Separation Hypothesis with the contradictory position that distribution is not separate from efficiency, but that there is an Equity-Efficiency Tradeoff, which we argued against in Section III.G.1(e). The value of these positions to L\&E's ideological agenda is to provide a "one-two punch" against considerations of distribution, equity, and justice. The first punch is the allegation that distribution is separate from

\footnotetext{
${ }^{198} I d$. at 31.

${ }^{199}$ Id. at 30.
} 
efficiency, and since distribution is totally subjective, while efficiency is an "objective" concept from "economic science," unprejudiced actors should ignore distribution and only make decisions based on efficiency. The second punch is the allegation that more equal distribution actually hurts efficiency, so one's outlook on more even distribution of wealth should not merely be neutral, it should be antagonistic.

Putting these criticisms in perspective, Harrison and Theeuwes only spend two sentences pushing this line of thought; we will see that other authors push it much harder. On the other hand, this problematic line of thought is absent from Posner's textbook.

A praiseworthy aspect of Harrison and Theeuwes is how straightforwardly they admit that "Kaldor-Hicks" is coercive. ${ }^{200}$

$$
\text { C. Hirsch (1999) }
$$

Early in the exposition of Hirsch we read, ${ }^{201}$ "When resources are being used where their value is greatest, they are being employed efficiently, they produce the largest possible output." Unfortunately, at this point Hirsch has not defined the words "value" or "efficiently," nor explained how to measure the size of "output" (it is distribution-dependent, as we remarked in Section III.G.1(c)). This renders the passage meaningless.

On the next page, ${ }^{202}$ Hirsch writes, "The question has also been asked whether value is indeed determined by people's willingness to pay or whether it is not determined rather by people's ability to pay for a good or service." That question indeed has been asked, and it has been answered: income in general affects all demands in neoclassical economics. Beyond this Hirsh does not explain efficiency or value at all. He does not mention Kaldor, Hicks, or "KaldorHicks."

As far as normative concerns, Hirsh writes, ${ }^{203}$

The theory is best equipped to deal with resource-allocation efficiency, but justice and fairness, which relate to distributional issues, must also be considered [citation to John Rawls' A Theory of Justice]. Our task would be so much easier if efficiency could be rigorously defended as the only and ultimate objective. Instead we face two all-too-often opposing objectives-efficiency and equity.

He adds a warning that "virtually every redistribution scheme is costly in that it distorts incentives." 204 While he wrote that efficiency should not be "the only and ultimate objective," his defense of the Equity-Efficiency Tradeoff fallacy ends up being much more insistent than that of Harrison and Theeuwes.

\footnotetext{
${ }^{200} I d$.

${ }^{201}$ Werner Hirsch, Law and Economics: An Introductory Analysis 7 (Academic Press 1999).

${ }^{202} I d$. at 8 .

${ }^{203} I d$.

${ }^{204} I d$. at 9.
} 


\section{Malloy (1990)}

Robin Malloy begins his discussion of Pareto and Kaldor-Hicks efficiency by saying "Economics is constantly concerned with efficiency, or in other words in acting with a minimum of expense, effort, and waste." ${ }^{205}$ Actually, Pareto Efficiency in a pure exchange economy has nothing to do with expense or effort or waste because there is no production. This is not an auspicious beginning.

Malloy also tells the student that "Kaldor-Hicks theory is ... concerned with... whether or not society's aggregate utility has been maximized," 206 which is wrong because "aggregate utility" is a cardinal quantity, and reflects Utilitarian ethics, while Kaldor-Hicks assume only ordinal utility and are not Utilitarian. The surplus approach, which is probably what Malloy means when he instead writes "Kaldor-Hicks," does have Utilitarian overtones, with its directive to maximize social surplus, but it is modern enough to avoid referring to "aggregate utility." Malloy then proceeds to teach Utilitarianism under the erroneous name of the "Kaldor-Hicks approach," measuring "value" in dollars to make value cardinal, with no hint of value's dual nature.

Malloy admits that "Kaldor-Hicks" can justify "a governmental taking," but makes no observations on the normative issues that should raise..$^{207}$

E. $\quad$ Cole and Grossman (2005)

Daniel Cole and Peter Grossman ${ }^{208}$ begin their discussion of efficiency in a way that resembles Hirsch, using important undefined words which we have set in italics: "Productive efficiency concerns the utilization of resources to achieve the highest possible level of production of a desired mix of goods and services. Allocative efficiency relates to the distribution of goods and services in an economy to maximize social welfare." These definitional oversights present more questions than they answer: how is one to measure "level of production"? In what ways is that measure affected by the distribution of wealth? "Desired" by whom? What if different people desire different things? What is "social welfare"? They write next, "When economists discuss efficiency, they most often mean either productive or allocative efficiency," but as we know from Section III.C, when economists discuss efficiency, they most often mean Pareto efficiency, which is a completely relevant concept in pure-exchange economies that have no production and hence no "productive" or "allocative" efficiency, only distributive efficiency.

Cole and Grossman next advance an incorrect definition of Pareto Optimality:209

Let's assume (arbitrarily) that Bill has 50 umbrellas and 50 hats, Hillary 50 umbrellas and 40 hats. If both parties are satisfied with the allocation and cannot be made better off with more hats or umbrellas, then this allocation is considered Pareto optimal. But consider a case where Bill loves hats but feels he only needs

\footnotetext{
${ }^{205}$ Robin Malloy, Law and Economics: A Comparative Approach to Theory and Practice (West Publ. 1990).

${ }^{206} \mathrm{Id}$. at 40.

${ }^{207} \mathrm{Id}$. at 42.

${ }^{208}$ Daniel Cole and Peter Grossman, Principles of Law and Economics (Pearson Prentice Hall 2005) at 10.

${ }^{209} \mathrm{Id}$.
} 
a few umbrellas, while Hillary likes both, but she has more than enough hats and could use a few more umbrellas. [Definition continues...]

Writing "cannot be made better off with more" and "he only needs" and "has more than enough" implies that Bill and Hillary's preferences have reached regions of negative marginal utility, ${ }^{210}$ where more of a good makes a person less well off. Such regions probably exist, but they have nothing to do with the definition of Pareto Optimality, and that definition depends in no way on being in such a region (which consumers in any kind of market would never be observed in anyway, because what rational agent would pay good money for commodity increments that decrease utility?).

A fairly conventional discussion follows, dismissing Pareto Efficiency because it cannot rank all choices, but then there is a twist: ${ }^{211}$

Two economists, Nicholas Kaldor and Sir John Hicks [...] came up with complementary theories, which when taken individually were significantly flawed, but when put together proved useful and robust. [...] Their combined efficiency criterion has come to be known as Kaldor-Hicks efficiency.

In economics (as opposed to L\&E), there is no such thing as "Kaldor-Hicks efficiency." There is a rigorously-defined Kaldor Test; a rigorously-defined Hicks Test; a loosely-defined

"Kaldor-Hicks approach" (or "Potential Pareto" approach) that consists of applying one or both Tests without saying what to do if the Tests contradict each other; and a rigorously-defined Scitovsky Double Criterion (supra note 104), which says that a policy should pass if and only if it passes both the Hicks Test and the Kaldor Test. What economists call the Scitovsky Double Criterion is what Cole and Grossman call Kaldor-Hicks efficiency. On the plus side, in the course of this discussion Cole and Grossman actually define the Hicks Criterion, which none of the other authors did. On the minus side, in Table 1, the Scitovsky Double Criterion would fail both Policy 3 and the reverse of Policy 3 in column $d$ (because both fail Hicks), and it would fail both Policy 1 and the reverse of Policy 1 in column $a$ (because both fail Kaldor), so it has problems of the "the grass is always greener on this side of the fence (regardless of which side of the fence it is)" sort. For more on its positive problems, see supra note 104.

Turning to normative concerns, Cole and Grossman write, ${ }^{212}$ "the Pareto criterion, and much of conventional economic analysis, is concerned with allocating entitlements to resources in order to maximize the welfare of society as a whole." This is wrong because the entire point of the Pareto criterion is to avoid any concept resembling maximization of "the welfare of society as a whole" because Pareto is in opposition to Utilitarianism, not in harmony with it.

On the same page ${ }^{213}$ appears the "pie" analogy of the Separation Hypothesis: Cole and Grossman write, "economics is concerned with the size of the economic pie, not with how the pie is sliced and distributed."

\footnotetext{
${ }^{210}$ The sign of marginal utility is an ordinal characteristic of consumer preferences although its magnitude is not.

${ }^{211} I d$. at $11-12$.

${ }^{212} I d$. at 11.

${ }^{213} \mathrm{Id}$.
} 
Cole and Grossman also write that "efficiency, thus, becomes the economists" proxy for social welfare." 214 That constitutes their definition of "social welfare." They later write that the Scitovsky Double Criterion (which they call "the Kaldor-Hicks criterion") "will be used throughout this book in discussing the efficiency of many [...] decisions that affect resource allocations." 215 Putting these together, Cole and Grossman equate "social welfare" with "using the Scitovsky Double Criterion." With this in mind, their assertion that the Scitovsky Double Criterion "assumes, correctly, that net social welfare can be enhanced by changes in entitlements, even if some individuals suffer losses as a result" 216 means much less than at first appears. It does not mean that the Potential Pareto approach, which advocates for some uncompensated transfers, is "correct." Normative criteria, of which the Potential Pareto approach is one, are impossible to classify as "correct" or "incorrect," instead the question concerning them is whether they are just or unjust (and "consistent" or "inconsistent," and "arbitrary" or "non-arbitrary," and "complete" or "incomplete"). All Cole and Grossman's sentence actually does is to confirm that the Scitovsky Double Criterion fits under the "Potential Pareto" umbrella of criteria which assume, controversially as we know, that some policies which hurt some people are good for society.

$$
\text { F. } \quad \text { Miceli (2004) }
$$

Thomas Miceli goes through the typical steps of defining Pareto Efficiency; dismissing it because it cannot rank all choices; and introducing a vaguely defined "Kaldor-Hicks Criterion" in its place. By "vaguely defined" we mean that Miceli writes: ${ }^{217}$

...suppose that the movement [...] yielded person two an increase in wealth of $\$ 500$ but cost person one $\$ 400$. Person two would thus still enjoy a net gain of $\$ 100$ after compensating person one....

But Miceli has not defined "wealth," nor described how its increase was measured (WATP for receiving a good? WTA if he had not received it?). Similarly, he does not precisely describe what the \$400 “cost" actually is (WATP for foregoing the movement? WTA compensation for the movement?).

Miceli gives the "Kaldor-Hicks Criterion" its usual misleading synonym "wealth maximization." As in Harrison and Theeuwes, Miceli takes "wealth maximization" literally: "if all changes dictated by Kaldor-Hicks were made, aggregate wealth would be maximized." 218 By now, we all recognize this error: value, having a dual nature, cannot be maximized, so this concept is flawed, almost certainly constituting a "social surplus" error; and for "wealth" refer as usual to Section V.B.

\footnotetext{
${ }^{214} I d$. at 10.

${ }^{215} \mathrm{Id}$. at 12 .

${ }^{216} I d$.

${ }^{217}$ Thomas Miceli, The Economic Approach to Law 6 (Stanford Economics and Finance 2004)

${ }^{218} I d$.
} 
Turning to normative concerns, Miceli very briefly appeals to the Equity-Efficiency Tradeoff fallacy ${ }^{219}$ and he also makes use of the "pie" analogy of the Separation Hypothesis. ${ }^{220} \mathrm{He}$ is our first author to supply a "Package Potential Paretian" argument ${ }^{221}$ of the sort we criticized in Section IV.I. On the plus side, in that same section Miceli straightforwardly admits that Kaldor-Hicks embodies "nonconsensual exchange."

\section{G. Friedman (2000)}

Near the beginning of the chapter on efficiency in David Friedman's L\&E textbook ${ }^{222}$ we read the following passage:

How do you put a pie containing everything that happens to every human being on earth, or even in the United States, on a scale, so as to get a single measure of its size? A little over a hundred years ago an economist named Alfred Marshall proposed a solution to that problem. It is not a very good solution. It is merely, for many although not all purposes, better than any alternative that anyone has come up with since. Marshall's argument starts by considering some change [...] The result of the change is to make some people better off and some worse off. In principle one could measure the magnitude of the effects by asking each person affected how much he would, if necessary, pay to get the benefit (if the change made him better off) or prevent the loss (if it made him worse off). If total gains were larger than total losses, making the net effect positive, we would describe the change as an economic improvement. ${ }^{223}$

"Willingness to pay" is Kaldor and Hicks, not Marshall, who used the older, surplus approach to measuring value. However, underlying Friedman's mistaken attribution is that Friedman, alone among these L\&E authors, correctly realizes the point we made when discussing Posner's positive economics: although most L\&E authors call their approach "Kaldor-Hicks," because it has none of Kaldor and Hicks's "dual nature of value" aspects, their approach is actually the "consumer surplus" approach of Marshall (perhaps updated to include different types of surpluses). L\&E textbooks should change from describing their approach to efficiency as "Kaldor-Hicks" to adopting Friedman's practice of calling it "Marshall's approach."224 Friedman, in turn, should stop using "willingness to pay" language, which is part of the KaldorHicks approach, and start using the language of the social surplus approach.

Friedman does not point out the positive problems of the social surplus approach ("Marshall's approach") which were outlined in Part V and which Kaldor and Hicks fixed by elucidating the dual nature of value.

\footnotetext{
${ }^{219}$ Id. at 3, "competing goals."

${ }^{220}$ Id. at 6.

${ }^{221} I d$.: "The hope is that those who lose from one policy will benefit from others and that, on net, everyone will gain as aggregate wealth is increased."

222 David Friedman, Law's Order 18 (Princeton Univ. Press 2000).

${ }^{223}$ Id.

${ }^{224}$ Id. at 19.
} 
Friedman admits the normative dependence-on-income flaw of "Marshall's approach" but defends that approach in five ways.

First, he posits that "the [alternative] statement that we should choose just rules, while emotionally satisfying, does not convey much information." 225 This conclusion carries very little force. The Equal Protection Clause of the $14^{\text {th }}$ Amendment to the U.S. Constitution "does not convey much information" either ("nor shall any State ... deny to any person within its jurisdiction the equal protection of the laws"), but that does not mean we ignore it. Justice is a valid goal even though figuring out how to do it is hard work.

Second, Friedman proffers that "In many cases principles we think of as just correspond fairly closely to rules that we discover are efficient."226 Evidently then one can perceive justice, contrary to what Friedman argued in the last paragraph - so why not pursue it directly?

Third, he suggests that "Defining value by what I act to get may not always give the right answer, but it is hard to see how one can do better." 227 One might instead propose this way to do better: define someone's values by what they act to get when their income is doubled, or tripled, or equals the income of Bill Gates. Then you will be able to see that they really do value their childrens' health; the reason you cannot see that now, when they are "choosing" to live next to a toxic waste dump, is because that is the only place they can afford to live.

Fourth, Friedman opines that " "pro-rich' or 'pro-poor"” laws are usually neither."228 Even if true, it is unclear how this is a valid defense for the surplus approach.

Fifth, Friedman resorts to the pie analogy. ${ }^{229}$

After this, Friedman gets around to introducing Pareto Efficiency and attacking it:230

If we want to make an overall evaluation of the effects of such changes, we are stuck with the problem of balancing gains to some against losses to others, a problem that Marshall solves, even if imperfectly, and Pareto only evades. It is therefore Marshall's approach defining economic improvements and the efficiency of legal rules that I will be using - and that other economists routinely use, whether or not they say so.

[...] I consider the Paretian approach that [readers] encountered in their textbooks, along with the more elaborate version due to Hicks and Kaldor that they may have also encountered, evasions of, not solutions to, the problem of evaluating changes that affect many people in a variety of ways.

\footnotetext{
${ }^{225} \mathrm{Id}$. at 22 .

${ }^{226}$ Id.

${ }^{227}$ Id. at 23.

${ }^{228} \mathrm{Id}$.

${ }^{229} \mathrm{Id}$. at 24.

${ }^{230} \mathrm{Id}$. at 25 .
} 
We have already demonstrated the fallacy of these statements. Contrary to Friedman's second sentence, when economists discuss efficiency, they most often mean Pareto efficiency, not "Marshall's approach" (see Section III.C and our discussion of Cole and Grossman). As for the first sentence and the last, rather than "solving" the problem of balancing gains and losses, "Marshall's approach" suffers from all the problems detailed in Part V. Indeed, "Marshall's approach" is inferior to the Potential Pareto approach of Kaldor and Hicks because it makes the (positive) mistakes we pointed out in discussing Figure 20, the very same mistakes that prompted Kaldor and Hicks to write in the first place. Of course, the Potential Pareto approach has problems too. That is why, if the "other economists" Friedman is referring to are modern theorists of welfare economics, most of them are going to use a "social welfare function" approach; ${ }^{231}$ the only choices are not Pareto, Kaldor-Hicks, or Marshall.

H. Cooter and Ulen (2004)

Robert Cooter and Thomas Ulen start with the Separation Hypothesis: "we will focus on efficiency not distribution." 232 They then supply four arguments to support their position that "private legal rights are usually the wrong way to pursue distributive justice."233

Their first argument is that the income tax system is a better instrument to reduce income inequality. Without expressing an opinion on that, "income inequality" is not the only concern of distributive justice. Changing income taxes is not going to give rise to less deadly working conditions for meatpackers during a pandemic, for example.

Their second argument is that "the distributive effects of reshuffling private rights are hard to predict." 234 This is no doubt sometimes true, but as we remarked when discussing Friedman, just because something is hard to do does not mean it is not worth doing.

Their third argument is that attorney's fees are higher than fees of income tax preparers. Yes, but each taxpayer has to pay an income tax preparer, whereas one successful legal action brought on behalf of a class of consumers or workers can benefit large numbers of people now and in the future, so the eventual, per-beneficiary cost of the legal fees could be low.

Last, Cooter and Ulen offer: 235

Besides these three reasons, there is a fourth: redistribution by private law distorts the economy more than progressive taxation does. For example, assume that a law favoring consumers of tomatoes causes a decline in the return enjoyed by investors in tomato farms. Investors will respond by withdrawing funds from tomato farms and investing in other businesses. Consequently, the supply of tomatoes will be too small and consumers will pay too high a price for them.

\footnotetext{
${ }^{231}$ Supra note 192.

${ }^{232}$ Robert Cooter and Thomas Ulen, Law and Economics 8 (Pearson-Addison Wesley $4^{\text {th }}$ Ed. 2004).

${ }^{233} I d$. at 9.

${ }^{234} I d$.

${ }^{235} \mathrm{Id}$.
} 
To demonstrate the fallacy of this reasoning, suppose that a new law protects the health of consumers of tomatoes by limiting the type of pesticides farmers can apply to that crop. On what grounds can Cooter and Ulen argue that the new supply of tomatoes is "too small"? The supply of healthful tomatoes is much larger than it was before. The supply of unhealthful tomatoes has shrunk, which is a good thing. "Too small" compared to what? Similarly, yes, the price of tomatoes will go up, but who is to say the new price is "too high?" Drinking water standards in the U.S. are rather stringent; by Cooter and Ulen's logic, these standards should be made more unhealthful because they cause the price of drinking water to be "too high."

Arguing that lower prices and a filthier, more dangerous environment are always better from an economic point of view is completely fallacious.

Cooter and Ulen conclude "that private legal rights are usually the wrong way to pursue distributive justice. Unfortunately, these facts are generally not appreciated by lawyers who have not studied economics." 236 Unfortunately for Cooter and Ulen, their "facts" fly in the face of the economic arguments given above.

Later, Cooter and Ulen go through the usual procedure of introducing Pareto Efficiency; ${ }^{237}$ dismissing it because it cannot rank all choices; and introducing what they call "The KaldorHicks Criterion," 238 even though their discussion shares none of Kaldor or Hicks's understanding of the dual nature of value. They contemplate difficulties with situations in which "the gainers gain more than the losers lose," with only ten words: "There are both theoretical and empirical problems with this standard." They give no hint to the student that measuring what "the gainers gain" and what "the losers lose" is fraught with difficulties and can give rise to contradictions.

\section{Shavell (2004)}

Shavell's work is not a textbook, and his discussions are much more careful than those of most of the textbooks we have discussed. Shavell describes the "social welfare function" approach to welfare economics, ${ }^{239}$ which is the approach taken by most experts in the field, as described in supra note 192, while other L\&E authors ignore that approach. When Shavell appeals to the "size of the pie" analogy, ${ }^{240}$ he makes not the generic, fallacious-with-respect-to-Paretoefficiency point, but rather a specific point about the cost of tax administration; and while we disagree (because the marginal cost of administering a more-equitable tax regime may be identical to administering a less-equitable tax regime: everyone still has to fill out a tax form, and the two may not differ in complexity), Shavell's argument cannot be dismissed out of hand. Shavell argues that high income taxes generate an incentive to decrease supply of useful labor. ${ }^{241}$ Again, we disagree (supra note 72), but Shavell is following in the long tradition of the "optimal income tax" literature.

\footnotetext{
${ }^{236} I d$.

${ }^{237} I d$. at 16.

${ }^{238} I d$. at 48.

${ }^{239}$ Steven Shavell, Foundations of Economic Analysis of Law 597 (Belknap/Harvard 2004).

${ }^{240} I d$. at 651 .

${ }^{241} I d$. at 651 note 7.
} 
Unfortunately, in Shavell's section on "Should Income Distributional Effects of Legal Rules influence their Selection," Shavell assumes the Equity-Efficiency Tradeoff. ${ }^{242}$ It is true that he later admits that the Equity-Efficiency Tradeoff might not exist: "If legal rules allowed income to be redistributed more cheaply than the income tax system does, then the conclusion that legal rules should not be chosen on the basis of their redistributive effects would not necessarily hold." ${ }^{243}$ However, over the next few pages, he reverts to assuming an Equity-Efficiency Tradeoff, then demonstrates that models with an Equity-Efficiency Tradeoff built into their assumptions do exhibit an Equity-Efficiency Tradeoff in their conclusions. This approach demonstrates competence in model-building but says nothing about the real world. We of course have argued that, in the real world, there is no Equity-Efficiency Tradeoff (see Section III.G.1(e)).

J. Barnes \& Stout (1992)

"Wealth maximization" is clearly commonly used in L\&E but Barnes and Stout, the leading case book on L\&E, ${ }^{244}$ define "wealth" in a unique way: as "the dollar value of scarce resources as measured by individuals' willingness and ability to pay for them." Their use of "and ability" is welcome. However, as we know from Section IV.A.5, in a Kaldor (CV) Test, WATP is the valuation of the person whose utility a policy would increase; in a Hicks (EV) test, WATP is the valuation of the person whose utility a policy would decrease. Kaldor and Hicks Tests work by comparing one person's WATP with the other person's WTA, not by comparing two WATPs, so it is unclear how Barnes and Stout's definition of wealth could be used to make social decisions. ${ }^{245}$

Barnes and Stout write, "in this book, an efficient allocation of resources is one that cannot be improved in either the Paretian or Kaldor-Hicks senses." ${ }^{246}$ If by "Kaldor-Hicks" they mean the actual Kaldor-Hicks approach (rather than the surplus approach), this means that they define efficiency as situations in which there are neither Pareto improvements nor Potential Pareto improvements possible. But if a Potential Pareto improvement is possible, a Pareto improvement is also possible (ignoring the results in supra Sections IV.E.1 and IV.F.1). Accordingly, the authors' definition of efficiency ends up being just Pareto Efficiency, which they do not seem to understand; nor do they understand that this conflicts with their advocacy of Potential Pareto Efficiency instead of Pareto Efficiency alone.

${ }^{242} I d$. at 655 note 9.
${ }^{243} I d$. at $656-7$.
${ }^{244}$ David Barnes and Lynn Stout, Cases and Materials on Law and Economics (West Pub. 1992) at 6.

${ }^{245}$ If one defines "wealth" as the sum of WATP, then for each consumer, summed over all goods, wealth would just equal the consumer's income, and for society as a whole, wealth would just equal national income, which is Net National Product (GNP minus depreciation) by the national income accounting identity (or perhaps wealth would equal net domestic income, which is Net Domestic Product (GDP minus depreciation)). Consistent with this, Barnes and Stout (id. at 9) say that "GDP is a familiar measure of wealth" (although they add that there is a problem with externalities). However, using WTA would be different because it is not constrained by income. Also, if people save, their WATP for all their current consumption is less than their income, and if they borrow, then it is more.

${ }^{246} I d$. at 17. 
On normative issues, Barnes and Stout utilize the "pie" analogy. ${ }^{247}$ However, they admit that "wealth maximizing inevitably requires that a greater share of resources go to wealthier people," 248 which acknowledges the effect of the Potential Pareto approach and the surplus approach on inequality. Furthermore, unlike the typical approach of hastily dismissing Pareto Efficiency as impractical - for example Heyer's regrettable position that "No serious antitrust analyst would propose that business conduct be permitted only if it leaves less efficient rivals equally well off" 249 - Barnes and Stout are to be commended for making the very important point that "United States v. Causby examines one possible method of expanding the usefulness of Pareto's classifications: compensation for forced reallocations." 250

K. Polinsky (2019)

Like Malloy, Polinsky ${ }^{251}$ measures value in dollars ("the dam...creates benefits of $\$ 40$ and costs of only $\$ 30 ”)$, with no hint of the dual nature of value. Unique among L\&E textbooks, Polinsky explicitly makes an assumption which eliminates the dual nature of value. That assumption is essentially the same as the highly unrealistic assumption of quasilinear preferences, that is, that the income effect lies precisely on the "zero" knife-edge. ${ }^{252}$ Polinsky refers to this as a "standard" assumption of economic analysis, ${ }^{253}$ but it is much more restrictive than the standard Arrow-Debreu assumptions. In Setting Pi, quasilinear preferences not only make EV and CV identical, they also make EV and CV equal to consumer surplus, making the social surplus approach equivalent to the Potential Pareto approach and eliminating the positive problems of these approaches (while not affecting their normative problems). Therefore, there is a sense in which the other L\&E authors' arguments require quasilinear preferences as wellonly with quasilinear preferences are the Kaldor-Hicks approach (which they claim to be using) and the surplus approach (which they are actually using) identical.

On normative issues, Polinsky begins with the "pie" analogy, ${ }^{254}$ then moves to the EquityEfficiency Tradeoff fallacy ("there may well be a conflict between equity and efficiency"). He admits that there might not be an Equity-Efficiency Tradeoff, but concludes that "income redistribution generally is costly," 255 which means there generally is an Equity-Efficiency Tradeoff in his opinion. He then argues like Cooter and Ulen (and, less insistently, Shavell) that in the face of this Equity-Efficiency Tradeoff, "efficiency should be the principal criterion for evaluating the legal system. This argument rests on the observations [...] that it is often impossible to redistribute income through the choice of legal rules and that, even when it is

\footnotetext{
${ }^{247}$ Barnes and Stout, supra note 244 at 9.

${ }^{248} I d$. at 10.

249 Heyer, supra note 147 at S28 note 9.

${ }^{250} I d$. at 15.

251 A. Mitchell Polinsky, An Introduction to Law and Economics 8 (Wolters Kluwer 2019).

${ }^{252}$ He assumes "...the values that individuals place on their benefits and costs are 'stable' in the sense that these values are not affected by changes in public policy. For example, an individual's evaluation of the desirability of cleaner air is assumed not to depend on whether the legal system establishes a right to clean air." Id. at 10-11.

${ }^{253} \mathrm{Id}$. at 10.

${ }^{254} I d$. at 7.

${ }^{255} \mathrm{Id}$. at 9.
} 
possible, redistribution through the government's tax and transfer system generally is cheaper and more precise." 256 We disagree, as explained in our discussion of Cooter and Ulen.

L. $\quad$ Seidenfeld (1996)

On positive issues, Seidenfeld ${ }^{257}$ introduces an idiosyncratic way to distinguish "Kaldor-Hicks" from "wealth maximization": using our terminology, he says that "Kaldor-Hicks" is in Setting Qq while "wealth maximization” is in Setting Qi. Although idiosyncratic definitions are not wrong per se, ${ }^{258}$ Seidenfeld errs in claiming that Setting Qq has much larger informational requirements than Setting Qi. He writes that Setting Qi does "not require that policy-makers know the preference function of every individual affected by a legal rule" but that Setting Qq does require this. ${ }^{259}$ Instead, the two settings have very similar informational requirements: they both require knowing how much a consumer is willing to pay or accept for a gain or a loss (or a foregone gain or loss) of a certain amount of one commodity, in terms either of a second commodity or of money.

On the more basic issue of acknowledging the dual nature of value, Seidenfeld is silent, and none of his examples reflect value's dual nature. Therefore, his "Kaldor-Hicks" and his "wealth maximization" frameworks should be understood as different ways of measuring social surplus, that is, as a "Part V" approach, not a "Part IV" approach.

On normative issues, Seidenfeld is the best textbook we review, doing an excellent job of pointing out where economic notions of efficiency raise normative concerns. Unique among these authors, he points out the normative problems raised by Pareto Efficiency, ${ }^{260}$ which we discussed in Section III.G.1(c). He notes correctly that "With respect to the criticism that notions of efficiency do not sufficiently take fairness into account, however, wealth maximization is more problematic than the Pareto measure." 261 He even discusses "other social welfare functions" (supra note 192) - the only other author to do that is Shavell - and he discusses John Rawls' Maximin Principle. ${ }^{262}$

Having discussed so many different authors, it is not easy for us to summarize this Appendix. However, it is clear that while a few authors have made progress in appreciating the normative problems with L\&E's approach to economic efficiency, the field is still in a state of confusion

\footnotetext{
${ }^{256} I d$. at 10.

${ }^{257}$ Mark Seidenfeld, Microeconomic Predicates to Law and Economics (Anderson 1996).

${ }^{258}$ Speaking pedantically, there is no such thing as a mis-definition: to drive home that point, President Jimmy Carter's Chairman of the Council on Wage and Price Stability, Alfred E. Kahn, decided to call economic depressions "bananas." But Wittgenstein warns us that "philosophy is a battle against the bewitchment of our intelligence by means of our language," and confusing definitions serve not philosophy but sophistry. (See Ludwig Wittgenstein, Philosophical Investigations §109 (Basil Blackwell 1953). Retrieved from https://www.oxfordreference.com/view/10.1093/acref/9780191826719.001.0001/q-oro-ed4-00011662. In the original German: "Die Philosophie ist ein Kampf gegen die Verhexung unsres Verstandes durch die Mittel unserer Sprache.")

${ }^{259} I d$. at 55.

${ }^{260} I d$. at 54.

${ }^{261} I d$. at 55.

${ }^{262} I d$. at 56. Hirsh did reference Rawls in a footnote.
} 
about fundamental positive concepts such as what notion of economic efficiency it is actually using and what the flaws of that notion are.

\section{APPENDIX 2: $\quad$ POSNER's POSITIVE ECONOMICS}

Richard Posner is such an important author in L\&E that it seems worthwhile to explain some of the flaws in the positive economics of his scholarly articles - with the caveat that Posner's ideas have evolved and we are only critiquing what he wrote at different moments in the past.

Based on what this paper has already discussed, we can characterize Posner's earlier works as constructing something of an Alice-in-Wonderland realm, where "Kaldor-Hicks" is the supreme law of the land but no one ever mentions the Kaldor Test; where "wealth maximization" is society's summum bonum but "wealth" does not mean what any economist thinks "wealth" means, and where "maximization" is applied to a correspondence which is not a function, even though such correspondences are impossible to maximize; and where the Arrow-Debreu assumptions, which much of the economics profession has spent the last half century trying to weaken, are thought to be too weak.

Concerning the Separation Hypothesis, Posner 263 invokes the "pie" analogy: "efficiency in the Kaldor-Hicks sense-making the pie larger without worrying about how the relative size of the slices changes..." Similarly, he implies ${ }^{264}$ that one can know what "productive activity" and "wealth" are without inquiring about distribution. We described the error in this approach in Section III.G.1(c), and authors such as Ashford ${ }^{265}$ are aware of it: "There is no one single paramount optimal efficiency to guide Judge Posner's Efficiency Ethic of the Common Law, but many distribution-dependent relative efficiencies."

While Posner usually identifies "wealth maximization" with what he calls "the Kaldor-Hicks Criterion," Posner has over the years given other definitions.

In 1987 Posner said wealth maximization was the same as maximizing social surplus. ${ }^{266}$ This is closer to the truth than saying it has anything to do with Kaldor or Hicks (see Section A).

In 1990 Posner said wealth maximization was Cost-Benefit Analysis using the greater of WATP (he calls it WTP) and WTA. ${ }^{267}$ To see the problems with assessing value this way,

\footnotetext{
${ }^{263}$ Richard A. Posner, Cost-Benefit Analysis: Definition, Justification, and Comment on Conference Papers, 29 J. of Legal Studies 1153-1177, 1155 (2000).

${ }^{264}$ Richard A. Posner, Wealth Maximization and Tort Law: A Philosophical Inquiry, in David G. Owen, ed, Philosophical Foundations of Tort Law 110 (Oxford 1995): "Maybe a system of tort law oriented by the principle of wealth maximization is the best approach for the Kantian. It seeks to accommodate conflicting activities in such a way that the scope for productive activity is maximized."

265 Robert Ashford, supra note 102.

266 Richard A. Posner, The Justice of Economics, 15 Economia delle scelte pubbliche 15-25, 17, 18 (1987), and, at id. 19: "Wealth is, however, much easier to measure than happiness even though hypothetical prices play so important a role in determining wealth. It is much easier to estimate a demand curve (and so consumer surplus) than to estimate any sort of aggregate happiness function."
}

${ }^{267}$ Richard A. Posner, supra note 1 at 356:

I must pause to define "wealth maximization," a term often misunderstood. The "wealth" in "wealth maximization" refers to the sum of all tangible and intangible goods and services, weighted by prices of 
suppose (as in Posner's example) that A's WATP for receiving B's stamp collection is $\$ 100$, while B's WTA for giving up his stamp collection is $\$ 90$. Then "the greater of WATP and WTA" is $\$ 100$, and the transfer of the stamp collection from B to A passes the Kaldor Test (the "CV" question of "if we do transfer the stamp collection to B"). However, for this transfer to also pass the Hicks Test (the "EV" question of "if we do not transfer the stamp collection to B"), A's WTA compensation for not receiving the stamp collection would have to be larger than B's WATP money to avoid turning over B's stamp collection. Empirically, WTA is usually greater than WATP (because WATP is constrained by income while WTA is not), so suppose A's WTA is $\$ 110$ (i.e., greater than \$100) and B's WATP is $\$ 85$ (i.e., less than $\$ 90$ ). According to these Hicks-Test measures, "the greater of WATP and WTA" is $\$ 110$. When Posner says that "wealth maximization" is Cost-Benefit Analysis using the greater of WATP and WTA, does he mean the greater of WATP and WTA of the Kaldor (CV) Test, which is $\$ 100$, or the greater of WATP and WTA of the Hicks (EV) Test, which is $\$ 110$ ? It does not appear that Posner is even aware that in any situation there are not one but two pairs of WATP and WTA, one for the Kaldor Test and the other for the Hicks Test.

In 2000, Posner said wealth maximization was Cost-Benefit Analysis using WTA. ${ }^{268}$ But whose WTA? After all, in the stamp collection example, B's (Kaldor) WTA is $\$ 90$ and A's (Hicks) WTA is $\$ 110$.

Posner's strangest claim, however, was that wealth maximization is the same as Pareto Optimality. He first put forth this claim in $1980^{269}$ and extended it in $1990^{270}$. Posner asserts the following syllogism, when discussing changes made under uncertainty:

two sorts: offer prices (what people are willing to pay for goods they do not already own); and asking prices (what people demand to sell what they do own). If A would be willing to pay up to $\$ 100$ for B's stamp collection, it is worth $\$ 100$ to A. If B would be willing to sell the stamp collection for any price above $\$ 90$, it is worth $\$ 90$ to B. So if B sells the stamp collection to A (say for $\$ 100$, but the analysis is qualitatively unaffected at any price between $\$ 90$ and $\$ 100$ - and it is only in that range that a transaction will occur), the wealth of society will rise by $\$ 10$. Before the transaction A had $\$ 100$ in cash and B had a stamp collection worth $\$ 90$ (a total of $\$ 190$ ); after the transaction A has a stamp collection worth $\$ 100$ and $\mathrm{B}$ has $\$ 100$ in cash (a total of \$200). The transaction will not raise measured wealth-gross national product, national income, or whatever-by $\$ 10$; it will not raise it at all unless the transaction is recorded, and if it is recorded it is likely to raise measured wealth by the full $\$ 100$ purchase price. But the real addition to social wealth consists of the $\$ 10$ increment in nonpecuniary satisfaction that A derives from the purchase, compared with that of B.

Posner confirmed his belief in this definition five years later:

'Value' is determined by what the owner of the good or service would demand to part with it or what a non-owner would be willing to pay to obtain it - whichever is greater. [Posner, supra note 264 at 99.]

${ }^{268}$ Richard A. Posner, supra note 263 at 1155: "I would, however, use willingness to accept rather than willingness to pay as the value measure when the policy the costs and benefits of which are being measured takes away property rights, as in the case where farmland will be flooded as a result of the building of a dam.

Willingness to accept provides better protection for property rights, which have an important economizing role in a market economy."

269 “....while Kaldor-Hicks is not a Pareto criterion as such, it will sometimes function as a tolerable, and, more to the point, administrable approximation of the Pareto-superiority criterion." Richard A. Posner, The Ethical and Political Basis of the Efficiency Norm in Common Law Adjudication, 8 Hofstra L. Rev. 487-507, 495 (1980).

270 "It may seem paradoxical to derive a norm of wealth maximization from the principle of Pareto superiority, when the hallmark of the latter is compensation of all potential losers (for remember that no one must be made 
(a) Some ex ante Pareto Improvements lead to ex post losses.

(b) All Potential Pareto Improvements lead to ex post losses.

(c) Therefore, there is no difference between Pareto Improvements and Potential Pareto Improvements.

The Venn Diagram of true statements (a) and (b) is Figure 21, which shows that (c) does not, in fact, follow from (a) and (b).

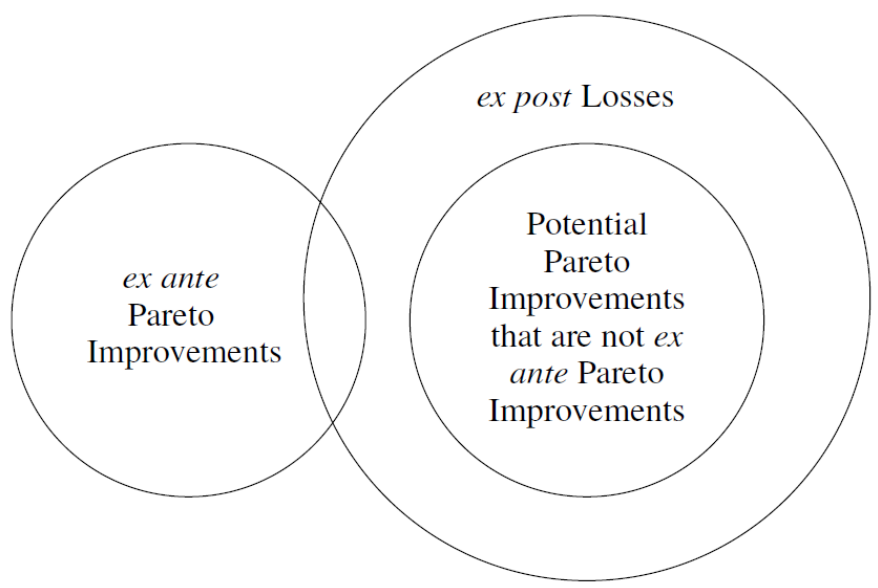

Figure 21. Pareto Improvements under uncertainty can lead to ex post losses, but this does not mean that Pareto Improvements and Potential Pareto Improvements are identical.

All this said, Posner proposed his most revealing definition in 1990, when he said that wealth maximization was the same as laissez-faire economic policies. ${ }^{271}$ That cemented his agreement with the Neoliberal agenda.

In reviewing a book by Posner on a different topic, economics Nobel laureate Robert Solow remarked that "in some respects, his [Posner's] grasp of economic ideas is precarious."272 Yes; but Posner unquestionably got many of his ideas from economists. Clearly Posner was wrong to treat "the" Kaldor-Hicks "sense" 273 as a single idea, as if there were no difference between

worse off by the transaction if it is to be Pareto superior), while wealth maximization requires only that the winners' gains exceed the losers' losses. But if, as in the contract example, compensation is permitted to be ex ante, the paradox disappears. The difference between the ex ante and ex post perspectives is fundamental, and failure to attend to it underlies much confused thinking about markets and transactional competence. Because many choices are made, unavoidably, under conditions of uncertainty, a fair number must turn out badly. Ex post, they are regarded as mistaken and engender regret, yet ex ante they may have been perfectly sensible." Richard A. Posner, supra note 1 at 389 .

271 "The strongest argument for wealth maximization is not moral, but pragmatic. Such classic defenses of the free market as chapter 4 of Mill's On Liberty can easily be given a pragmatic reading... We look around the world and see that in general people who live in societies in which markets are allowed to function more or less freely not only are wealthier than people in other societies but have more political rights, more liberty and dignity, are more content (as evidenced, for example, by their being less prone to emigrate) — so that wealth maximization may be the most direct route to a variety of moral ends." Richard A. Posner, supra note 1 at 382.

${ }^{272}$ Robert M. Solow, How to Understand the Disaster, The New York Review of Books (May 14, 2009). Solow is speaking in the context of macroeconomics, not L\&E.

${ }^{273}$ Richard A. Posner, supra note 264. 
the Kaldor Test and the Hicks Test, but there are also economists who make this error. It is about them that Griffin writes, ${ }^{274}$ "when professionals say or write K-H in their work, they risk having their work questioned. There's not just one compensation test, and there are normative questions that should not be swept under a rug by [implying] a single test." Yes, Posner's understanding of WATP and WTA was flawed, and he should have indicated, in his contradictory writings on that subject, how his viewpoint was changing; but at least he showed curiosity about the implications for social decision-making of WATP not equaling WTA, a topic missing from the almost-1000-page-long tome of Mas-Colell, Whinston, and Green. ${ }^{275}$ It should surprise no one that Posner used the incorrect surplus method to measure welfare change when Paul Samuelson, who in a specialist text almost no one will read said

It is for these reasons that my ideal Principles would not include consumer's surplus in the chapter on welfare economics except possibly in a footnote, although in my perfect Primer the concept might have a limited place, provided its antidote and alternatives were included close at hand. ${ }^{276}$

went on to write in his extremely-widely read introductory textbook that "the gap between the total utility of a good and its total market value is called consumer surplus" in the midst of a presentation of (cardinal!) utility and consumer surplus ${ }^{277}$ so uncritical and out of date that even Marshall knew better. Similarly, who can blame Posner for advocating the Separation Hypothesis when Nobel laureate Jean Tirole writes in the introduction to his graduate-level textbook on Industrial Organization that: 278

The goods and industries considered in this book generally represent only a small share of consumer expenditure. Price changes are therefore likely to generate small income effects, and it may be appropriate to assume that demand is downward-sloping and that consumer surplus is a good approximation of welfare.... In this book, I will treat income distribution as irrelevant.... I will focus on the efficiency of markets.... The "compensation principle" of Hicks (1940) and Kaldor (1939) hold that we need only be concerned with efficiency; if total surplus increases, the winners can compensate the losers and everyone is made better off.

\footnotetext{
${ }^{274}$ Ron Griffin, Some margin notes for the 2004 JHS text, http://www.waterecon.com/courses/agec636/margin notes.html (December 2015). "JHS" refers to Richard E. Just, Darrell L. Hueth, and Andrew Schmitz, The Welfare Economics of Public Policy (Edward Elgar 2004).

${ }^{275}$ They do devote four sentences and two homework exercises to "paradoxes" in a related context: supra note 55 at 831 .

276 Supra note 175 at 197.

${ }^{277}$ Paul A. Samuelson and William D. Nordhaus, Economics 456 (McGraw-Hill 13 ${ }^{\text {th }}$ ed 1989). The only nod to a correct treatment of the topic appears in a completely unexplained three-word phrase beginning a sentence in the chapter summary: "In simplified cases, we can measure consumer surplus as the area between the demand curve and the price line" (ibid. at 459). And even this is wrong: consumer surplus is always the area between the demand curve and the price line. That is its definition. What can only "in simplified cases" be measured as the area between the demand curve and the price line is the change in welfare. Both Samuelson and Nordhaus are Nobel Laureates in economics.

${ }^{278}$ Jean Tirole, The Theory of Industrial Organization 31-32 (MIT Press 1988).
} 
Tirole asks ${ }^{279}$ that it be "borne in mind in all our welfare conclusions" that "compensation need not occur," but expecting the reader to bear in mind this "classic drawback" for the rest of a more-than-1000-page-long book which will not mention it again veers close to being disingenuous, as does saying that it "may be appropriate" to use consumer surplus as a measure of welfare and then to do so unquestioningly for the rest of the book. In conclusion, if Richard Posner's economics has flaws, large responsibility rests on the economists he learned from.

${ }^{279} I d$. at 32. 